\title{
WestVirginiaUniversity
}

THE RESEARCH REPOSITORY @ WVU

Graduate Theses, Dissertations, and Problem Reports

2008

\section{Mechanical characterization of fabrics for inflatable structures}

Juan Cruz Molina Pombo

West Virginia University

Follow this and additional works at: https://researchrepository.wvu.edu/etd

\section{Recommended Citation}

Molina Pombo, Juan Cruz, "Mechanical characterization of fabrics for inflatable structures" (2008).

Graduate Theses, Dissertations, and Problem Reports. 1913.

https://researchrepository.wvu.edu/etd/1913

This Thesis is protected by copyright and/or related rights. It has been brought to you by the The Research Repository @ WVU with permission from the rights-holder(s). You are free to use this Thesis in any way that is permitted by the copyright and related rights legislation that applies to your use. For other uses you must obtain permission from the rights-holder(s) directly, unless additional rights are indicated by a Creative Commons license in the record and/ or on the work itself. This Thesis has been accepted for inclusion in WVU Graduate Theses, Dissertations, and Problem Reports collection by an authorized administrator of The Research Repository @ WVU. For more information, please contact researchrepository@mail.wvu.edu. 


\title{
Mechanical Characterization of Fabrics for Inflatable Structures
}

Juan Cruz Molina Pombo

\author{
Thesis submitted to the \\ College of Engineering and Mineral Resources \\ at West Virginia University \\ in partial fulfillment of the requirements \\ for the degree of
}

Master of Science

in

Aerospace Engineering

Ever J. Barbero, Ph.D., Chair

Javier Martinez, Ph.D

Chuanyu Feng, Ph.D

Department of Mechanical and Aerospace Engineering

Morgantown, West Virginia

2008

Keywords: tunnel plug, fabric tensile strength, fabric friction, static friction coefficient, improve friction 


\title{
ABSTRACT
}

\section{Mechanical Characterization of Fabrics for Inflatable Structures}

\author{
Juan Cruz Molina Pombo
}

Several mechanical properties of fabrics for inflatable structures have been characterized. In this work, the characterization was done for fabrics in a tunnel plug. As a plug the structure should seal the tunnel and maintain itself static, for that reason the characterization of the frictional system tunnel wall / structure fabric is done. Also, by the study of the maximum stresses under this configuration, the tensile strength of the structural fabrics is studied. In order to characterize the fabric properties, friction and strength, a test for each of them was done.

The tensile strength test was performed for two fabrics, according to the standards ASTM D5034 and ISO 1421. Also a tensile test for welded specimens was done. The information recovered from these tests where useful to determine, first, the optimum fabric that will be used in the plug structure, and second to characterize the behavior of welded fabrics.

The friction test was done according to the real system involve. The experiment was designed to simulate the real frictional behavior between the concrete wall of the tunnel and the fabric used in the inflatable structure. Once the friction concrete / fabric system was characterized for various sliding surfaces, a study to improve the friction force in this system was performed. Consequently several tests were conducted for different concrete treatments sliding over a fabric sample. 


\section{DEDICATION}

This thesis is dedicated to my parents Maria Susana Pombo and Juan Carlos Molina. Without their support this would not have been possible, GRACIAS (thanks). 


\section{ACKNOWLEDGEMENTS}

I would like to express my sincere thanks to Dr. Ever Barbero for encouraging me to pursue my master's degree and being my advisor on this project. I would also like to thank Dr. Javier Martinez and Dr. Chuanyu Feng for serving on my committee. I would also like to thank Dr. Tim Norman, Dr. Eduardo Sosa and Sebastian Sanchez for their help on this project. Thanks to Chuck Coleman for providing support in the laboratory and for helping in the purchase of the materials used on this project. I would also like to express my gratitude to Dr. Chuanyu Feng for helping me in the laboratory set up.

Additionally, I would like to express my sincere thanks to all of the professors in the Mechanical and Aerospace Engineering Department at West Virginia University for helping me through the difficult process of learning. I would like to thanks Dr. Ever Barbero for advising me throughout my time at West Virginia University. I would like to express my gratitude to Dr. Javier Martinez for advising me and providing constructive suggestions relating to this project.

Finally, thanks to all of my friends who supported me throughout my time in West Virginia University. I would also like to thank my family for helping me throughout my time in West Virginia and for always being there with me. 


\section{TABLE OF CONTENTS}

ABSTRACT

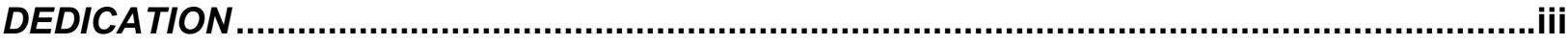

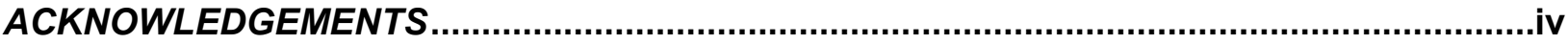

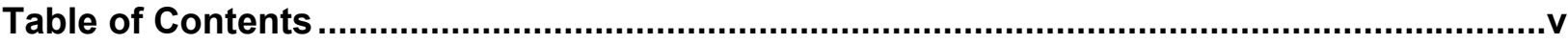

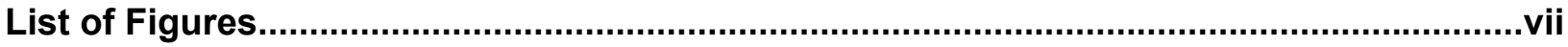

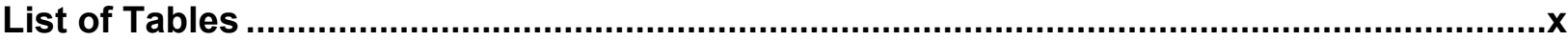

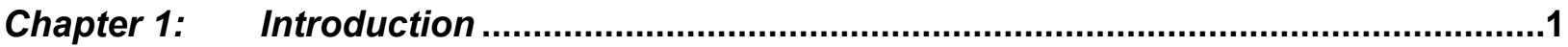

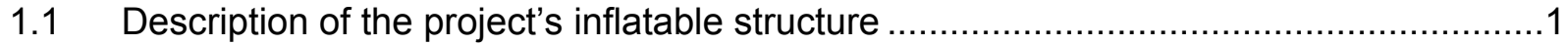

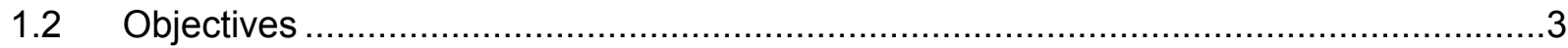

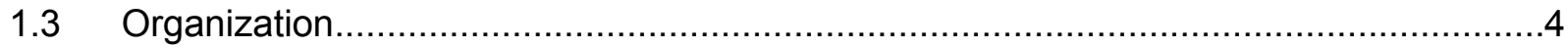

Chapter 2: Inflatable structures - Overview..............................................................

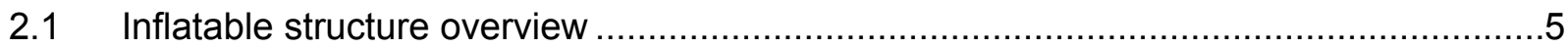

2.2 Membranes theory in a thin walled pressure vessel ...............................................

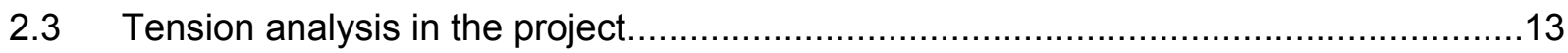

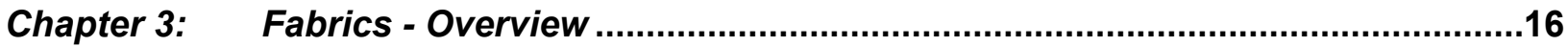

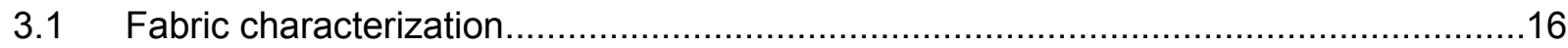

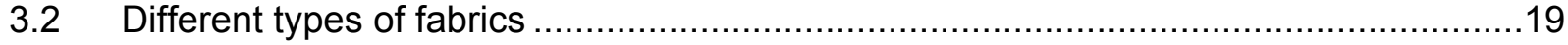

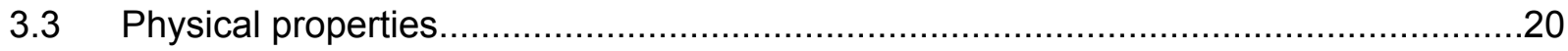

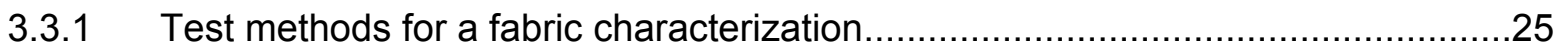

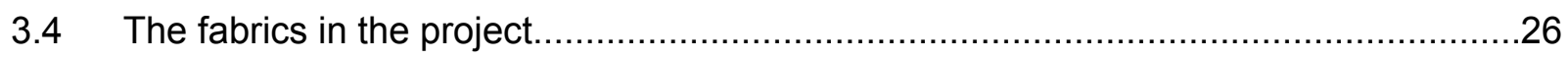

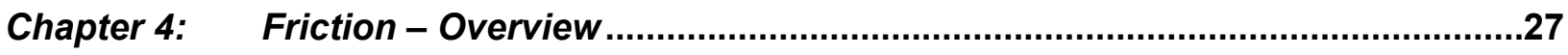

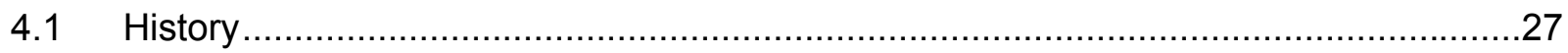

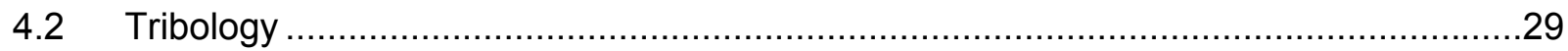

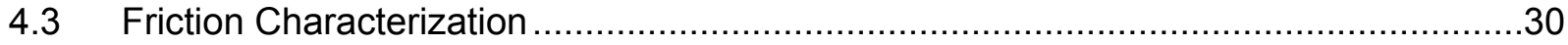

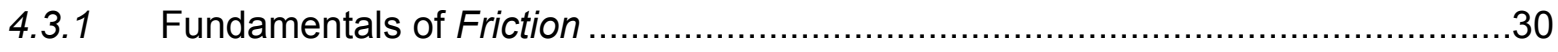

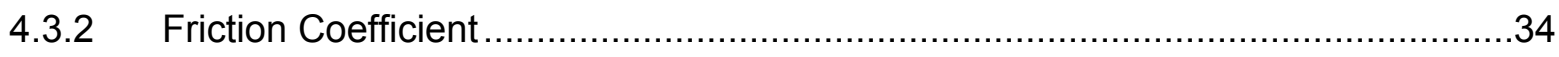

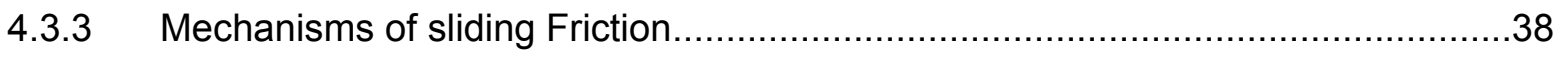


4.3.4 Behavior of friction in metals and non - metals.

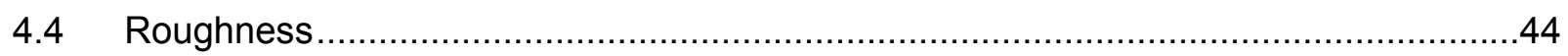

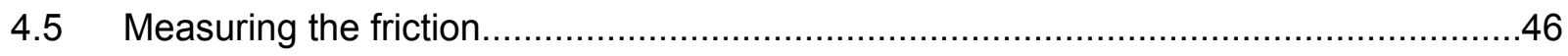

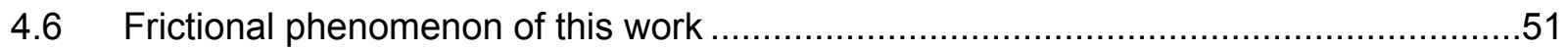

Chapter 5: Test methods to determine the fabric's physical properties .....................54

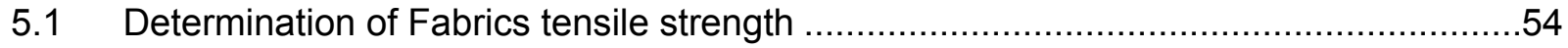

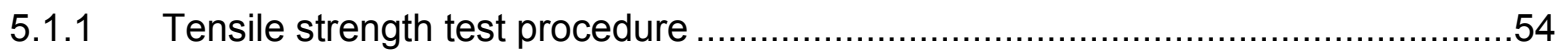

5.1.2 Results and analysis of the strength in different fabrics ..............................61

5.2 Estimation of fabric's static friction coefficient against different superficies ................69

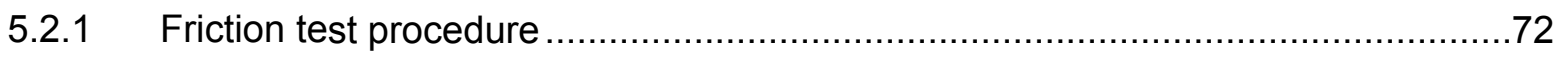

5.2.2 Results and analysis of fabric's static friction coefficient against different

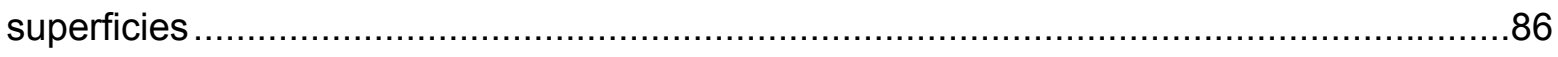

Chapter 6: Conclusions and Future work...............................................................102

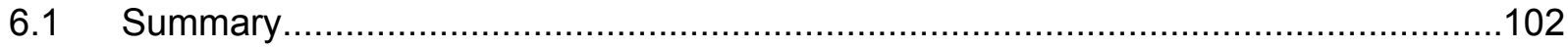

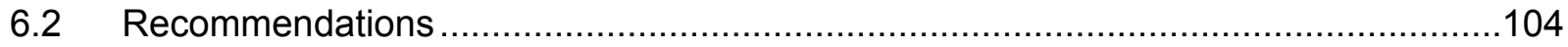

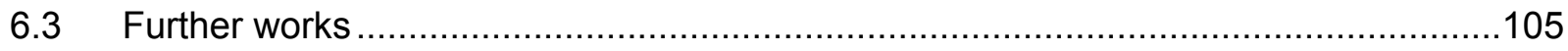

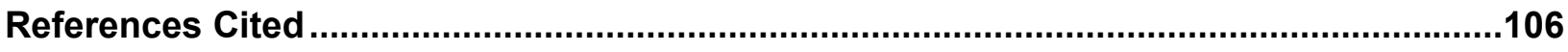

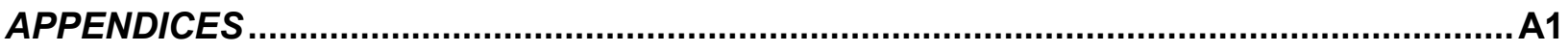

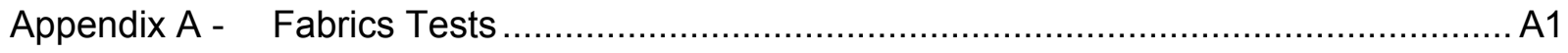

Appendix B - Lab View data acquisition program .............................................. A3

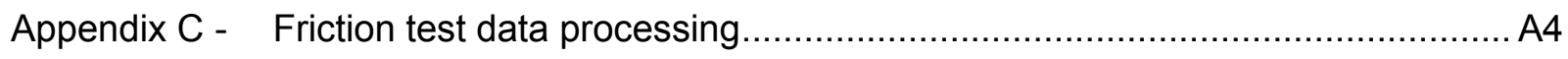




\section{LIST OF FIGURES}

Figure 1.1.1 - Schematic figure of the inflatable tunnel plug inside the tunnel - .....................3

Figure 2.1.1 - Airbags used in the NASA Mars Exploration mission - [18] .........................5

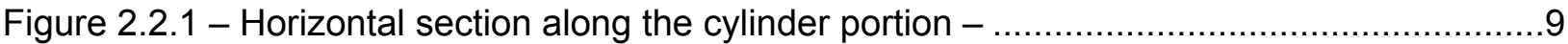

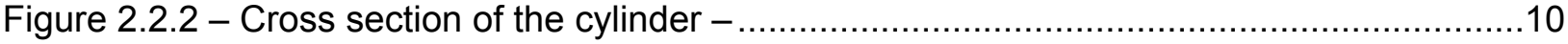

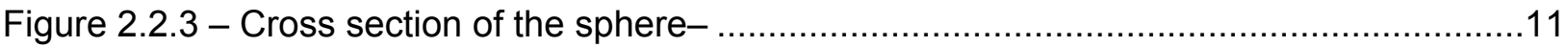

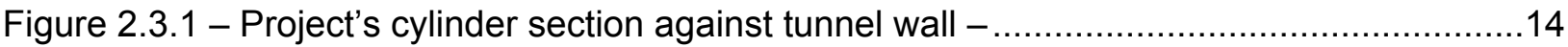

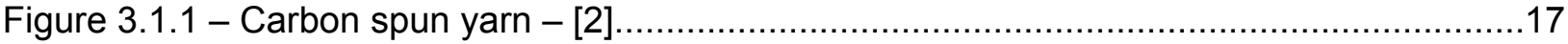

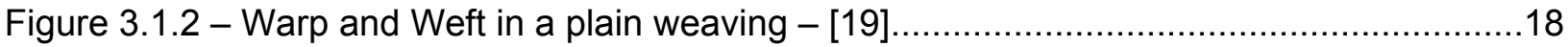

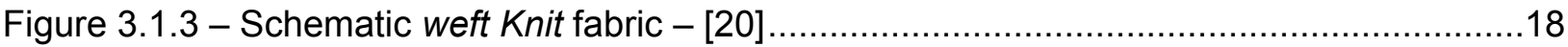

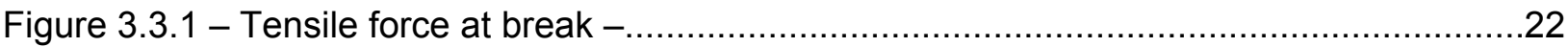

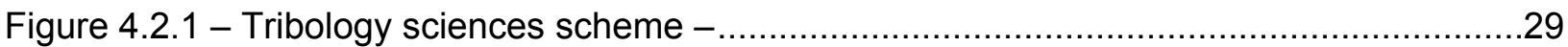

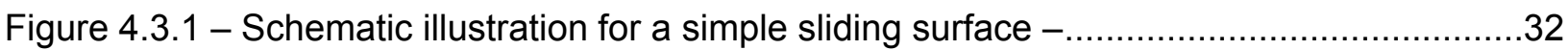

Figure 4.3.2 - Schematic illustration for an inclined frictional system - ..............................35

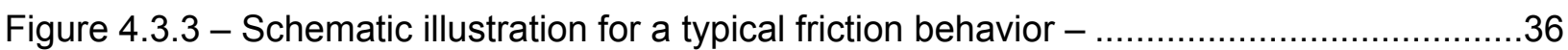

Figure 4.3.4 - Mechanisms of friction: ploughing, adhesion and viscous drag - [9] .................39

Figure 4.3.5 - Factors influencing frictional behavior [12] - ..........................................44

Figure 4.4.1 - Schematic surface representation [11] - ...............................................46

Figure 4.5.1 - Some factors influencing involved in designing a friction experiment [10] - .......51

Figure 4.6.1 - Principal components of elastomeric friction [13] $-\ldots \ldots \ldots \ldots \ldots \ldots \ldots \ldots \ldots \ldots \ldots \ldots . . . . . \ldots 2$

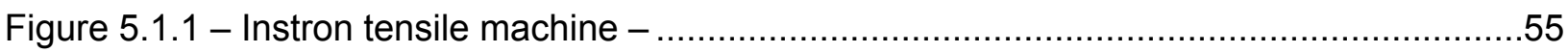

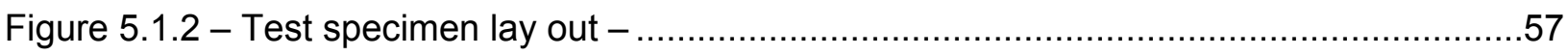

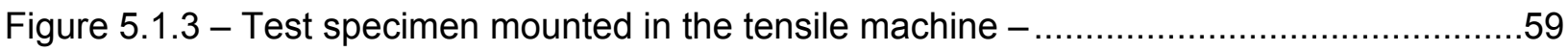

Figure 5.1.4 - Ferrari fabric sample tensile test,

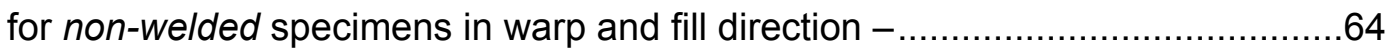

Figure 5.1.5 - Ferrari fabric sample tensile test, for non-welded and weld specimens in warp direction -

Figure 5.1.6 - Seaman fabric sample tensile test, for non-welded specimens in warp and fill direction -

Figure 5.1.7 - Seaman fabric sample tensile test, for non-welded and weld specimens in warp direction 67

Figure 5.2.1 - Schematic sample of the tribological system fabric/concrete .70 
Figure 5.2.2 - Schematic contact between tunnel wall and structure fabric:

a) Real tunnel circumferential shape,

b) Flat surface hypothesis,

c) Water influence between the tunnel and the fabric .71

Figure 5.2.3 - Structural inflatable pressure diagram over the tunnel wall .72

Figure 5.2.4 a) - Friction machine and its mechanical components -

b) - Friction machine, hydraulic system.73

Figure 5.2.5 a) - Data acquisition system -

b) - data acquisition system lab view running program .75

Figure 5.2.6 - Normal force specimen fixture .79

Figure 5.2.7 - Concrete specimen .80

Figure 5.2.8 - Sliding surface over the car .82

Figure 5.2.9 - Correct position of the fixed and sliding specimens .83

Figure 5.2.10 - Concrete specimen inside the wet fixture .86

Figure 5.2.11 - Normal load behavior for concrete, with 13.3, 24.4 and $44.5 \mathrm{lbs}$ normal weight -

Figure 5.2.12 - Proportionality for normal load behavior for concrete, with 13.3, 24.4 and 44.5 lbs normal weight -

Figure 5.2.13 - Roughness influence, texturate paint, anti-skid paint and rough concrete, $24.5 \mathrm{lbs}$ normal weight, at $\mathrm{V} 1$ -

Figure 5.2.14 - Adhesion influence, epoxy paint, acrylic surface, steel surface and concrete,

24.5 lbs normal weight, at $V 1$ and $V 2$

Figure 5.2.15 - Hydrodynamic influence, anti-skid paint, steel surface and concrete, 44.5 lbs normal weight, $V 2$-.....

Figure 5.2.16 - Frictional forces differences between concrete, and asphalt and latex wall treatments, $13.3 \mathrm{lbs}$ normal weight, $\mathrm{V} 2$-.

Figure 5.2.17 - Vinyl and PVC coated fabrics sliding against wet and dry, 44.5 lbs normal weight, $V 1-$. .99

Figure 5.2.18 - PVC coated fabric sliding against WET concrete, and asphalt and latex wall treatments, $13.3 \mathrm{lbs}$ normal weight, $\mathrm{V} 2$ 100 


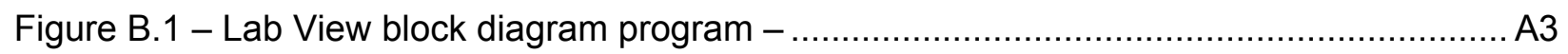

Figure C.1 - Anti-Skid, dry, V2, 13.3 [lbs] -............................................................. A5

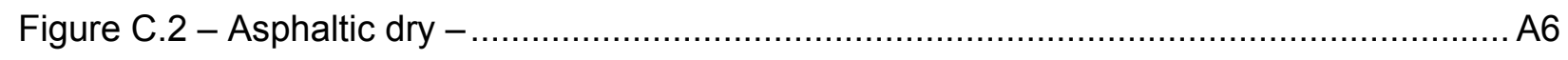

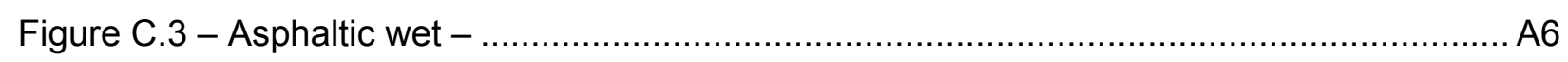

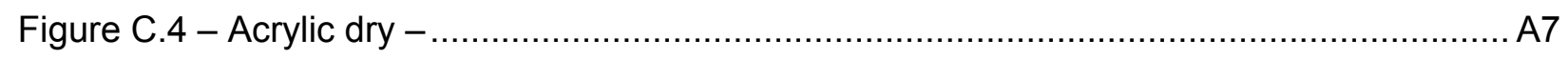

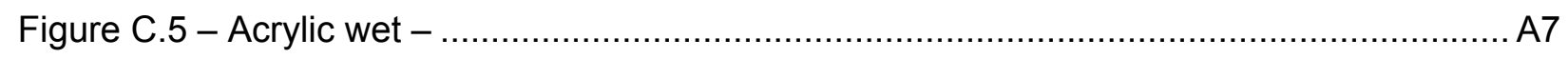

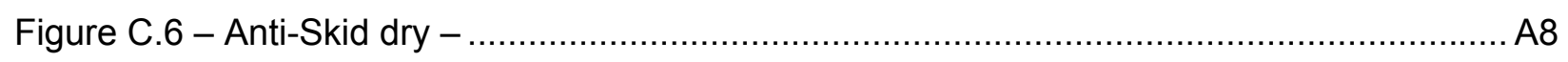

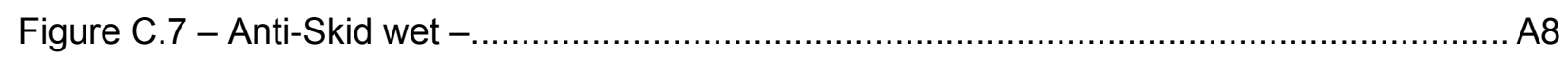

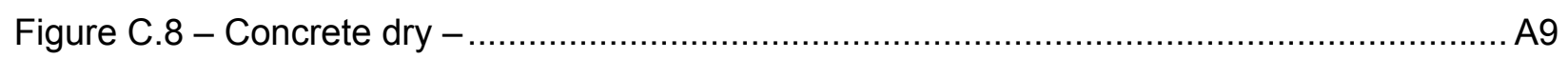

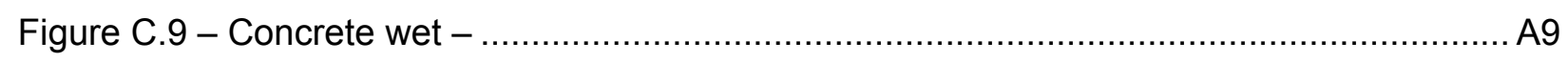

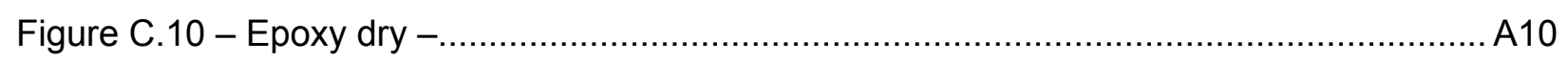

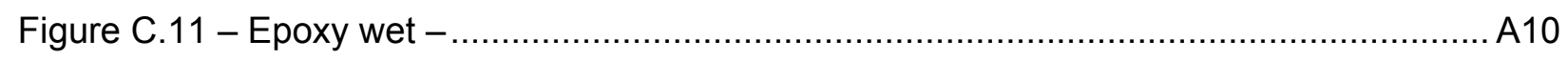

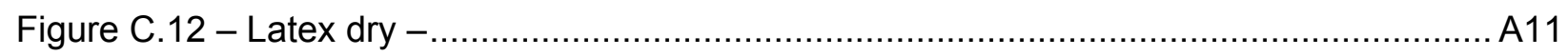

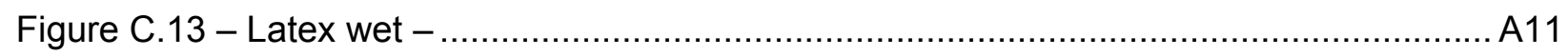

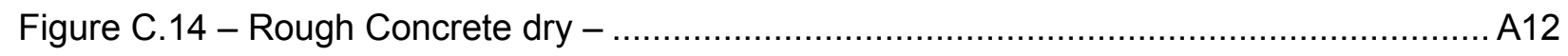

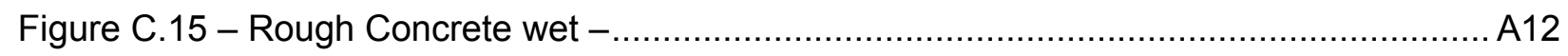

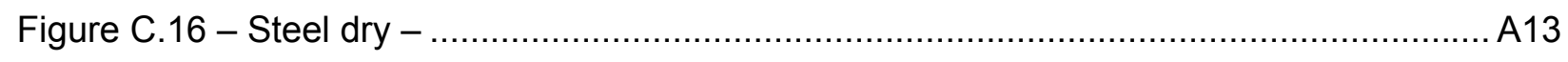

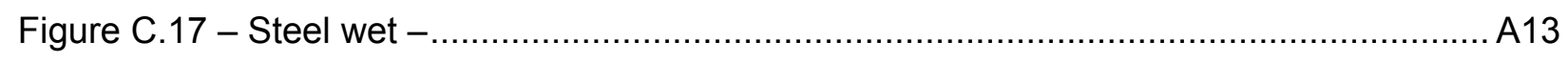

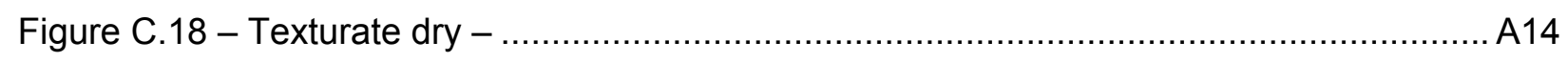

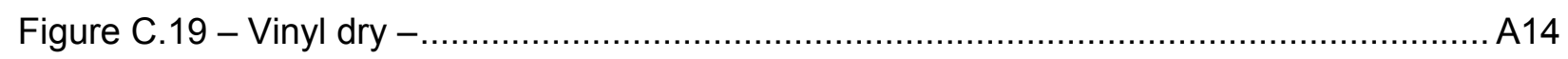

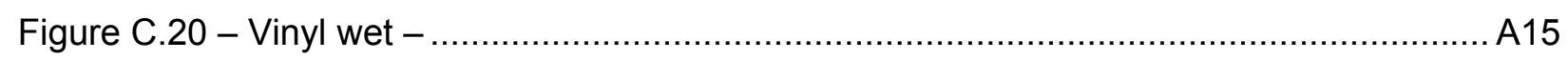




\section{LIST OF TABLES}

Table 3.3.1 - Standard for each respective property .25

Table 4.3.1 - List of friction coefficient for well know materials -

Table 5.1.1- Tensile strength test denomination -

Table 5.1.2 - Ferrari (Precontraint 1002) fabric tensile test results 62

Table 5.1.3 - Seaman (Style 7150 PTFF) fabric tensile test results .65

Table 5.1.4 - Strength difference between the tensile test results and manufacturer values

Table 5.2.1- List of tests and materials specifications in dry (D) surfaces 68

Table 5.2.2 - List of tests and materials specifications in wet (W) surfaces .77

Table 5.2.3 - List of tests in dry and wet surfaces -

Table 5.2.4 - List of the different static friction coefficient, $\mu_{S}$, in dry and wet surfaces for the PVC coated fabric -

Table 5.2.5-PVC and vinyl coated fabrics static friction coefficient, $\mu_{S}$, in dry and wet concrete surface 100

Table 5.2.6- PVC coated fabric static friction coefficient, $\mu_{S}$, in dry and wet, concrete, latex and asphalt surfaces 101

Table A.1 - Ferrari (Style 7150 PFF) fabric tensile test results A1

Table A.2 - Seaman Corporation (Style 7150 PFF) fabric tensile test results A2 


\section{Chapter 1: Introduction}

Fabric composites structures have become increasingly popular for a variety of applications in civil engineering, architecture and aerospace engineering. Therefore in the design process of this kind of structures a mechanical characterization of the properties for the fabrics is required to be done.

According to the structure under studied, the properties of the fabrics to study will be different. For example, for an airbag fabric the tensile properties should be good but it is not necessary to be waterproof, however, for an architectural building where protection from the raining, the fabric should be waterproof.

Among all this possible combination of structural design, fabrics should be characterized for each special case.

\subsection{Description of the project's inflatable structure}

This work is a part of project where a big inflatable structure is designed. This structure will consist in a tunnel plug capable to stop among a flood, gases or any other fluid risk inside the tunnel. This safety structure is passive device that when is not used, it is positioned at the top of the tunnel. And when the risk fluid event happen (flooding), a sensor detects the threat and triggers the inflate system which inflates the plug in few minutes. When it is inflated the danger (flood) is stopped, and the people, infrastructures or environment are protected. Then, when the risk is controlled or finished, the structure can be deflated, packed and loaded to use it again. 
When the inflatable plug is inflated, the flooding (fluid risk pressure) is stopped because the structure seals the tunnel. Then the friction between the structure's fabric and the tunnel concrete will prevent the displacement of the structure backwards. This means that the plug has a "self static behavior". This design concept is not a detail that should not be forgotten in the design process, if the friction between the tunnel wall and the structure fabric is not enough to stop the threat (flooding, gas pressures) the idea of this structure will not work.

Another design issue is the inflate pressure. In order to maintain the structure in its place and guarantee the sealing of the tunnel, the area of contact between the tunnel wall and the fabric structure should be as large as possible. Consequently, the structure should be inflated as much as possible, so the area of contact with the wall is guaranteed.

However, this inflatable pressure is limited by the tensile strength of the fabric used in the structure. The combination between pressures outside and inside creates a stress state that the fabric, as the main structural component, should support. Furthermore, the size of the structure also is related with the tensile stresses. In both cases, pressure and size, if they are increase the stresses will increase too, therefore the selection of the fabric from the structure will be an important issue in the design process.

Summarizing, the main objective of this tunnel plug structure is seal the tunnel if a flooding occurs inside it. The next figure shows a schematic drawing of the inflatable structure inside the tunnel. As it can be seen, in the front of the tunnel the flooding threat (risk pressure), that is bigger than the pressure at the end (atmospheric), will try to push the structure backwards. When this occur the friction force between the tunnel wall and the structure will prevent this sliding movement. 


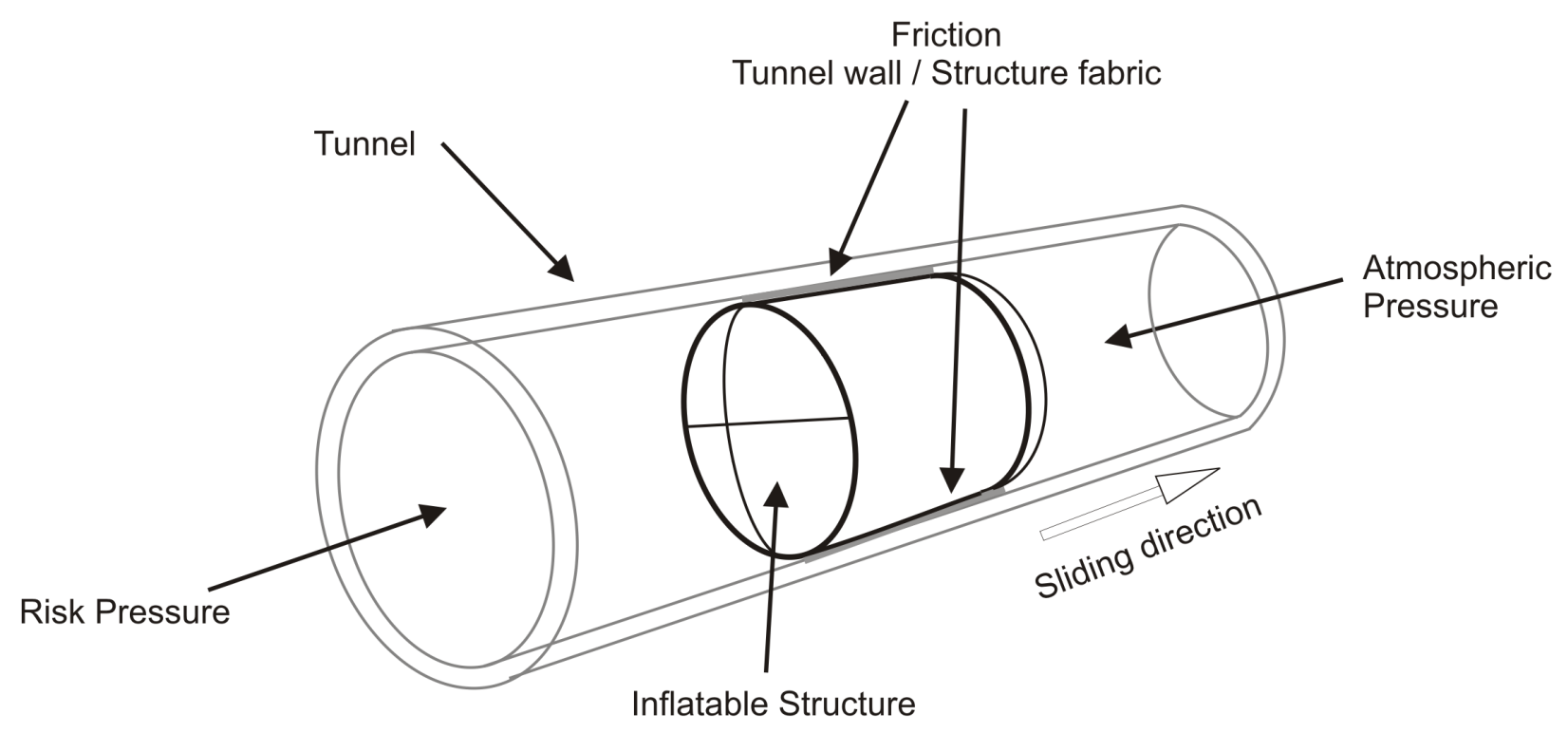

Figure 1.1.1 - Schematic figure of the inflatable tunnel plug inside the tunnel -

\subsection{Objectives}

This work will consist to characterize the fabric for the inflatable structure previously defined. According to the application that this structure will be used, the main fabric properties that characterize the inflatable structure are:

- the tensile strength

- the friction that the fabric has against the concrete tunnel wall

Therefore the main objectives of this research are to characterize these two fabric properties.

On one side, to find the tensile strength of the fabric a tensile test using standards methods should be done in different fabrics. Also a study of the tensile strength in welded 
fabrics should be performed. After testing several fabrics, the designer will be able to use the more convenient for the project structure. Although the tensile strength of the fabrics is known from the manufacturer data sheet, it is required to check if the values are reliable.

On the other hand, to find the friction coefficient of the fabric against the tunnel wall, a friction test should be done. In contrast with the tensile test, for the friction test there is no standard to follow. Therefore another objective is to design an experimental procedure to reproduce the friction coefficient of the fabric/tunnel system. Finally, since it is necessary to ensure the no-sliding of the structure when is sealing the tunnel, several ways to improve this frictional system are studied.

\subsection{Organization}

This thesis is organized into six chapters. In this first chapter the scope of the project and the project's objectives have been defined. Chapter two presents a literature review of inflatable structures and discusses the theory behind them (membranes theories). Chapter three presents a generic literature review for fabrics, discussing some properties and the standard tests for them. Chapter four presents a literature review of friction, detailing the concept and the mechanism of friction, and then discussing the tests method. Chapter five is divided into two main parts: the tensile test and the friction test. In this chapter a description of both tests is done, also a detailed analysis of the results is performed. Lastly, chapter six presents a summary of what has been investigated, conclusions and further works. 


\section{Chapter 2: Inflatable structures - Overview}

\subsection{Inflatable structure overview}

Inflatable structures are flexible, lightweight structures that prior to inflation can be packaged into a very small volume. As the word "inflatable" suggests, the structure is pressurized inside, giving a predefined form that can vary to a wide variety of shapes and sizes. The pressure inside the structures is the one that provides the necessary structural support to the whole structure. This kind of structures are able to absorb loads over a large surface area, this is why some authors say that "Inflatable structures are inherently strong" [1]. Generally the inflatable structures are made with fabrics, being this material the "alma matter" of the structure. However, some structures are reinforced with a stiffness material in order to increase the rigidity and strength of the structure. [1]

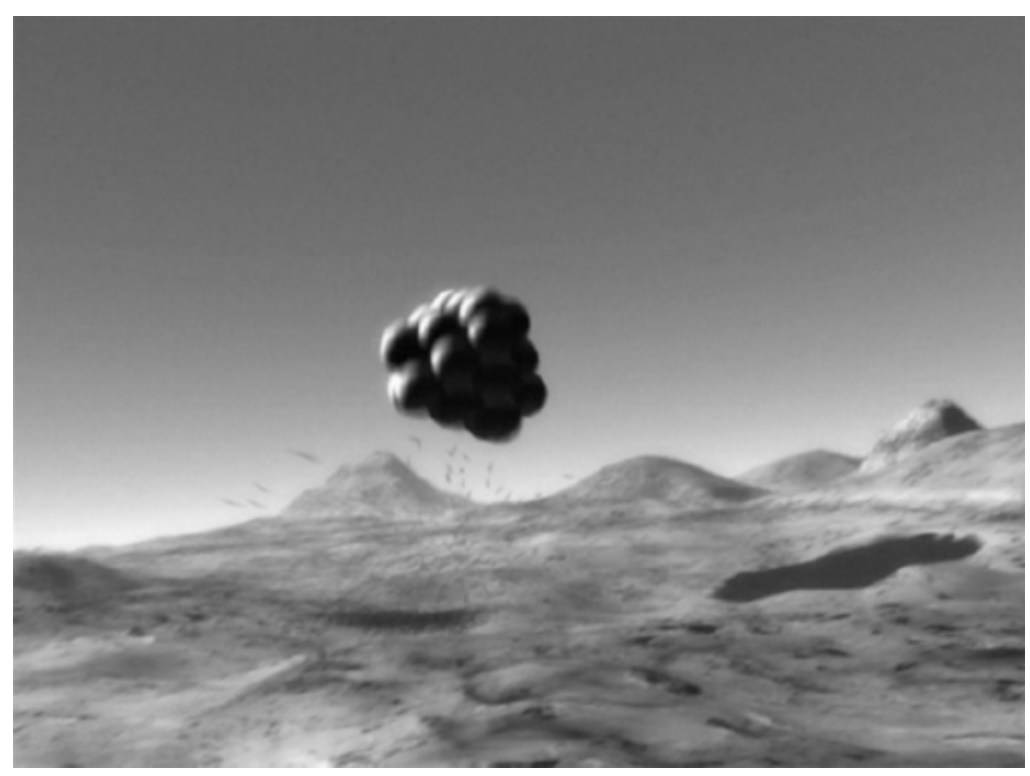

Figure 2.1.1 - Airbags used in the NASA Mars Exploration mission - [18] 
Typical examples of inflatable structures include membrane roofs and covers, inflatable buildings and pavilions, airships, airbags, inflatable furniture, airspace structures, etc.

The main advantage of inflatable structures is the possibility to reduce the overall structural weight. Another important benefit for using inflatable structures is that they can be the packaged in a reduced volume, besides, that can be essentially folded any shape. For that reason, they are easy to transport and handle.

In addition it is important to notice that turning a folded piece of fabric into a rigid structure with a specific shape involves many challenges that exceed those of the structural analysis for the inflated structure. That is why the deployed system became vital in the structure. While packed, the structure has all its flow passages reduced to the minimum, so care must be taken on the design process to allow for enough flow space for the start of the inflating process. The dynamics involved in this process show a different problem as the flow passages will be continuously changing shape. Troubles may still occur if flow passages get blocked due to a bend of the still not completely rigid structure preventing it to follow the desired inflation process. Also, sudden flow passage blocking or reopening will give uneven rise in pressure inside the structure making the movement of the structure unpredictable. A final issue for this type of structures is to accomplish structural accuracy when fully inflated.

Obviously, even noting that the design process presents some drawbacks, the advantages of inflatable structures still makes them worthy for a variety of applications. Some other advantages not mentioned previously include energy absorption, economy in fabrication and less mechanical components than conventional structures. The later being 
very important, as its makes these type of structures greatly independent on mechanical components that are heavy, complex, and prone to cause failure.

Summarizing, inflatable structures are light structures that can be packed in small volumes, they can be easily transported from one place to another and they are simple to build in different scenarios; all this advantages without loosing the strength that a structure should have.

\subsection{Membranes theory in a thin walled pressure vessel}

To analyze better the inflatable structures and moreover the structure regarding to this project is necessary to introduce the concept of membrane tension. This term refers to the design tension that the fabric, as the main structural component, suffers in the inflatable structure. In this section a review of the main concept of membrane tension in thin walls is going to be explained.

Structural analysis of inflatable structures is performed by using membrane theory. However, before introducing this concept, it is required to mention that the strength of the fabrics (main structural component in inflatable structures) is measured in units of force per unit of length and not per units of area (e.g. $\mathrm{lbs} / \mathrm{in}$ or $\mathrm{kg} / \mathrm{cm}$, etc.). The reason for that is because fabrics are thin composite materials, where along its thickness fibers and coating (as the composite matrix) can be found. Therefore, it has no sense to distribute the load along the thickness.

Consequently, the tensile strength in fabrics is quantified by force per unit of length, being this assumption the adopted in the engineer fabric's world. As a result of all 
these, the tensile strength of the fabrics is going to be consider as the force that can be applied to the fabric per unit of length, or in other words the stress times the thickness; hence the fabric tensile strength $\sigma^{*}$ is defined as:

$$
\sigma^{*}=\sigma t
$$

where is $\sigma$ is the strength per unit of area and $t$ is the thickness of the fabric.

After explain this assumption for inflatable structure the concept of membrane theory in thin walled vessels is described. From that theory it can be assumed that the internal forces applied on the walls are always tangent to the surface of the structure, where no bending moments are placed on the walls. So the resulting stresses along the wall will be in a plane tangent to the surface of the vessel, in other words the structural element can be analyzed as a two-dimension case (plane stress ${ }^{1}$ state). For the analysis the vessel structure could be separate into two parts: the cylindrical and spherical.

If the cylindrical part has an inner radius $r$ and a wall thickness $t$, containing a gage pressure $P$ on the inner surface, the plane stresses along the walls can be simplified as:

- The axial stress along the length of the vessel, $\sigma_{A}$.

- The hoop stress, $\sigma_{H}$, which is normal to the axial stress.

To determine the hoop stress, the cylinder is split in half along a plane that passes through the cylindrical axis as shown in Figure 2.2., where $\Delta x$ is a differential portion of the vessel length.

\footnotetext{
${ }^{1}$ Due to the "thin wall" hypothesis, a state of plane stress exist when one of the principal stresses is zero (stresses with respect to the thin surface are zero).
} 


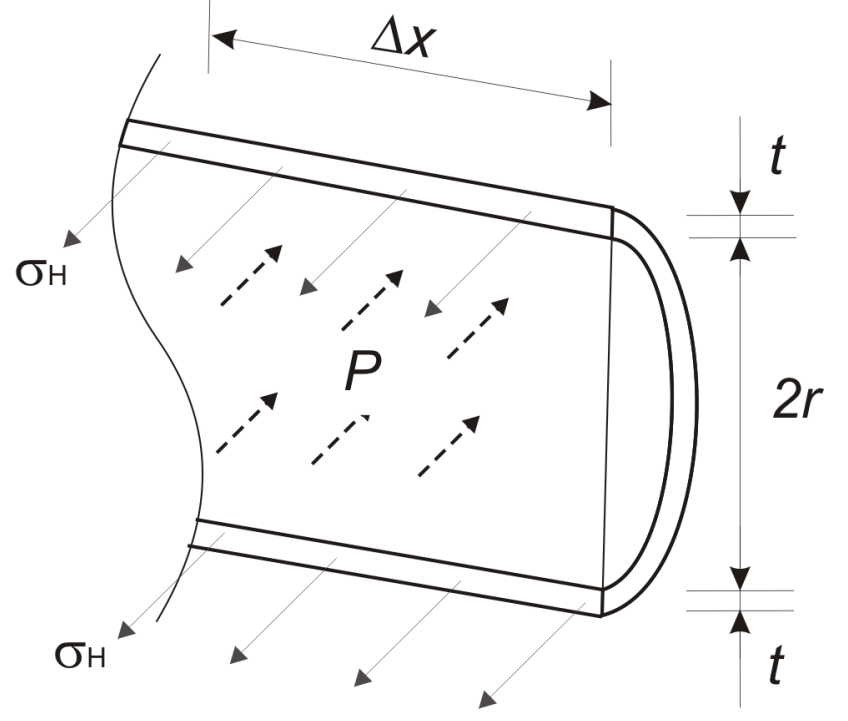

Figure 2.2.1 - Horizontal section along the cylinder portion -

Now, the resulting forces acting perpendicular to the cut section are:

$$
\begin{aligned}
& \text { - The internal force } \quad \sigma_{H} \times 2 t \Delta x \\
& \text { - The pressure force } \quad P \times 2 r \Delta x
\end{aligned}
$$

If these forces are placed in an equilibrium equation perpendicular to the cut plane, the next result is obtained:

$$
P \times 2 t \Delta x=\sigma_{H} \times 2 \Delta x
$$

Finally, simplifying the hoop stress for the cylindrical part of the structure is:

$$
\sigma_{H}=\frac{P r}{t}
$$


To determine the longitudinal stress, the cylinder is cut in the circumferential plane perpendicular to the cylindrical axis as shown in Figure 2.3.

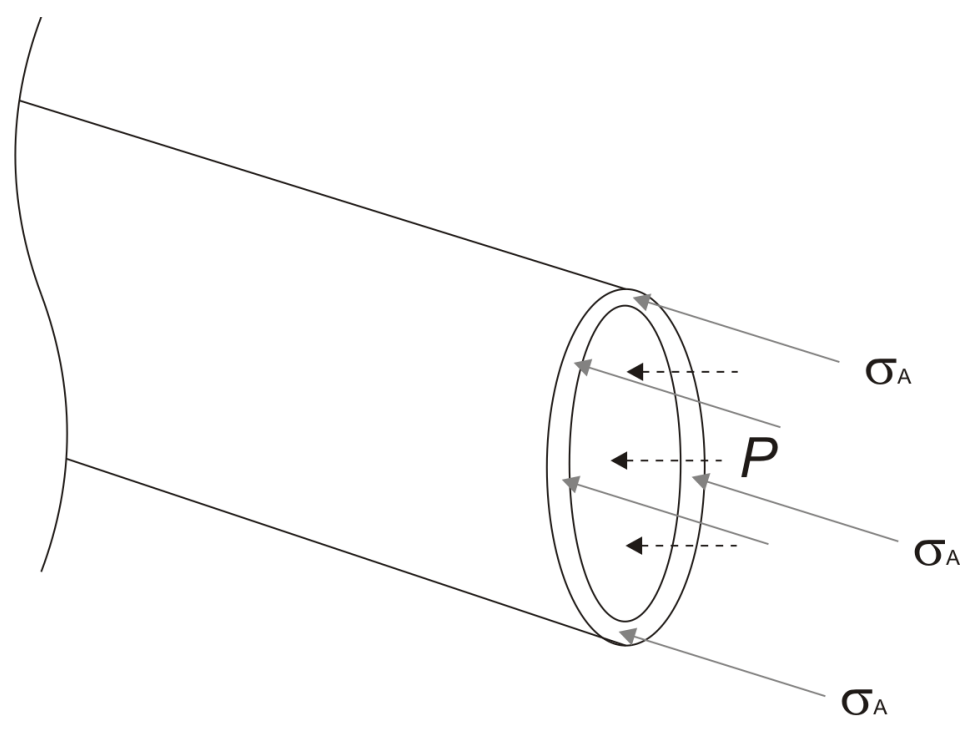

Figure 2.2.2 - Cross section of the cylinder -

Now, the resulting forces acting on the cut section are:

- The internal forces

$$
\sigma_{A} \times 2 \pi r t
$$

- The pressure force

$$
P \times \pi r^{2}
$$

When the equilibrium solution is solved, the internal stress is given by:

$$
\sigma_{A}=\frac{P r}{2 t}
$$


On the other hand, the spherical part of the structure has an inner radius $r$ and a wall thickness $t$, with internal a gage pressure $P$. Now since a sphere is symmetric in all directions there is only one stress that can be described, this stress is called radial stress. In order to find the radial stress, a plane cut can be made along the center of the vessel as shown in Figure 2.4 .

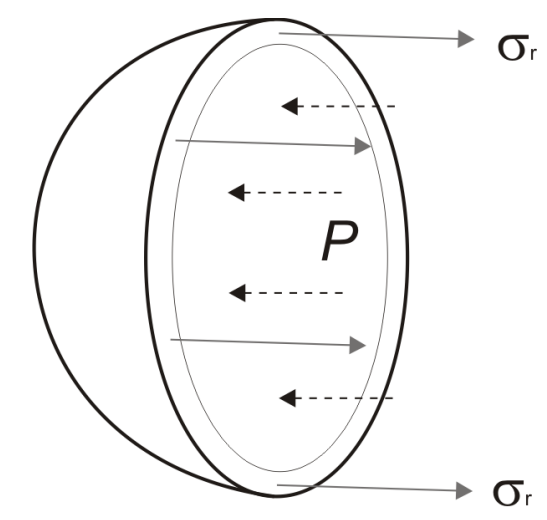

Figure 2.2.3 - Cross section of the sphere-

This cut section shows the same applied forces that act on the longitudinal section of the cylindrical vessel. The equilibrium solution can then be solved for the radial stress, which is given by:

$$
\sigma_{r}=\frac{P r}{2 t}
$$


Now replacing equation 2.1 into equations $2.5,2.8$ and 2.9 , the tensile strengths in the different sections of the structure in terms of $\sigma^{*}$ (strength in fabrics) are:

- Cylinder part

$$
\begin{array}{ll}
\text { Hoop tension } & \sigma^{*}{ }_{H}=P r \\
\text { Axial tension } & \sigma^{*}{ }_{A}=\frac{P r}{2}
\end{array}
$$

- Sphere part

$$
\text { Radial tension } \quad \sigma_{r}^{*}=\frac{P r}{2}
$$

From these three final equations it is really important to notice that any tensile strength that a thin walled vessel structure is going to suffer is going to be between a minimum corresponding to the sphere radial strength $\sigma_{r}^{*}$ or a maximum corresponding to the cylinder hoop strength $\sigma_{H}^{*}$. Hence any strength in a thin walled vessel structure, where no bending moments are placed on the walls, will be between:

$$
\frac{\operatorname{Pr}}{2} \leq \sigma^{*} \leq \operatorname{Pr}
$$




\subsection{Tension analysis in the project}

The project's inflatable structure can be modeled as a thin walled vessel pressurized. Now with this assumption, from the previous section is easy to observe that the maximum tension is going to be along the circumferential part of the cylinder, being two times bigger than the axial tension from the cylinder or the tension in the sphere portion. However, from the practical view in this project this tension is not going to be considered because the cylinder part of the structure is supported by the tunnel wall, therefore the gradient of pressure (or gage pressure) is going to be zero. Hence the only equation that is going to govern the design of the project's structure is equation (2.12), corresponding to the spherical part of the structure:

$$
\sigma_{r}^{*}=\frac{\operatorname{Pr}}{2}
$$

Regarding to this equation, there are two design factors: the gradient of pressure $P$ and the radius $r$ of the sphere portion of the structure. The pressure $P$ is given by the pressure at which the structure is inflated and the pressure outside the structure; in the front of the structure the gradient of pressure will depend on the "risk pressure" (column of water, toxic gas pressure, etc.) and in the back of the structure the gradient will depend on the atmospheric pressure of the tunnel. 


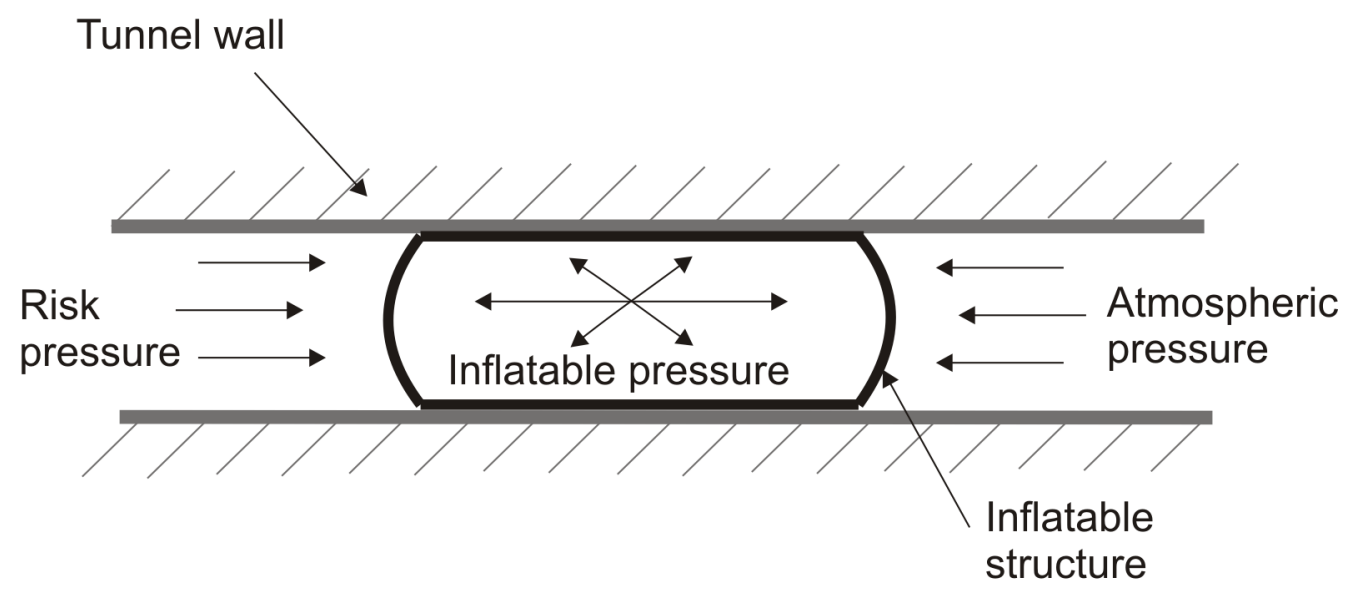

Figure 2.3.1 - Project's cylinder section against tunnel wall -

In the design process the outsides pressures (front and back) are well known, so this is a fixed parameter. However, the inflation pressure is a parameter that the designer will have to study. If the outside pressure is bigger than the inflatable one, the structure will deform until equilibrium is reached; in this case the internal structural pressure is fixed and defined by the exterior pressure. The gradient of pressures $P$ is defined with the external pressure in front of the tunnel and the atmospheric pressure in the back.

Another situation is when the inflatable pressure is bigger than the risk pressure. Hence, in this case, the gradient of pressure $P$ is defined by the inflatable pressure inside the structure and the atmospheric one at the back of the tunnel.

Summarizing, whichever the situation is, if the gradient $P$ of pressure increases in magnitude the used fabrics in the structure should be stronger (larger tensile strength). Therefore the designer will have analyzed all the possible pressure combinations, calculating by this way the maximum tensile stress that the fabric should support. 
On the other hand, the radius $r$ of the sphere part of the structure also depends on the tensile strength of the fabric. A bigger radius implies a larger tensile stresses, and with small radius the tensile stress is reduced. In this project, the radius depends on the diameter of the tunnel, the bigger the tunnel diameter is the bigger the front radius of the spherical part of the structure.

It is important to see that the diameter of the tunnel not necessarily is two times the radius of the sphere, the designer is the one who fixes this "dome" radius. However the smallest radius that a designer can use is rightly the half of the tunnel diameter, therefore, the most convenient for the project.

Since the radius of the "dome" structure is almost predetermined by the tunnel diameter and the inflatable pressure is determined by the external ones, the only parameters that the designer is allowed to change are the fabrics from the structure and new geometrical shapes that let the designer reduced the radius of the dome. 


\section{Chapter 3: Fabrics - Overview}

\subsection{Fabric characterization}

Basically a fabric is a flexible material produced by interlacing yarns. Each yarn is done by interlocking fibers or filaments, in suitable form for knitting, weaving, or otherwise intertwining to form a textile fabric.

Fiber is called "the unit of matter", which is either natural or manufactured. It forms the basic element of fabrics and other textile structures, and it is characterized by having a length 100 times its diameter or width.

Filament is a single long fiber. Synthetic fiber is initially produced as single filaments made when liquid polymer is forced through fine holes in a device called a spinneret. The resulting filaments are hardened, drawn, and twisted to produce a yarn, or cut to form staple (shorter) fibers.

Instead of a group of filaments being extruded through a spinneret to form a yarn, monofilaments generally are spun individually. Monofilaments can be used for textiles such as hosiery or sewing thread or for non-textile uses such as bristles, papermaker's felts, fishing lines, etc. 
Again, yarn is a generic term for a continuous strand of textile fibers, filaments, or material which can occurs in the following forms:

(1) a number of short fibers (staple) twisted together (spun yarn) (see figure 3.1);

(2) a number of filaments laid together without twist (a zero-twist yarn);

(3) a number of filaments laid together with a degree of twist;

(4) a single filament with or without twist (a monofilament);

(5) a narrow strip of material, such as paper, plastic film, or metal foil, with or without twist, intended for use in a textile construction.

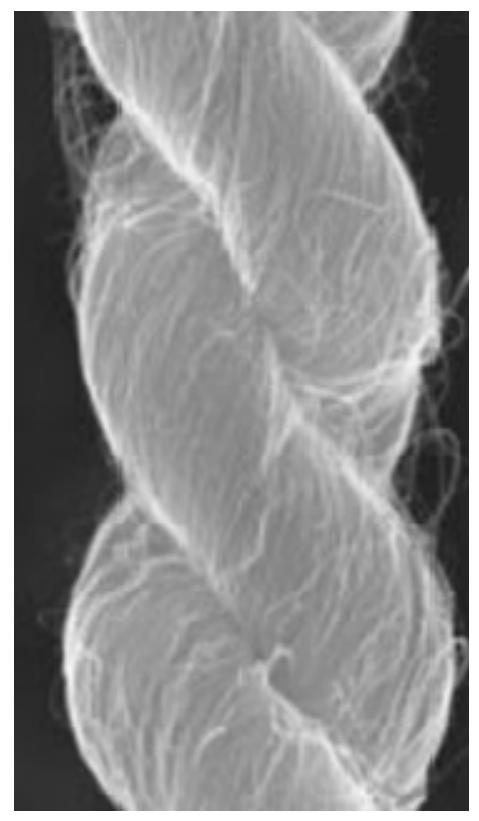

Figure 3.1.1 - Carbon spun yarn - [2]

Again, to produce a fabric it should necessary to interlace these yarns, to perform that the most common methods are the weaving and the knitting. The weaving is a textile production method which involves interlacing a set of longer threads (called the warp) with a set of crossing threads (called the weft or fill). 


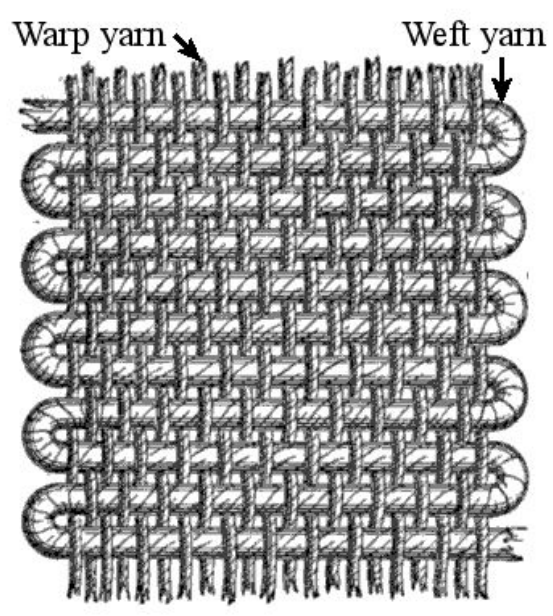

Figure 3.1.2 - Warp and Weft in a plain weaving - [19]

The knitting and crocheting involve interlacing loops of yarn, which are formed either on a knitting needle or on a crochet hook, together in a line. The two processes are different in that knitting has several active loops at one time, on the knitting needle waiting to interlock with another loop, while crocheting never has more than one active loop on the needle.
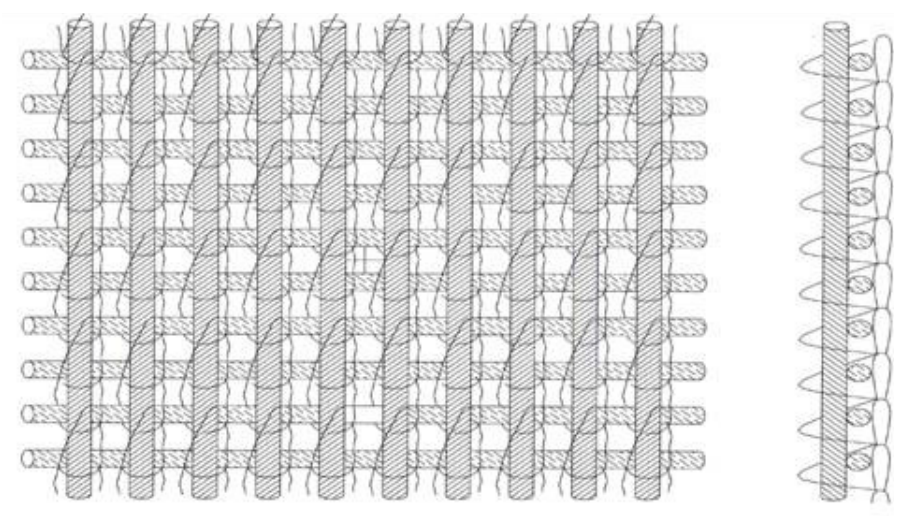

Figure 3.1.3 - Schematic weft Knit fabric - [20] 
Fabrics can be made only with fibers yarns, or as other composite material they can be constitute by a matrix, called in this case coating. Hence, fabrics could be uncoated or coated.

\subsection{Different types of fabrics}

The main constituent in the fabrics are the fibers, which can be made from many materials that come from four main sources: animal, plant, mineral, and synthetic. Although the mineral fibers such as carbon or glass have excellent properties, there are not suitable because they are too rigid for the inflatable structures; therefore, the synthetic fibers are the ones that have more interest in this research.

There are many different synthetic fibers; however, for the research proposes the most suitable are the followings [3]:

(1) Polyester and nylon are the two most common fibers in use today, they are inexpensive and they have a well known behavior.

(2) Aramid (Kevlar) is a light fiber that has an outstanding strength-to-weight property, high tenacity and young's modulus, low creep, low elongation at break, etc. They are common used for flame-retardant clothing, cut-protection, armor, etc.

(3) Spectra is form by oriented-strand synthetic fibers of "ultra high molecular weight polyethylene", also it has an excellent strength/weight ratio as much as 15 times stronger than steel and up to $40 \%$ stronger than Aramid. They are used in bulletproof 
vests, bow strings, sports equipment, spear lines for spear guns, high performance sails, etc.

(4) PBO (Poly Benzol Oxylene) is a of thermoset polyurethane polymer used for applications that require very high strength with excellent thermal stability.

(5) Vectran is a spun fiber made from a liquid crystal polymer. These fibers are noted for thermal stability at high temperatures, high strength and modulus, low creep, and good chemical stability. They are used as reinforcing fibers for ropes, cables, and advanced composite materials, professional bike tires, and in electronics applications [4].

On the other hand, coating is usually an adherent polymeric material that provides consistency and protects the fibers. There are different coatings, like PVC (Polyvinyl chloride), Vinyl, PTFE (Teflon), Silicone, Neoprene, etc.

\subsection{Physical properties}

To do the structural analysis for fabric structures is it necessary to choose the proper fabric for the project, in this work for an inflatable structure. Therefore it is very important to characterize the fabrics, and for that, is essential to know the physical properties of the fabric, as a composite material. 
Thus it is important to know the properties of each composite constituent (fibers and matrix). The more concerning properties of the fabric for an inflatable structure are listed below:

- Abrasion Resistance

- Aging

- Blocking

- Bow and Skew

- Breaking Force \& Elongation (Tensile Strength)

- Burst Strength

- Coating Adhesion

- Fatigue Behavior
- Flammability

- Damping characteristics

- Mass per unit the area

- Packability

- Permeability

- Temperature effects

- Coating Weight

The majority of the definitions of these properties are covered by the standard ASTM D $6799-07$, where most of the terminology for inflatable structures is commented. For a better interpretation of the analysis in this work, some of them are defined:

- Aging is the physical or chemical change in a textile material due to the exposures to heat, humidity, ozone, chemicals gases, etc., or a combination of all of them. Also, these environmental conditions may be cycled in combination. Since this effect can produce the partial or total loose of the strength in the fabric, it is required to consider it in the design of the structure. For that, is recommended to test the using a controller environmental chamber; ASTM D 5427 - 03 describes the procedures for the accelerated aging.

- Tensile strength is the force applied to a fabric carried to rupture, in other words, is the force at the moment of break (see figure 3.6). The tensile test is the test in which a fabric material is stretched in the longitudinal direction of the yarns to determine its ultimate tensile strength (the maximum force that the fabric can 
withstand). This test is also useful to determine elongation characteristics of the fabric. There are different procedures to determine the tensile strength (and elongation), but for coated fabrics used in inflatable structures the most suitable standards are the ASTM D 5034 - 95 and the ISO 1421:1998 (E).

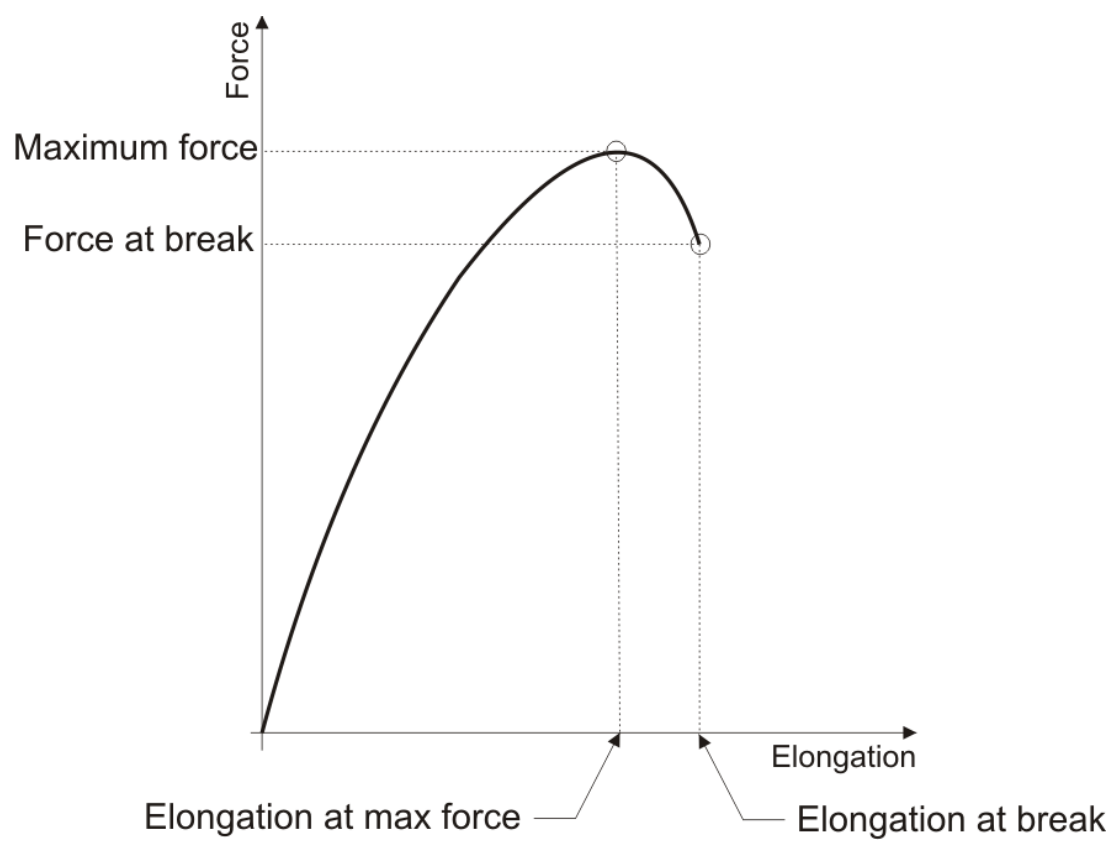

Figure 3.3.1 - Tensile force at break -

Specifically, the maximum tensile stress is expressed in force per unit length of the unstrained specimen, e.g., kilograms per centimeter or pounds per inch.

- Flammability is the ease with which a fabric will ignite, causing fire or combustion, the flammable properties of the fabrics are given by the flammable characteristics of it constituents: fiber and coating. The degree of difficulty required to cause the combustion of the fabric is subject to quantification through fire testing. Internationally, a variety of test protocols exist to quantify flammability, for the fabrics it is recommended to use the Federal Motor Vehicle Safety Standard 302. 
- Packability means the compressibility of a folded fabric relative to the space available in a storage module. The volumetric index of compressibility for this folded fabric measured at specified levels of compression is called specific packability. ASTM D 6478 -02 describes the procedures for determining the ability to fold and pack fabrics using the index of specific packability.

- Permeability is the state or quality of being penetrable by fluids or gases. A particular case is when the fabric is waterproof; this term is applied to fabrics that are impermeable to water, waterproof fabrics have all their pores closed and are also impermeable to air. ASTM D 6476 - 05 covers the procedures used to determine the permeability of uncoated fabrics under dynamic airflow conditions; for the determination of air permeability of fabrics under low pressure conditions at steady-state air flow, is necessary to refer to the ASTM D 737.

Also, if it is necessary to join two or more pieces of fabric, it will be indispensable to study the way that this union is performed. In the fabric structures manufacture world exits two type of process to join the fabric elements: sewing or welding. Therefore, an analysis of the sewing or welding is needed:

- Sewing is a process where sewing machine is used to join the elements of the structure; the element of union is called seam, which is made with a needle and a thread. The way how the seam is made and the material properties of the thread is what gives the sewing strength property, seams can fail as a result of rupture, slippage, or a combination. Rupture can be categorized as failure of the fabric or the seam sewing thread. Sewing offers several advantages, including that the seam can be removed (welded unions cannot be removed without destroying the material); also, sewing provides a very strong seam, particularly with industrial 
sewing machines. However, since sewing makes holes in the material, the resulting seam is generally not waterproof and the holes may weaken the fabric. ASTM D 1683 measures the sewn seam strength in woven fabrics by applying a force perpendicular to the sewn seams.

- Welding in fabrics as other welding method is a process that joins fabrics materials by melting the work pieces (thermoplastic process). When these joint cools down, the coating of the two fabrics became only one, carrying the loads to the fibers from both welded fabric pieces. Generally welding is done by adding heat and pressures, in the case of fabric welding joints there several welding methods available: High Frequency or Radio Frequency (HF or RF), Hot Air, Impulse Welding, Ultrasonic Welding and Laser Welding. [3] 


\subsubsection{Test methods for a fabric characterization}

To characterize the properties of the fabric listed in previous section several tests

have to be performed. Besides the ones commented in the previous section, table 3.1

shows a complete list of the different properties and the existing standards to characterize each property.

Table 3.3.1 - Standard for each respective property -

\begin{tabular}{|c|c|}
\hline Property & Standard \\
\hline Abrasion Resistance & $\begin{array}{l}\text { ASTM D } 4157 \text { Test Method for Abrasion Resistance of Textile } \\
\text { Fabrics (Oscillatory Cylinder Method) }\end{array}$ \\
\hline Aging & $\begin{array}{l}\text { ASTM D } 5427 \text { Practice for Accelerated Aging of Inflatable } \\
\text { Restraint Fabric }\end{array}$ \\
\hline Blocking & SAE Standards J912-A Resistance to Blocking \\
\hline Bow and Skew & $\begin{array}{l}\text { ASTM D } 3882 \text { Test Method for Bow and Skewness in Woven } \\
\text { and Knitted Fabrics }\end{array}$ \\
\hline Breaking Force \& Elongation (Tensile Strength) & $\begin{array}{l}\text { ASTM D } 5034 \text { and ISO 1421:1998 (E) Tests method for } \\
\text { Breaking Force \& Elongation of textile fabrics (grab test) }\end{array}$ \\
\hline Burst Strength & $\begin{array}{l}\text { ASTM D } 3786 \text { Test Method for Hydraulic Bursting Strength of } \\
\text { Knitted Goods and Nonwoven Fabrics-Diaphragm Bursting } \\
\text { Strength Tester Method }\end{array}$ \\
\hline Coating Adhesion & $\begin{array}{l}\text { ASTM D } 4851 \text { and Ford Motor Company Standards FLTM } \\
\text { BNI3-I Tests Method for Coated and Laminated Fabrics }\end{array}$ \\
\hline Coating Weight & $\begin{array}{l}\text { ASTM D } 3776 \text { option C Test Method for Mass Per Unit Area } \\
\text { (Weight) of Woven Fabric }\end{array}$ \\
\hline Damping characteristics & $\begin{array}{l}\text { No specific standard, see ASTM D 5279, D 5026, D 5023, D } \\
\mathbf{5 0 2 4} \text { for a general characterization of the thermomechanical } \\
\text { behavior of plastic compositions using a very small amount of } \\
\text { material }\end{array}$ \\
\hline Fatigue Behavior & See aging \\
\hline Flammability & Motor Vehicle Safety Standard 302 \\
\hline Mass per unit the area & $\begin{array}{l}\text { ASTM D } 3776 \text { option C Test Method for Mass Per Unit Area } \\
\text { (Weight) of Woven Fabric }\end{array}$ \\
\hline Packability & $\begin{array}{l}\text { ASTM D } 6478 \text { Test method for determining the index of specific } \\
\text { packability }\end{array}$ \\
\hline Permeability & $\begin{array}{l}\text { ASTM D } 6476 \text { Test method determining the permeability of } \\
\text { uncoated fabrics under dynamic airflow conditions } \\
\text { ASTM D } 737 \text { Test Method for Air Permeability of Textile Fabrics } \\
\text { at steady state conditions }\end{array}$ \\
\hline Temperature effects & See aging \\
\hline Seam Strength & $\begin{array}{l}\text { ASTM D } 1683 \text { Test method to measure the sewn seam strength } \\
\text { in woven fabrics by applying a force perpendicular to the sewn } \\
\text { seams. This test method is used in conjunction with Test Method } \\
\text { D } 5034\end{array}$ \\
\hline Welding Strength & No specific standard \\
\hline
\end{tabular}


For a more detail list of standard see ASTM D 5446. This standard list the test methods commonly employed in determining the physical properties of fabrics and yarns used in the manufacture of inflatable structures (such as airbags, balloons, etc.).

In addition, if it is necessary to look for definitions and terminology is recommended to see ASTM D 123 and D 3990. Also ASTM D 6799 covers the terminology which is used in the evaluation of inflatable restraints fabrics.

\subsection{The fabrics in the project}

In this first stage of the project, in which the feasibility of the solution is studied, there are two important properties of the fabrics for the interest in this work:

- $\quad$ tensile strength (non-welded and welded)

- friction of the fabric against the concrete wall of the tunnel

In chapter 5 (section 5.1) there is an analysis of the tensile strength for different fabrics, where different tensile tests are performed. In chapter 4 (section 4.4) the friction of fabrics as an elastomer is described. Later, in chapter 5 (section 5.2) an analysis of the fabric/tunnel wall frictional system is performed. 


\section{Chapter 4: Friction - Overview}

\subsection{History}

The phenomenon of Friction has been subject of systematic, documented studies and measurements for thousands of years. From the use of friction in the lightening of fires to the super rolling bearings in the jet engines, Friction has represented always a concern to the scientist and to the engineering world.

The scientific study of this phenomenon started in the sixteenth century when Leonardo da Vinci (1452-1519) sketched several types of apparatus to study sliding friction. However, da Vinci never mentioned the term "Friction" in any of the works that he wrote.

Later, with the help of the Newton's first law, enunciated in the seventeenth century, more intensive investigations took place. The main investigators in the subsequent centuries include G. Amontons (1663-1705), L. Euler (1707-1783), C. Coulomb (1736-1806) and A. Morin (1795-1880). The main hypothesis of these engineers and scientists was that friction is due to the interference between the mechanical protuberances or asperities on the surface of the contacting materials.

However Amontons was the first one to introduce the two classical laws of friction:

1. The force friction is directly proportional to the applied load.

2. The force friction is independent of the apparent area of contact. 
Although these concepts are the first ones that an engineer will learn, these two simple laws are not always obeyed and there are a number of cases where do not hold.

Euler was the first one to understand and clarify the distinction between static and kinetic friction. After doing different experiments he concluded that the magnitude of the static friction coefficient must be bigger that the kinetic one for classical materials. Also Euler was the first to introduce the Greek symbol $m u(\mu)$ to name the friction coefficient.

Coulomb studied the behavior of contacting materials, the influence of the surface area, the consequence in the contact are due to different normal pressures (load), and the "time of response" (length of time that the surfaces remained in contact). Most of these concepts are still used today for friction applications: like bearing, seals, brakes or piston rings.

Morin did a great contribution to the understanding of the rolling and sliding friction during the industrial revolution. He helped to improve the machinery of that time: researching about the friction in bearings for grain mills, the friction in windmill and waterwheels, friction in belting and the friction in brakes.

In addition during the industrial revolution and in the subsequent years the relation between contacting surfaces and lubrication was investigated more deeply. Also a new hypothesis about the cause of the friction was introduced: "the adhesion", the friction is due to adhesion forces between the contacting surfaces.

With the help of the technological advances in microscopy during the twentieth century investigations were focused to study and characterize the structure and micro- 
geometry of real surfaces. Therefore the studies of friction were focused to the hypothesis of "adhesion". Beside these studies, engineering and scientist started to investigate the interaction between friction, wear and lubrication, bringing to the engineering world a new mechanical science called Tribology.

\subsection{Tribology}

Before talking about the characteristics of friction, it is necessary to introduce the science that is under the friction: Tribology.

Tribology is defined as the science technology of interacting surfaces in relative motion, the word Tribology is based upon the Greek word tribos, meaning rubbing. Hence the studying of the interrelation between of friction, lubrication and wear is the most important challenge of this science.

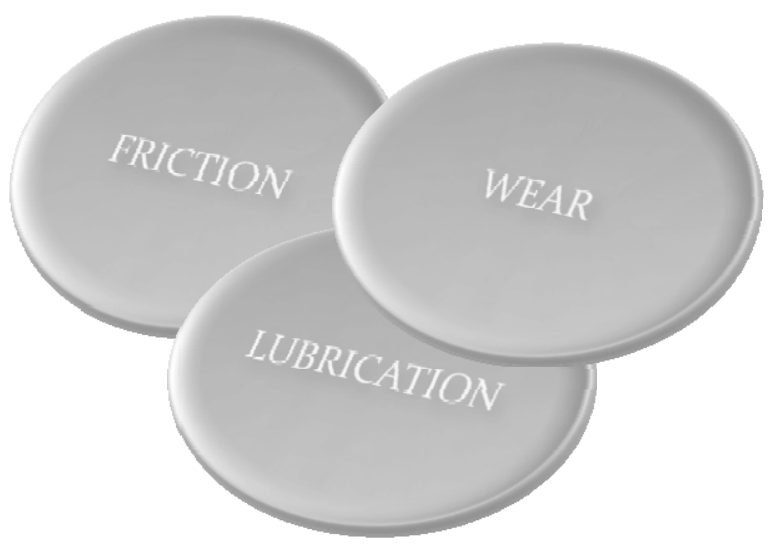

Figure 4.2.1 - Tribology sciences scheme -

In any machine there are lots of component parts that operate by rubbing together. Some examples are bearings, gears, cams and tappets, tires, brakes, etc. All of these 
components have two surfaces which come into contact, support a load, and move with respect to each other. Sometimes it is desirable to have low friction, to save energy, or high friction, to stop movements. Besides this, to control the wear in these rubbing machines, it is necessary to lubricate the components; therefore is required to use the tribology to analyze and understand the interrelation of friction (rubbing), lubrication and wear between the components.

\subsection{Friction Characterization}

\subsubsection{Fundamentals of Friction}

Friction is around in everyday life, from bearings in aerospace jet propulsion engines to the sole of our shoes. There are many cases where a low friction is required (e.g. bearings, mechanisms, materials manufacturing), and there are sometimes where high friction is desired (e.g. brakes, shoe's sole, screw threads). Hence, in order to better understand this phenomenon it is necessary to study, analyze, quantify and predict it.

Friction is generally defined as "the resistance to motion which exits when a solid object is moved tangentially with respect to the surface of another which it touches, or when an attempt is made to produce such friction" [5].

In engineering words, the friction could be expressed and quantify as a force, being a non conservative force ${ }^{2}$, resisting to relative motion between two surfaces in contact.

\footnotetext{
${ }^{2}$ Any force field which the work done in moving an object from one point to another is dependent of the path that is taken.
} 
Other authors define friction as:

- "The resisting force tangential to the interface between two bodies when, under the action of an external force, one body moves or tends to move relative to the other" [6].

- "The force exerted by either of two contacting bodies tending to oppose relative tangential displacement of the other." [5]

After defining the friction force it is helpful to distinguish two situations: when the frictional force is enough to prevent the movement (static behavior) and when the sliding is not occurring (kinetic behavior). The "static behavior" could be characterized as the situation where the friction force will be equal and opposite to the resultant of the applied forces and no motion will occur. The "kinetic behavior" refers to the condition where the forces applied are enough to cause movement, when this motion occurs the friction force will always act in a direction opposite to the relative displacement of the surfaces.

Although the previous statements are true from a macroscopic point of view, exceptions are found in a microscopic scale. For the "static behavior", it could be found when the frictional system is in repose and a force is applied, a very small displacement occurs despite the friction force is equal and opposite to the ones applied. And for the "kinetic behavior", when the movement occurs, the instantaneous friction force may has very small fluctuations in the direction (stick-slip behavior, see section 4.3.3). 
Once the definition of friction is cleared, it is necessary to identify the principal laws of friction. From the principal frictional scientists three laws can be enumerated:

1. The force of sliding friction $F$ is proportional to the force perpendicular to the surface $N$. [7]

$$
F=\mu N
$$

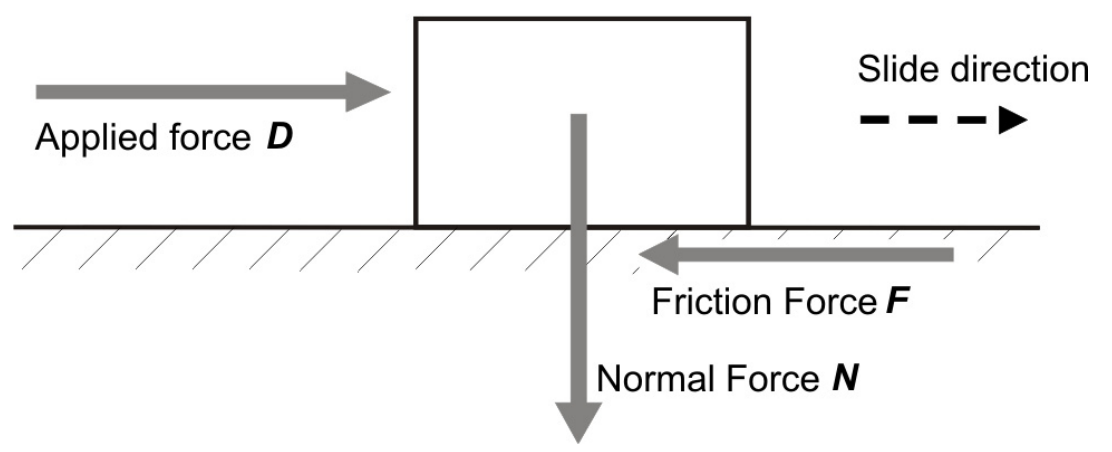

Figure 4.3.1 - Schematic illustration for a simple sliding surface -

In equation $4.1 \mu$ stands for the friction coefficient. A more detailed description of this concept is provided afterwards (see section 4.3.2).

2. The friction force is independent of the apparent $\mathrm{area}^{3}$ of contact. Therefore large or small objects have the same force proportionality (same friction coefficients). [7]

\footnotetext{
3 "The apparent area is the total interference area, consisting of both the real area (the sum of areas for all the contacting junctions) of contact and those regions that appear as if contact might have been made there (but was not)" [Rabinovicz]
} 
3. The friction force is independent of the sliding velocity. This involves that the force required to initiate motion will be the same as the force to maintain sliding at any specified velocity. [5]

These three laws imply that the friction systems are proportional to the normal force $(\mathrm{N})$, and independent of the apparent area or the sliding velocity. They are simple laws, easy to understand and very useful in the engineering world. However, there are not always true, some examples of this will be described in the following next.

A case where the friction force is not proportional to the load (1st law) could be when a solid with a thin hard surface layer slides in a softer one, when high loads are applied the hard surface brakes the softer one and the properties of the substrate (softer surface) become more important in the frictional system.

A condition where the second law is not obeyed could be when the area of contact is very smooth and very clean. In this system, the friction force will be independent of the normal force; however, it becomes proportional to the area of contact.

Finally, the last law which states that friction force is independent of velocity it is not as well obeyed as the first two. Experimental works has shown that the friction coefficient, specially the kinetic one, is a function of velocity throughout a range of velocities [5].

Besides all this examples, the previous three historical laws are useful for most of the simple frictional systems. If specials cases are under studied and a more detailed 
analysis is required, it is necessary to take those considerations that were explained in the examples.

\subsubsection{Friction Coefficient}

In the previous section the friction coefficient was defined as the "Proportionality between the sliding friction force $F$ and the force perpendicular to the surface $N$ "' (see figure 4.1.1.1), this is symbolized by $m u \mu$ (equation 4.1.1.1). Hence in other words, the friction coefficient could be expressed as:

$$
\mu=\frac{F}{N}
$$

Also, like an alternative, the friction coefficient could be expressed as the tangent of a constant angle of repose $\theta$, called friction angle.

$$
\mu=\tan \theta
$$

The friction angle $\theta$ is the maximum angle of an inclined plane for which any object, whatever its weight, placed on the plane will remain stationary. If the angle is increased by any amount the object will start to slide down. Hence in other words, higher friction angle implies higher friction coefficient. The next figure shows the schematic force diagram for an object on an inclined plane. 


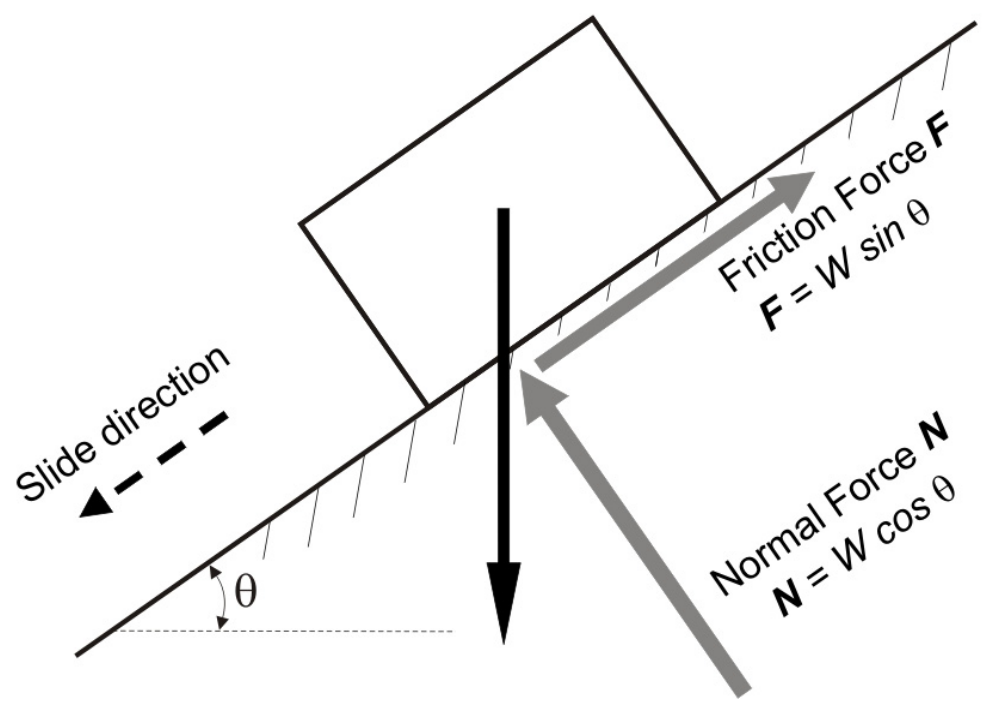

Figure 4.3.2 - Schematic illustration for an inclined frictional system -

After defining the friction coefficient it is necessary to note that there are two friction coefficients: the static friction coefficient for surfaces that are in rest and the kinetic friction coefficient for surfaces in motion.

The static friction is the force that holds back a stationary object up to the point that it just starts to move. Thus, the static friction coefficient $\mu_{\mathrm{s}}$, concerns the force restricting the movement of an object that is stationary. It is calculated by finding the initial peak force (frictional force $F$ ) required to move the object and dividing the value by the normal force $N$ (weight of the object).

$$
\mu_{S}=\frac{F_{P E A K}}{N}
$$


Once the static friction is overcome, kinetic friction follows and is the force holding back regular motion. This kinetic friction coefficient $\mu_{\mathrm{K}}$ concerns the force restricting the movement of an object that is sliding. It is calculated by finding the average load (frictional force $F$ ) during the test and dividing this by the normal force $N$ (weight of the object).

$$
\mu_{K}=\frac{F_{A V E R A G E}}{N}
$$

Figure 4.4 shows a typical case of the behavior of two objects sliding against each other. As this figure shows, the kinetic friction force is generally smaller than the static one, therefore, the kinetic friction coefficient $\mu_{\mathrm{K}}$ is smaller than the static one $\mu_{\mathrm{s}}$.

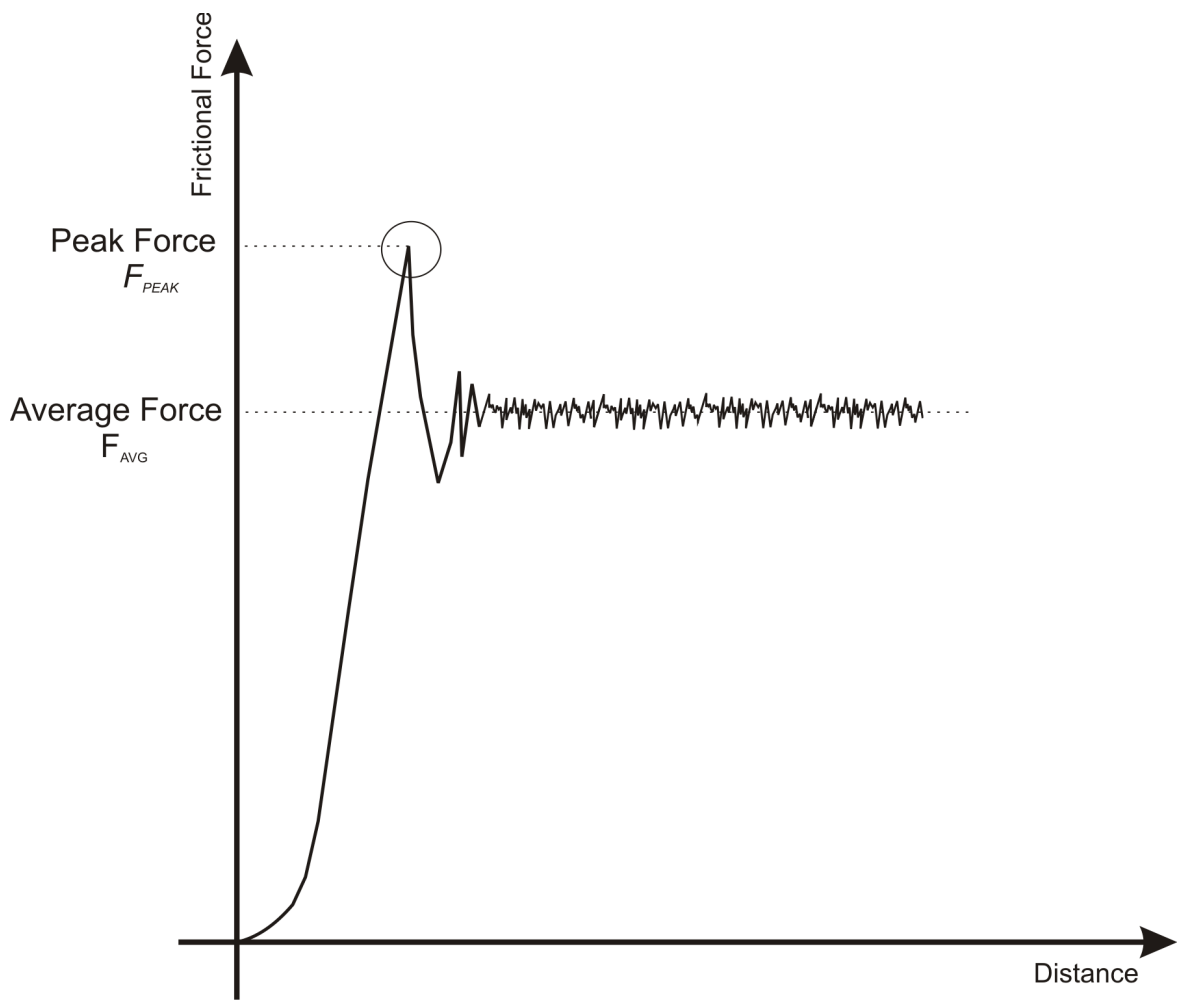

Figure 4.3.3 - Schematic illustration for a typical friction behavior - 
Values for static and kinetic friction coefficient are conveniently tabulated in engineering handbooks. The following table [8] shows a list of different friction coefficients for the more frequent used materials.

Table 4.3.1 - List of friction coefficient for well know materials -

\begin{tabular}{|c|c|c|c|}
\hline \multirow{2}{*}{ MATERIAL 1} & \multirow{2}{*}{ MATERIAL 2} & \multicolumn{2}{|c|}{ Coefficient of Friction } \\
\hline & & Static & Kinetic \\
\hline Aluminum & Aluminum & $1.05-1.35$ & 1.4 \\
\hline Copper & Copper & 1 & - \\
\hline Diamond & Diamond & 0.1 & - \\
\hline Glass & Glass & $0.9-1.0$ & 0.4 \\
\hline Glass & Metal & $0.5-0.7$ & - \\
\hline Graphite & Graphite & 0.1 & - \\
\hline Iron & Iron & 1 & - \\
\hline Leather & Wood & $0.3-0.4$ & - \\
\hline Leather & Metal & 0.6 & - \\
\hline Nylon & Nylon & $0.15-0.25$ & - \\
\hline Plexiglas & Plexiglas & 0.8 & - \\
\hline Plexiglas & Steel & $0.4-0.5$ & - \\
\hline Polystyrene & Polystyrene & 0.5 & - \\
\hline Polystyrene & Steel & $0.3-0.35$ & - \\
\hline Rubber & Concrete & - & $0.6-0.85$ \\
\hline Rubber & Solids & $1.0-4.0$ & - \\
\hline Silver & Silver & 1.4 & - \\
\hline Steel & Aluminum & 0.45 & - \\
\hline Steel & Brass & 0.35 & - \\
\hline Steel & Graphite & 0.1 & - \\
\hline Steel & Polystyrene & $0.3-0.35$ & - \\
\hline Steel & Steel & 0.74 & 0.57 \\
\hline Teflon & Teflon & 0.04 & - \\
\hline Wood & Wood & $0.25-0.5$ & - \\
\hline Wood & Concrete & 0.62 & - \\
\hline
\end{tabular}


As table 4.1 shows there is a wide range of values for the static and kinetic friction coefficient. The lowest the value of friction coefficient is, easier the relative movement between the components is; and vice versa for the higher ones. To have a physical sense (big or small) what the friction coefficient value is, lets say that for a static friction coefficient equal to one, the force needed to move one of the surfaces must be the same as the normal load applied to the surfaces.

\subsubsection{Mechanisms of sliding Friction}

In section 4.3.1 friction was defined by forces between two contacting bodies, tending to oppose relative tangential displacement.

Now, when these surfaces approach one to another, contact starts to occur at the asperities of the bodies, and there is when the friction mechanism starts. Scientists have discussed for years which are the mechanisms and a lot of hypothesis where carried out; of all mechanism defined, there are three that can be considered the most important ones: the ploughing, the adhesion and the viscous drag. Figure 4.5 shows a representation of these three hypotheses. 


\section{PLOUGHING}

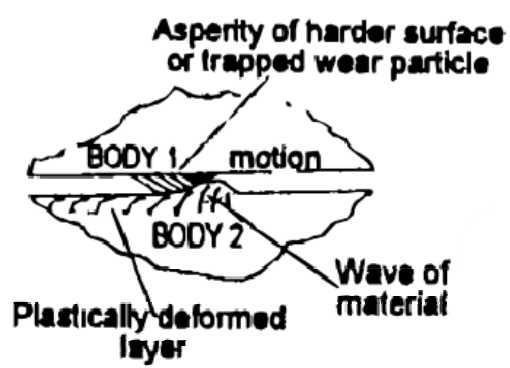

ADHESION

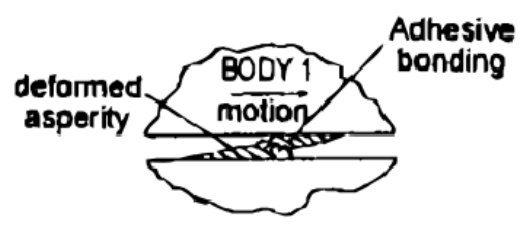

VISCOUS DRAG

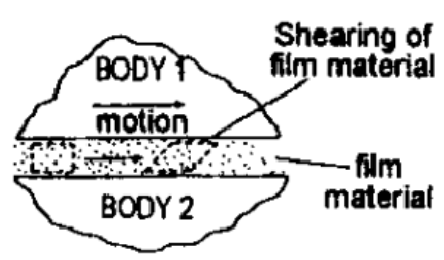

Figure 4.3.4 - Mechanisms of friction: ploughing, adhesion and viscous drag - [9]

The ploughing (plowing) is the first hypothesis that was became important around the friction science, authors explained the cause of friction as the elastic and plastic deformation of the asperities between two rough surfaces. This interaction, during sliding, is simply explained as the necessary energy to move one surface over the roughnesses of the other. For example, if a hard surface with sharp asperities slids over a soft surface, it will tend to dig into the softer surface producing damage (groove); the energy of deformation represented by the damage must be supplied by the friction force. Similarly, sharp asperities on a hard surface can produce scratches when slid over a softer surface, and again an addition to the friction force is involved.

Adhesion is defined as "the molecular force of attraction in the area of contact between two unlike bodies that acts to hold them together" [10]. With this definition scientists understand the adhesion as a mechanism that is based on an environment in which two rough surfaces are placed close together, where the asperities of the surface 
touch each other, causing that molecular bond between the surfaces. To begin the relative motion the bonds must be broken, hence, the force to overcome the shear strength of the bonds results in the friction force.

As the normal force $N$ increases, the contact area increases where the asperities peaks became flat (depends on the hardness of the surfaces). Hence, new adhesive bonds are formed at that real contact area. So, it is significant to comment that when the area of contact is bigger the friction is larger, therefore, polish surfaces have more friction than the rough ones. With the use of this hypothesis, scientists explain why several materials in certain conditions have very high friction coefficients; e.g. aluminum against aluminum $\mu_{\mathrm{S}}$ bigger than 1 , glass against glass $\mu_{\mathrm{S}}$ equal to 1 , etc.

In addition to adhesion, a frequently behavior that could be seen in friction systems is the "Stick-Slip", which is as a fluctuation of the friction coefficient as the surfaces are sliding. This is a consequence of by the formation and destruction of the surface junctions on a microscopic scale, and it depends on the sliding speed and on the elastic properties of the system.

Finally, the viscous mechanism states that the surfaces are separated completely between them by the presence of another strange body (contaminants, water, oil, etc.). Thus the resistance to relative motion is caused by the need to overcome frictional resistance on the third body. This hypothesis is basically the idea of lubrication, where anything in between the contacting surfaces is consider as a lubricant, be it a powder, a contaminant, oil, water, etc. 
Summarizing, it could be said that the ploughing is the most well know mechanism of friction. Although the adhesion is almost a universally accepted hypothesis, the friction forces are not directly predictable by this theory because a lot of factors depend very much on particular conditions. The viscous drag is essentially the hydrodynamic Iubrication, causing low frictional resistance.

\subsubsection{Behavior of friction in metals and non - metals}

Always in the study of different frictional system scientists made a distinction between metals and non-metal. In this section a brief explanation of the behavior of metals and non-metals is done.

\section{Friction in metals}

In today machines the most predominant constituent materials are metals, therefore the study of the friction on them has been a big interest around the engineering world.

The friction in metals could be affected by different environmental variables such as sliding speed, contact pressure, temperature, atmospheric pressure and relative humidity. Besides this, the frictional properties of metals will be greatly affected by the presence of surface films on them.

The surface films could be characterized as several layers from the inner layer (virgin metal) to the outer one. From the interior, first there is an oxide layer produced by 
reaction of oxygen from the air with the metal (except with noble ones), then there are molecules of water vapor and oxygen, and finally there is usually grease or an oil film.

Due to the environmental variables and because the metal can have different varying surface layers, it is impossible to state that the kinetic friction coefficient will always be the same.

Essentially the cause of friction in metals could be characterized by [5] [11]:

1- Adhesion between the surfaces. If the metal surface is very clean high friction forces will be reached. This phenomenon is very important in high vacuum applications, where values of friction coefficient from 5 to 200 can be reached.

2- Plastic deformation and ploughing are caused by deformation of one surface by hard asperities form the other. The result is the formation of permanent grooves in the surface of the softer metal.

3- Viscous drag, where third body particles are trapped between the surfaces. These appear after some distance of sliding and are usually agglomerations of small wear particles. Their friction contribution corresponds to a plastic deformation, as they indent the surfaces roll between them.

Metal surfaces generally have initial friction coefficients in the range of 0.1 to 0.3 when they slide between themselves. If the surfaces continue to slide over each other higher values are reached; with these conditions the grease film will eventually be worn 
off. Also it is remarkable to observe that the friction coefficients between similar metals tend to be higher in general than for dissimilar ones.

\section{Friction in non-metals}

As well as the metals, the majority of non-metals generally obey the laws and mechanism of friction as outlined in sections 4.3.1 and 4.3.2. Beside this, when nonmetals slid over other materials, either metal or non metal, the frictional properties tend to be those from the softer material.

However, there are marked differences from metals in the frictional properties. These differences arise, basically, from the fact that the metal surfaces have high reactivity with the oxygen and humidity, so gases and grease films tend to be strongly adsorbed on them. Consequently wide variations in the frictional properties of metals are found, depending on the exact degree of cleanliness of the metal surfaces. On the other hand, the superficial contamination in non-metals is less important; therefore, the frictional properties in non-metals are not generally altered profoundly as they do in of metal surfaces.

Furthermore, in contrast with metals, which are fairly homogeneous, non metals vary much more widely dissimilar substances, from diamond, rubber, concrete, leather, nylon, graphite, wood to ice. Although this wide difference, it is found that frictional properties of non-metals are fairly uniform.

Figure 4.6 shows a flow chart detailing most the frictional parameters that can affect to a frictional system, either to metals or to non-metals. 


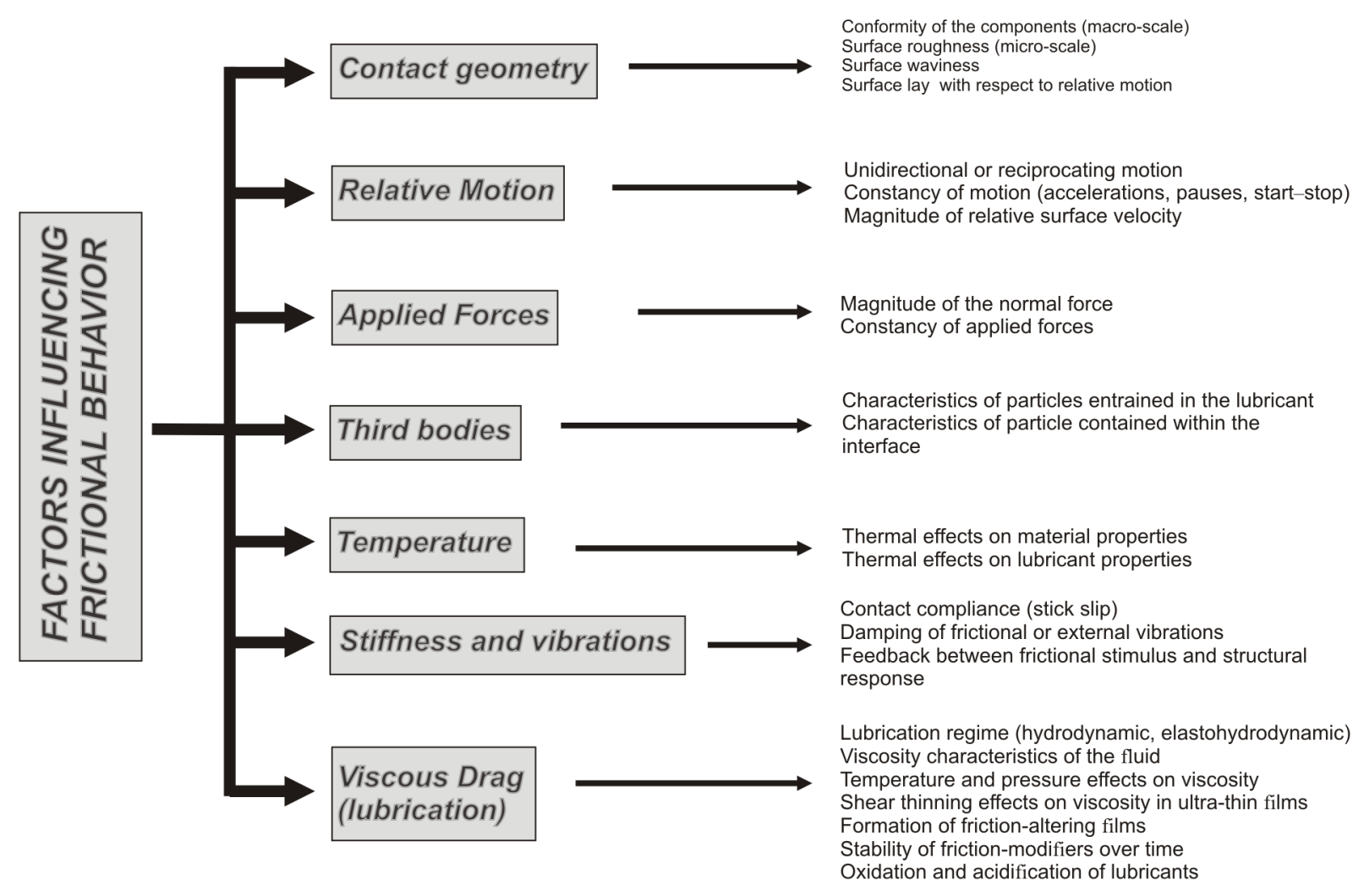

Figure 4.3.5 - Factors influencing frictional behavior [12] -

\subsection{Roughness}

When friction was defined and characterized in the previous section the word surface was used frequently. Indeed, friction is greatly dependent on the surfaces of the different materials.

Consequently it is important to characterize the surfaces in the friction system. However, to describe the surfaces is extremely complicated because of their composition and microstructure, which may be very difficult to determine accurately, creating further complications; besides, the topography or the chemical reactivity, which makes it even more complicated. 
In the surfaces there will be undulations of wavelengths that range from atomic dimensions to the length of the component. Also, there can be additional peaks and valleys caused by local micro-processes, such as uneven deformations of hard mircrostructural constituents, local fracture, or corrosive pitting. This geometric shape or topography is determined basically by the finishing process used to produce the material.

The most used parameter to characterize the surface geometry of an object is the roughness. Since the topography at micro scale level influences in the friction behavior it is useful to distinguish among roughness and microroughness.

Roughness is a measure of the texture of the surface, is defined by the deviation of the wavy perturbations from its ideal flat form, see figure 4.7; caused by geometry of the cutting tool and its wear, machining conditions, microstructure of the workpiece, vibrations in the system and so on. Surface roughness changes as a surface goes through the wearing in process, but may then stabilize. Also, roughness is typically considered to be the high frequency and short wavelength component of a measured surface. [11]

Also roughness might be defined as the slope of a profile taken along some prescribed line. Consequently the measure must be made by suitable methods; there are several techniques and methods, but the most commonly-used are: the arithmetic roughness, the root mean square (RMS) roughness, and the peak and valley roughness.

\section{[10] [5]}


Microroughness is a finer roughness superimposed on the surface roughness. It may extend down to the near-atomic scale and may be caused by internal imperfections in the material, see figure 4.7, non uniform deformation of individual grains at the surface, or corrosion and oxidation processes that occur while the surface is being generated or during its exposure to the environment.

Besides this it is good to define the Waviness of surfaces, which is defined as the periodic deviations from the geometric surface, where they often tend to be sinusoidal. Typically, wavelengths range from 1 micrometer to millimeters and wave heights from a few to several hundred micrometers.

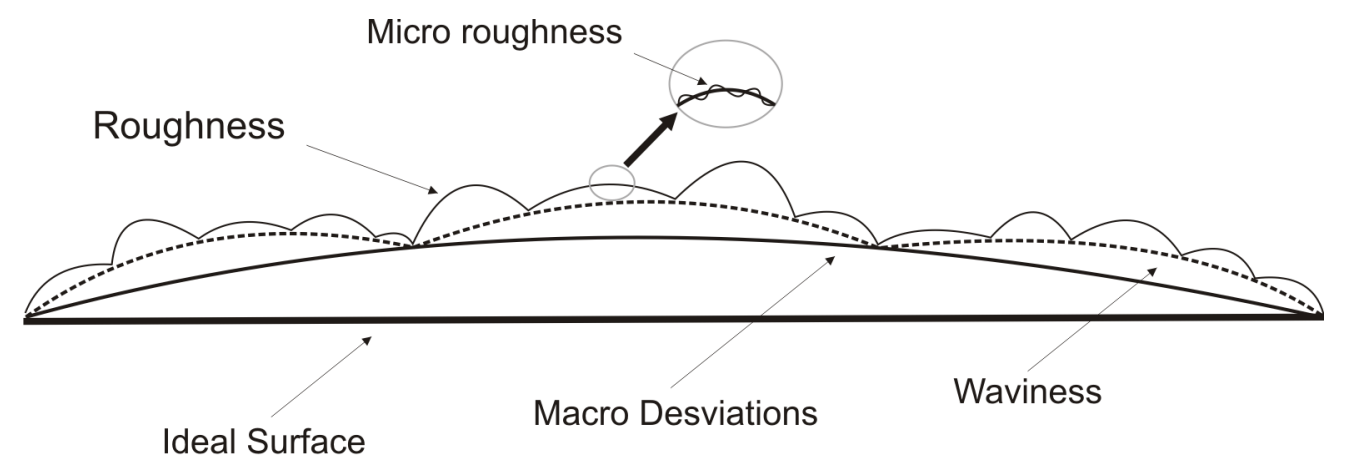

Figure 4.4.1 - Schematic surface representation [11] -

\subsection{Measuring the friction}

Friction coefficients have been measured for hundreds of years, and many different methods how to perform a test have been studied. However, each of the tests was made for that particular frictional system, from measurements on operation machines to devices specially constructed in a laboratory. Consequently, measuring the friction should be carefully performed; in this section several general ideas are discussed. 
The starting point to measure the friction is to study and analyze the particular friction system. After it, is properly to identify the materials involved in the system and the test parameters. "A friction test is valid if the test simulates the system in interest" [10].

The materials used in the test not only should be the same as the one that compose the system, moreover, the surface textures of all the components should duplicate the conditions in the real system [11]. Besides this, and when the test is performed, special care to the surface preparation is required. There are three elements involved in surface preparation [10]:
a) forming the proper component geometry (flatness, contour, etc.)
b) cleaning the specimens
c) handling the specimens

There is no best way to prepare surfaces for friction testing: "the method selected in each instance must fit the situation" [10].

There are hundreds of test parameters concerning to friction but the most important regarding to the friction itself is the loads and the sliding speed (beside the materials). These parameters should be as close as possible to the real conditions. Sometimes, however, it is difficult to simulate these parameters in a laboratory environment, the loads and speeds may be out of the range of the laboratory equipment, or testing at actual conditions may take too long; therefore, the idea of scaling tests became necessary [10]. 
Under certain conditions, the speed of the frictional system should be duplicated as closely as possible. For example in a system where an elastomer is involved, slow speeds could display a stick-slip behavior, while for higher speeds this does not occur. However, sometimes this stick-slip behavior results from the testing system, hence, to eliminate this phenomenon a high stiffness movement (increment the inertia) system attached to the sliding member may eliminate it [11]. Finally, to perform a valid test, in most of the tribosystem, the sliding speed must be constant. [5]

The same type of reasoning should be applied to the test loads. If a system under study uses insignificant loads, the system should be duplicated. Also if it is subjected under extreme loads, there is little option other than use these very high forces [10]. Special care is required if the test speeds and loads produce significant wear, this should be avoided unless that part of the system is under study.

Also a particular attention in measuring the static friction is required. To measure the static friction is required to observe the initial force spike, $F^{\prime}$ (see section 4.3.2, friction coefficient), so it is important to differentiate whether the internal force spike is due to the sliding system or is the result of elastic behavior in the force-measuring system. Therefore, if the system under study involves elastic components, a high-elasticity forcemeasurement system should be used. [11] 
Other parameters, different from loads or speeds, are those regarding to sense and measure the friction force and sliding distance. The friction force, $F$, is measured by an electrical signal or a mechanical device ${ }^{4}$. Both types of sensors have elastic and damping characteristics that can affect the measurement.

Regarding to measuring devices, probably the most important is the one that measures the friction force. For that, authors recommend a sensor with a capacity not more than 10 times the force to be measured should generally be selected for a given application. Also, is necessary to have a particular attention regarding to the friction force recording frequency; high frequencies of reading could imply the loosing of some information (for small normal load systems), and low frequencies imply that some forces are not measured (for high speed systems); however, authors have found that $1000 \mathrm{~Hz}$ is adequate for the majority of the tests [10].

Finally, another important parameter to get valid results is to know how many times the test should be repeated. Hence, the sample size must also be considered; there are a number of ways to calculate it, but most statisticians prefer large number of replicate tests (e.g 40). However most friction tests are very repeatable within in a laboratory, so authors suggest that the statistical accuracy is achieved with 10 replicates per system.

As a final point, it is important to include a well description of the experimental test configuration, materials, surface preparation, applied conditions, and state of lubrication in detail so the interpretation and usefulness of friction test results can be determined. Standard documents have been developed by ASTM to help reporting frictional data (see

\footnotetext{
${ }^{4}$ See ASTM G 115 - 04 for more test devices
} 
ASTM G115 - 04), but the most important results suggested by the authors could summarized by:

- the average of the static and kinetic friction coefficient

- the starting friction coefficient

- the maximum or minimum friction value during running

- the time to reach the steady state

- the variation of friction force a steady state

- the presence and time over which friction transitions may occur.

Although these results are suggested to be reported, each scientist has the freedom to inform what is necessary for his project [10].

To summarize, friction is a system property, and as a system must be modeled carefully (same materials, same treatments, and so forth). Also, the length of time that the system is tested should be a similar to the one in the real service. Other factors that can affect the validity of a friction test include sample preparation, method of friction measurement, and interpretation of data. The next figure resumes all the parameters that are necessary to pay attention when the friction is measured. 


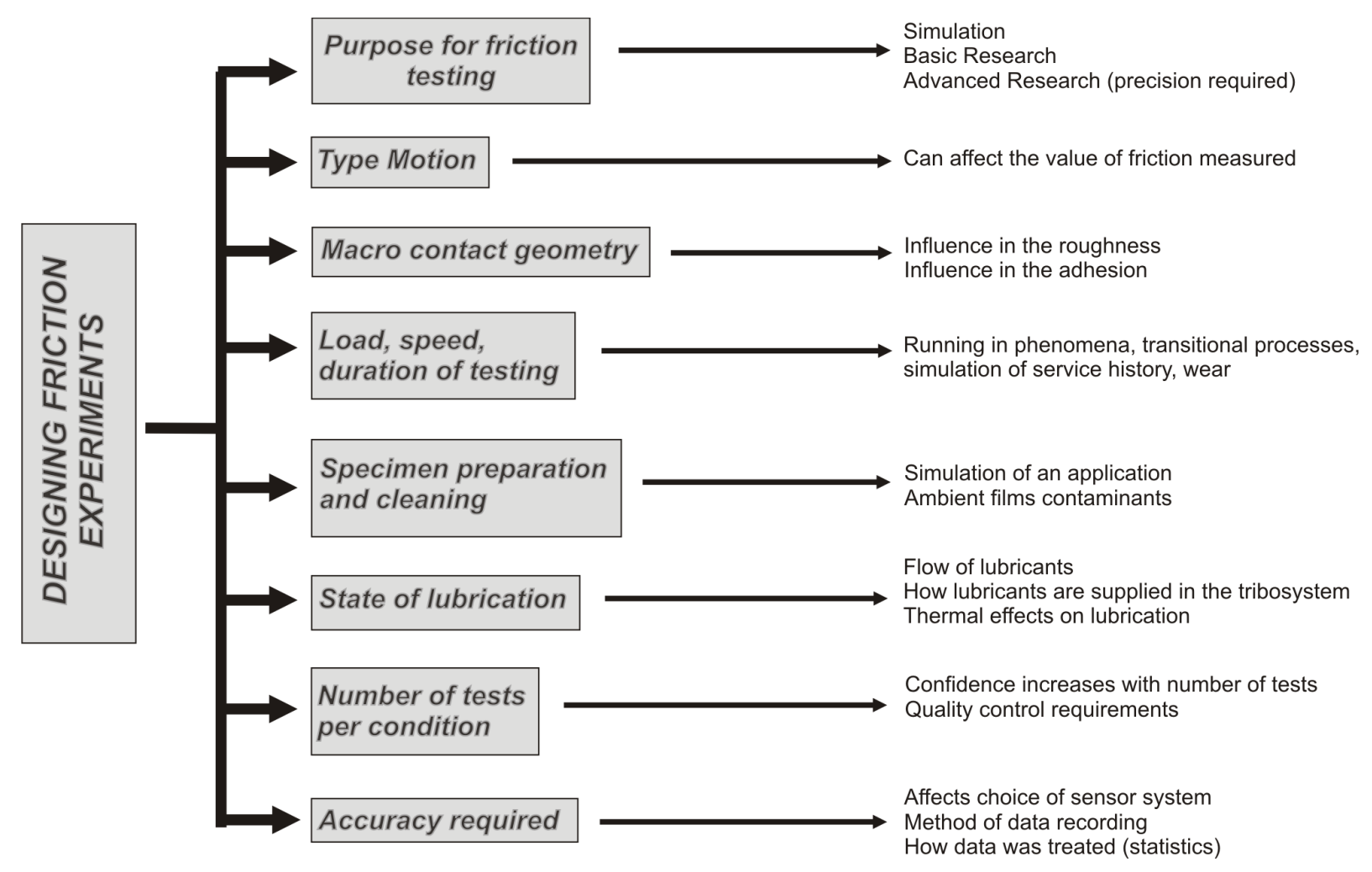

Figure 4.5.1 - Some factors influencing involved in designing a friction experiment [10] -

\subsection{Frictional phenomenon of this work}

As it was described in the chapter 1 , the frictional phenomenon that occurs at the sliding between concrete tunnel and fabric interface is very complex. However, expanding the idea of mechanism explained in section 4.3 .3 and focusing on the interrelation between the concrete wall and the elastomer (fabric coating) it can be settled that the friction force $F$ at the interface during the sliding motion is the sum of several terms, the most important are:

$$
F=F_{A}+F_{P}+F_{H}
$$


where,

- The term $F_{A}$ is the adhesion contribution, that is a consequence of the series of formation (stick) and ruptures (slip) of molecular bonds between the matrix of the fabric and the concrete surface.

- The term $F_{P}$ is the ploughing component indicative of the shape effects, or indicative of the roughness influence in the phenomena.

- $\quad$ The $F_{H}$ is referred to the hysteresis mechanism that is due to the periodic deformation of the mass of elastomer sliding over the asperities or pattern of the surface coating.

Figure 4.9 shows the influence of the adhesion and hysteresis components in a classic elastomer.

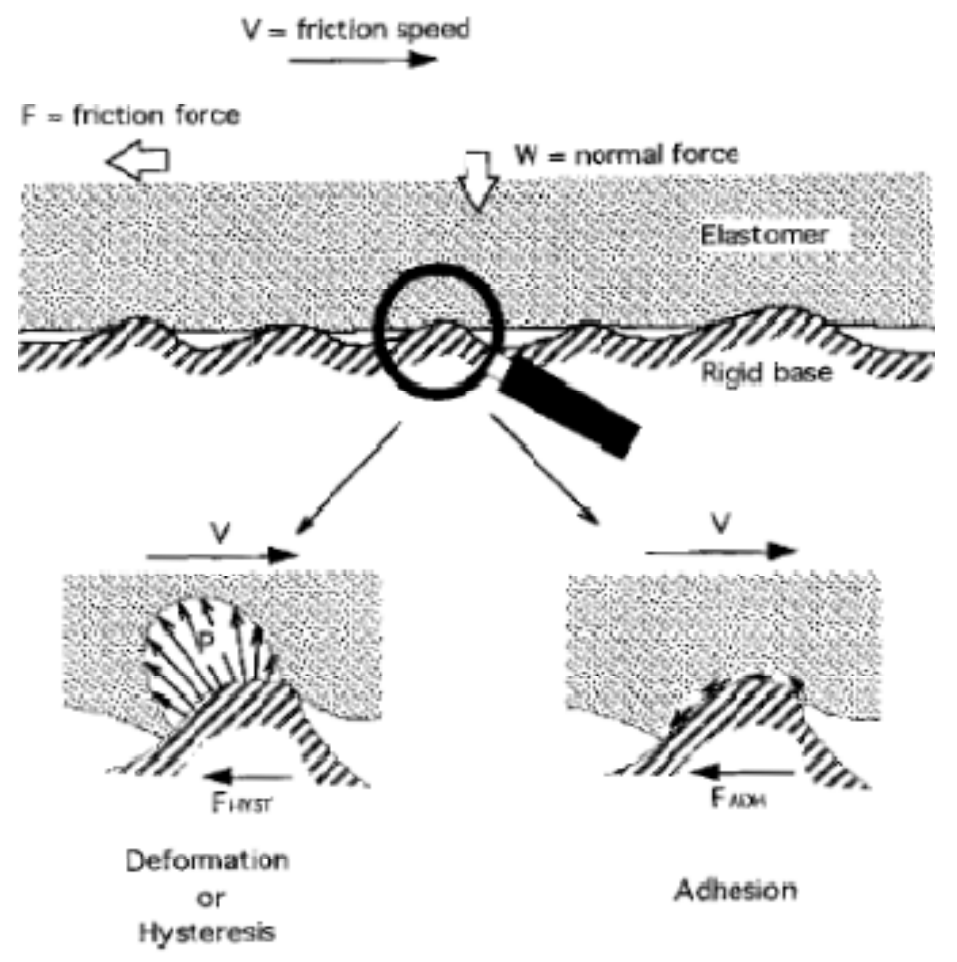

Figure 4.6.1 - Principal components of elastomeric friction [13] - 
The dynamics of the forces occurring during the slip (column of water flattering, structure inflation evolution, etc), as well as the surface properties of both main components (roughness of the surface, contaminants present on the concrete wall, matrix material, etc.) will determine the frictional force $F$, indeed the relative importance of each of the components.

As a result of all the variables that are in a continuous change in this tribological phenomenon, plus many other factors that can influence the friction system; it is almost unfeasible to describe with precision what happens in this system.

Although, this is a particular frictional case and there is no any direct reference available, is it useful to review other frictional systems. One similar case is a shoe sole (as the fabric matrix) sliding in regular concrete floor (as the tunnel wall), several authors have tried to analyze these phenomena in order to better understand the system, and measure the slip resistance and its variability. Although the studied phenomenon is the same, different approaches and different results were found [14]. Consequently, not always a result, where an elastomer is involved, is extensive for other similar situations.

Next in chapter 5 , and section 5.2 , the methodology used to analyze and measure the tribological phenomenon of this work, as well as the results obtained are described. 


\section{Chapter 5: Test methods to determine the fabric's physical properties}

\subsection{Determination of Fabrics tensile strength}

As it was stated in section 2 and 3 , fabrics is the main component of the inflatable structure, where one of the most important property of the fabric is the "Tensile strength". As it was explained in section 2, one of the goals of this project is to find a fabric with enough tensile strength to prevent any failure of the structure. For that purpose different fabrics from different manufacturers were studied; it is well know that each manufacturer provides the value of the tensile strength, however, is necessary to verify that value performing the tensile strength test.

Furthermore, since there are different components of the inflatable structure joined by welded procedures, it is also required performing a tensile test to the welded parts of the structure too.

In sections 5.1.1 and 5.1.2 the tensile test procedures, the results and analysis are presented for two different fabrics non-welded and welded.

\subsubsection{Tensile strength test procedure}

Testing was done following the directions of the International standard ISO 1421:1998. Although the test was in accordance with these standards, some modifications were done to adapt these procedures to the American Standard system; for that, ASTM D 5034 - 95 was used. 
The test consists in extend a fabric specimen at a constant rate of extension (CRE) until it breaks. Hence when break the maximum force is determined. The apparatus and grips used to perform the test are:

- INSTRON Tensile Test Machine, model 3365.

Load capacity 1124 lbs.

Crosshead Speed Accuracy $\pm 0.2 \%$ at steady state and no load.

Position Accuracy $\pm 0.05 \%$ of displayed reading

Load Weighing Accuracy $\pm 0.5 \%$ of reading down to $1 / 100^{\text {th }}$ of capacity. In-built controller.

- INSTRON Series IX Software, M12-13984.

- INSTRON Screw Action Grips, model 2710-105.

- INSTRON Grip faces (jaws), model 2702-022, Rubber coated.

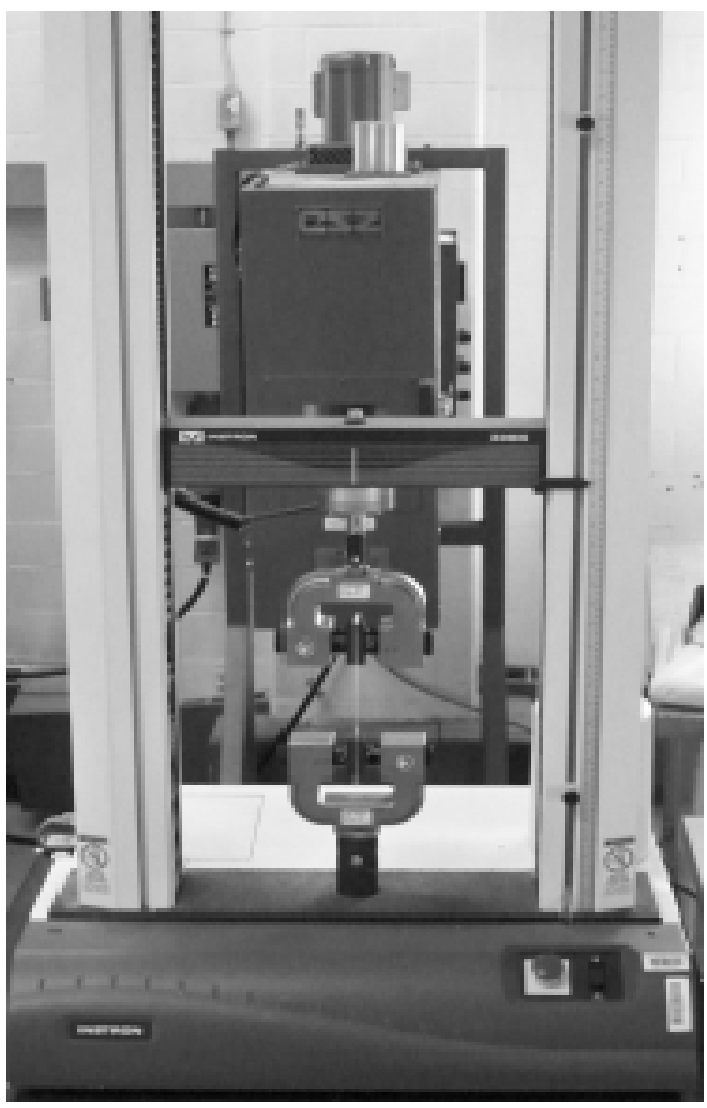

Figure 5.1.1 - Instron tensile machine - 
In this machine, the rate of increase of specimen is uniform with time (CRE). Also this machine provide a controller which reads, processes and records the force applied to the specimen in the stretching until it breaks, the corresponding extension, the time of the test, and so on. The jaw faces, in the grips, are smooth, flat and made with a rubber cover to provide a gripping surface. Also, the faces are parallel and match the centers with respect to one another in the same grip.

All tests were performed in the West Virginia University's laboratory located in room G86 of the Engineering Science Building. The atmosphere used for conditioning and testing were those for standard day:

$\begin{array}{lll}\text { - } & \text { Temperature } & 59{ }^{\circ} \mathrm{F} \\ \text { - } & \text { Pressure } & 14.7 \mathrm{psi}\end{array}$

\subsubsection{Materials}

In this study two different woven coated fabrics were tested, both of them are made with nylon fabric. These materials are commercially available, hence, some properties are given by the manufacturer, next table shows the tensile strength characteristics of these fabrics.

Table 5.1.1 - Tensile strength of the tested fabrics (data provided by the manufacturer) -

\begin{tabular}{|c|c|c|}
\hline Project designation & Fabric & $\begin{array}{c}\text { Tensile Strength } \\
\text { (warp/fill) }\end{array}$ \\
\hline $\mathbf{1}$ (white coated color) & Ferrari & $440 / 435 \mathrm{lb}_{\mathrm{f}} / \mathrm{in}$ \\
\hline $\mathbf{2}$ (brown coated color) & $\begin{array}{c}\text { Seaman Corporation } \\
\text { Style 7150 PFF }\end{array}$ & $750 / 750 \mathrm{lb}_{\mathrm{f}} / \mathrm{in}$ \\
\hline
\end{tabular}




\subsubsection{Sampling and specimens preparation}

In this test two different sets of samples were prepared, one non-welded and the other one welded. For both samples, two sets of specimens were cut in strips, one with their long dimensions parallel to the warp (machine) direction and the other one to parallel the filling (cross) direction. For the non-welded sample there are four specimens in each direction (warp or fill). And for the welded one there are three also en each direction.

For all the samples, the specimen width is 1 inch and the length ${ }^{5}$ is 14 inches. On each test piece a horizontal centerline, perpendicular to the horizontal direction was drawn, the line is located at 7 inches from the long edges. Also, two horizontal lines are located at 2 inches on non-welded specimens, and at 3 inches for the welded, away from the centerline were drawn. In those lines the jaw faces from the grips should be positioned. The next figure shows a scheme of the testing sample.

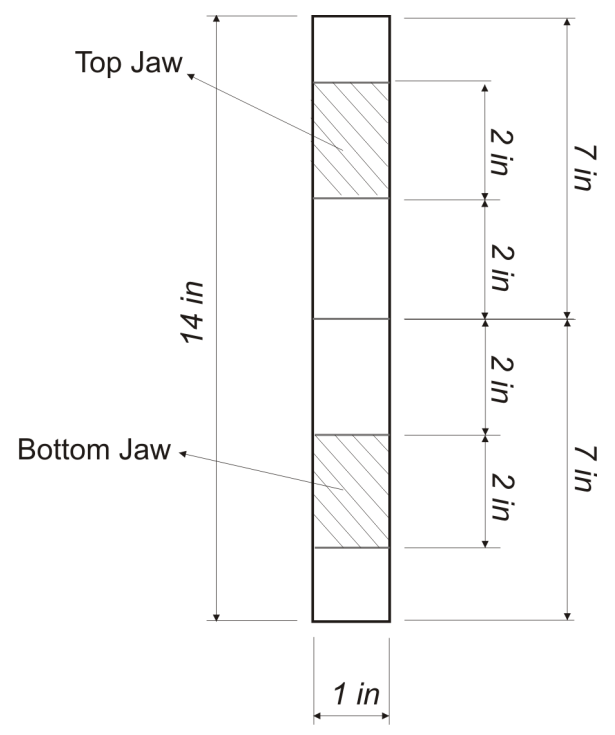

Figure 5.1.2 - Test specimen lay out -

\footnotetext{
${ }^{5}$ Always the length direction is parallel to the direction of elongation and force application.
} 
Note that for the welded specimens, the horizontal centerline should be on the center of the welded joint.

\subsubsection{Test operation}

Once the specimens are prepared and ready to test, the next step is to mount that test pieces in the Instron machine. For that, first is necessary to the set distance between the grips (gage length) at 4.0 inches.

Then the specimen is clamped in the top grip, where the jaw faces of the top grip shall coincide with the appropriate line drawn in the specimen (see figure 5.1.2); finally, following the same procedure as before, the specimen is clamped in the bottom jaw. This parallel lines serve as a guide to ensure that the same lengthwise yarns of the fabric are gripped in both clamps and that the force application is not at an appreciable angle to the test direction of the fabrics. The tension on the specimen should be uniform across the clamp width.

Once the specimen is clamped, is necessary to adjust the specimen to the grips. To tight the test pieces a torque of $22 \mathrm{lb} \times \mathrm{ft}$ is applied to the grips with a torquimeter. In this step especial attention is required because if the clamp is too tight will produce breaks of the fabrics at the edge of the jaws. Figure 5.1 .3 shows the how the specimen should be positioned in the tensile test machine. 


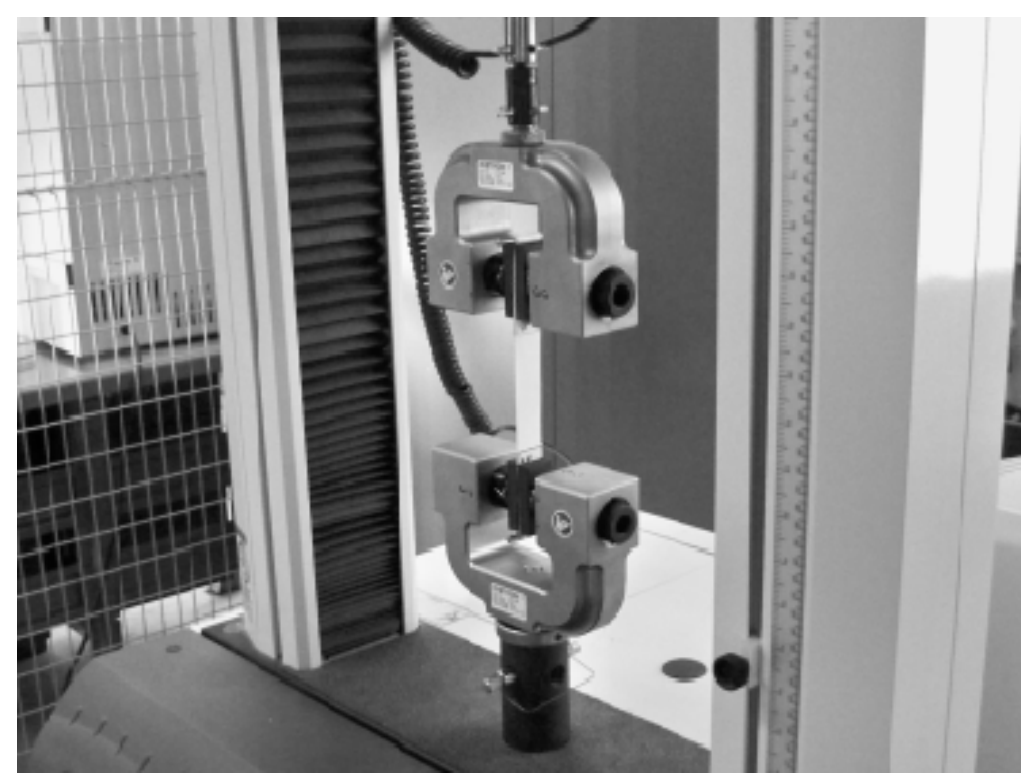

Figure 5.1.3 - Test specimen mounted in the tensile machine -

After, the specimen is located and tightened in the tensile machine; the machine calibrated and is set it to a constant moving rate of 12 inches per minute according to both standards (ASTM D5043 and ISO 1421). Later, to guarantee a correct reading in the equipment a lightly pretension load is applied. Then is necessary to eliminate the residual displacement and load shown by the controller, for that is needed to calibrate the test machine again so the reading devices show zero displacement and zero load. Finally, the machine is operated and the specimen is extended until it reaches the breaking point ${ }^{6}$. Later, to continue the experiment, the specimen is changed and the operation is repeated; the welded fabrics were tested also with this procedure.

It is important to mention that is critical to prevent slippage between the fabrics and the grip jaws. If slippage occurs is required to re-adjust the torque in the clamps, but if tighten cannot be increased without causing jaw breaks, other techniques for eliminating

\footnotetext{
${ }^{6}$ The results are shown in the computer installed Instron equipment.
} 
slippage should be implemented, e.g. placing the fabric specimen around steel pins and the top part of the grip faces.

Nevertheless, sometimes if the specimen slips or breaks at the edge of or in the jaws, or for any reason the result falls markedly below the average for the set of specimens. If those situations happen the results should be discarded and is necessary to take another specimen measurement.

Finally, the software included in the Instron controller calculates the breaking force and elongation and gives the averages and the standard deviations. Therefore all the results are obtained and processed by that software, helping, later, to analyze all the tests (see section 5.1 .1 for the software specifications). Although the strain is not an important parameter for this work, it was measured using the extensometer of the INSTRON machine. 


\subsubsection{Results and analysis of the strength in different fabrics}

Following the procedures as it was detailed in the previous section a tensile test in two different fabrics was done. On each of the test the tensile strength in the fill and warp direction of the fabric was measured. This procedure was repeated for the non-welded and welded fabrics. In the next table a resume of all the samples test is presented.

Table 5.1.1- Tensile strength test denomination -

\begin{tabular}{|c|c|c|c|}
\hline Fabric & Non-Welded / Welded & Direction & Test denomination \\
\hline \multirow{4}{*}{$\begin{array}{l}\text { Ferrari Precontraint } \\
1002 \text { (formula S) } \\
\text { (white coated color) }\end{array}$} & \multirow{2}{*}{$\begin{array}{c}\text { Non - Welded } \\
\text { (8 samples) }\end{array}$} & $\begin{array}{c}\text { Fill direction } \\
\text { (4 samples) }\end{array}$ & Test 1 NWF \\
\hline & & $\begin{array}{c}\text { Warp direction } \\
\text { (4 samples) }\end{array}$ & Test $1 \mathrm{NWW}$ \\
\hline & \multirow{2}{*}{$\begin{array}{l}\text { Welded } \\
\text { (8 samples) }\end{array}$} & $\begin{array}{c}\text { Fill direction } \\
\text { (3 samples) }\end{array}$ & Test $1 \mathrm{WF}$ \\
\hline & & $\begin{array}{l}\text { Warp direction } \\
\text { (3 samples) }\end{array}$ & Test $1 \mathrm{WW}$ \\
\hline \multirow{4}{*}{$\begin{array}{l}\text { Seaman Corporation } \\
\text { Style } 7150 \text { PFF } \\
\text { (brown coated color) }\end{array}$} & \multirow{2}{*}{$\begin{array}{l}\text { Non - Welded } \\
\text { (6 samples) }\end{array}$} & $\begin{array}{c}\text { Fill direction } \\
\text { (4 samples) }\end{array}$ & Test 2 NWF \\
\hline & & $\begin{array}{l}\text { Warp direction } \\
\text { (4 samples) }\end{array}$ & Test 2 NWW \\
\hline & \multirow{2}{*}{$\begin{array}{l}\text { Welded } \\
\text { (6 samples) }\end{array}$} & $\begin{array}{l}\text { Fill direction } \\
\text { (3 samples) }\end{array}$ & Test 2 WF \\
\hline & & $\begin{array}{l}\text { Warp direction } \\
\text { (3 samples) }\end{array}$ & Test $2 W W$ \\
\hline
\end{tabular}

The test denomination is an acronym based on the following:

- $\boldsymbol{N W}$ is Non Welded fabrics - $\boldsymbol{F}$ is Fill direction

- $\boldsymbol{W}$ is Welded fabrics $\quad$ - Wa is Warp direction

Therefore, for example, to the acronym NWF represents a test that was done for NonWelded fabrics in the Fill direction. 
Once the denomination of each test has been explained and after performing the corresponding test, the results of the tensile test for the two fabrics are obtained. The results analyzed not only include maximum tensile strength of the fabrics, also includes the displacement and strain at the maximum load point. The next table shows the averages results obtained in the Ferrari fabrics sample, also includes the standard deviation for each set test. In the Appendix A there is a table with all the test results.

Table 5.1.2 - Ferrari (Precontraint 1002) fabric tensile test results -

\begin{tabular}{|c|c|c|c|c|}
\hline & \multirow{2}{*}{$\begin{array}{c}\begin{array}{c}\text { Maximum Tensile } \\
\text { Strength } \\
\text { [lbf / in }]\end{array} \\
502.10\end{array}$} & & \\
\hline 응 & Average & & $\begin{array}{c}\begin{array}{c}\text { Displacement at } \\
\text { maximum Load } \\
\text { [in] }\end{array} \\
0.8389\end{array}$ & $\begin{array}{c}\begin{array}{c}\text { Strain at maximum } \\
\text { Load } \\
{[\%]}\end{array} \\
20.97\end{array}$ \\
\hline Зे. & $\begin{array}{l}\text { Standard } \\
\text { Deviation }\end{array}$ & 18.50 & 0.0359 & 0.87 \\
\hline \multirow{2}{*}{$=\frac{气}{\stackrel{0}{0}}$} & Average & 436.08 & 0.8685 & 21.71 \\
\hline & $\begin{array}{l}\text { Standard } \\
\text { Deviation }\end{array}$ & 11.19 & 0.0217 & 0.54 \\
\hline \multirow{2}{*}{ 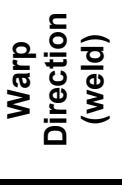 } & Average & 477.77 & 0.8888 & 16.69 \\
\hline & $\begin{array}{l}\text { Standard } \\
\text { Deviation }\end{array}$ & 18.41 & 0.1842 & 0.25 \\
\hline \multirow{2}{*}{ 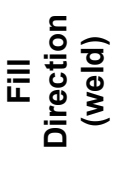 } & Average & 420.47 & 1.0723 & 17.8767 \\
\hline & $\begin{array}{l}\text { Standard } \\
\text { Deviation }\end{array}$ & 11.94 & 0.0425 & 0.72 \\
\hline
\end{tabular}

The principal analysis that could be done from table 5.1 .2 is that the fabric is stronger in the warp direction than in the fill one. Not only this phenomenon happens in the non-welded fabrics, it is also happened in the welded ones. This fact is a consequence of the process of manufacturing of the textile, generally the fill does not have to be stretched in the way that the warp, so it becomes less strong.

\footnotetext{
${ }^{7}$ The tensile strength in fabrics is measured in units force per unit width (length).
} 
Another important analysis is that the tensile strength of welded samples is reduced by $5 \%$ in each direction ( $5 \%$ warp direction and $4 \%$ fill direction). One reason that this reduction of strength occurs is because there is a stress concentration around the weld joint, making by this way the fabric specimen weaker. Although the strength is reduced by $5 \%$, if the welded area increases, the strength will be more close to those in the non-welded specimens.

Regarding to the displacement when the fabrics reach the maximum tensile force, it can be said that all the samples tested broke in a close range of distances, between 0.84 in and $1.07 \mathrm{in.} \mathrm{However,} \mathrm{independent} \mathrm{from} \mathrm{the} \mathrm{direction,} \mathrm{the} \mathrm{strain} \mathrm{on} \mathrm{the} \mathrm{non-}$ welded fabrics is bigger than the ones in the welded samples. This means that the weld joint makes the fabrics more fragile.

All these results can be understood better by looking the following figures. These figures are the actual test results. Figure 5.1 .4 shows the tensile strength difference between the warp and the fill direction. As it was mentioned, the warp direction is stronger than the fill one. Also in this picture it can be seen that both set of samples have the same strain at break. 


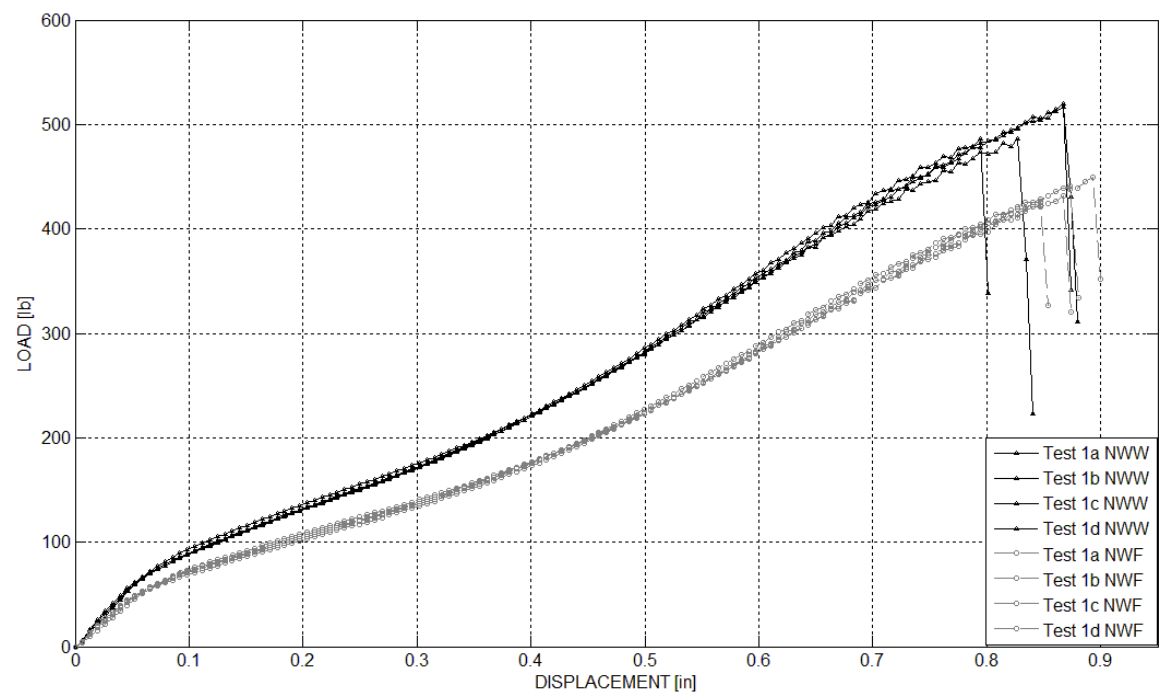

Figure 5.1.4 - Ferrari fabric sample tensile test, for non-welded specimens in warp and fill direction -

In the next figure, 5.1.5, a comparison of the behavior of a non-welded and a welded fabric is shown. In this figure it can be easily seen that the fabrics without weld are stronger than the welded ones.

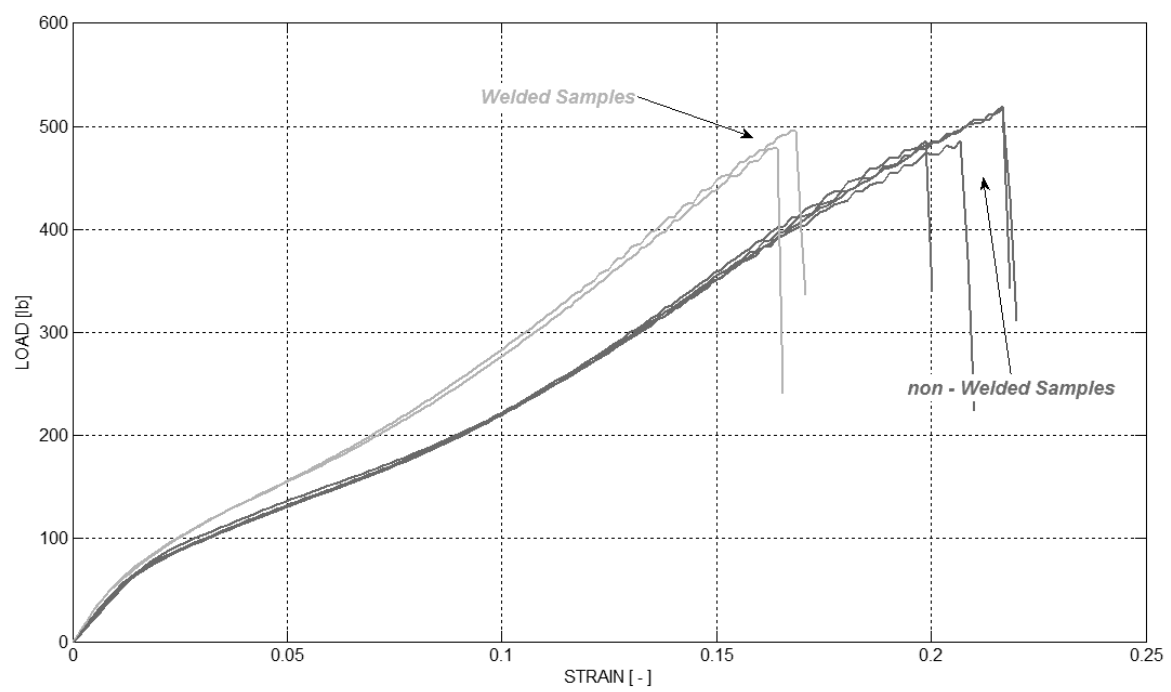

Figure 5.1.5 - Ferrari fabric sample tensile test, for non-welded and weld specimens in warp direction - 
Finalizing with the Ferrari's samples, the next table shows the averages results obtained in the Seaman ones. In the Appendix A there is a table with all the test results.

Table 5.1.3 - Seaman (Style 7150 PTFF) fabric tensile test results -

\begin{tabular}{|c|c|c|c|c|}
\hline & & $\begin{array}{c}\text { Maximum Tensile } \\
\text { Strength } \\
\text { [Ibf / in] }\end{array}$ & $\begin{array}{c}\text { Displacement at } \\
\text { maximum Load } \\
\text { [in] }\end{array}$ & $\begin{array}{c}\text { Strain at maximum } \\
\text { Load } \\
{[\%]}\end{array}$ \\
\hline \multirow{2}{*}{ 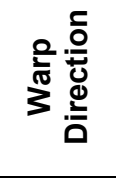 } & Average & 932.70 & 1.0917 & 27.29 \\
\hline & $\begin{array}{l}\text { Standard } \\
\text { Deviation }\end{array}$ & 139.52 & 0.1324 & 3.31 \\
\hline \multirow{2}{*}{$=\frac{\stackrel{0}{0}}{\overline{0}}$} & Average & 661.10 & 1.6090 & 40.22 \\
\hline & $\begin{array}{l}\text { Standard } \\
\text { Deviation }\end{array}$ & 19.72 & 0.0686 & 1.71 \\
\hline \multirow{2}{*}{ 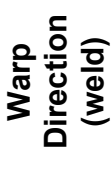 } & Average & 878.17 & 1.3833 & 23.06 \\
\hline & $\begin{array}{l}\text { Standard } \\
\text { Deviation }\end{array}$ & 35.12 & 0.0640 & 1.06 \\
\hline \multirow{2}{*}{ 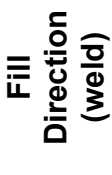 } & Average & 660.53 & 2.1077 & 35.13 \\
\hline & $\begin{array}{l}\text { Standard } \\
\text { Deviation }\end{array}$ & 9.36 & 0.0912 & 1.51 \\
\hline
\end{tabular}

Again in these fabrics, it can be seen that the warp direction is stronger than the fill one, not only for the non-welded samples, also for the welded specimen. However, in this case the difference is bigger. Also, the non-welded specimens are stronger than the welded ones, but, in the fill direction this difference is small $(6 \%$ warp direction and $0.15 \%$ fill direction).

Besides, in this case also the welded samples are stiffer than the non-welded in both directions. Conversely, it can be seen that there is considerable difference in deformation according to the direction. Either on the non-welded or welded samples there 
is more strain in fill direction than in the warp one. This fact can be attributed to the fact that the fibers in the fill direction were less stretched.

All these results can be understood better by looking the following figures. These figures are the actual test results. Figure 5.1.6 shows the tensile strength difference between the warp and the fill direction. As it was mentioned, the warp direction is stronger than the fill one. Also in this picture it can be seen that both set of samples have the same strain at break.

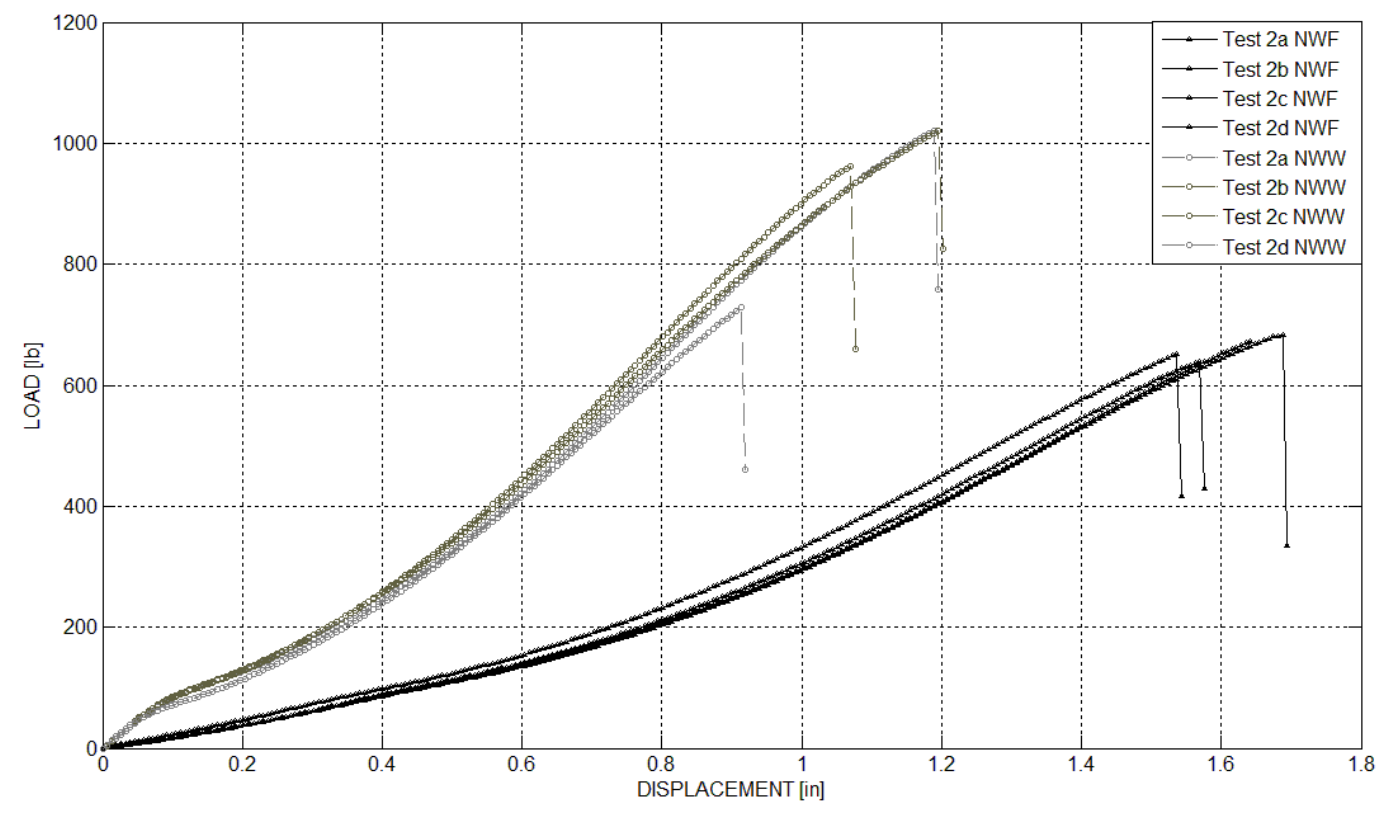

Figure 5.1.6 - Seaman fabric sample tensile test, for non-welded specimens in warp and fill direction -

In the next figure, 5.1.7, a comparison of the behavior of a non-welded and a welded fabric is shown, where the fabrics without weld are stronger than the welded ones. Also it can be seen that the specimens with welded can be more stretched than the non- 
welded ones. Concluding again that elasticity modulus in non-welded fabrics is bigger than in the welded ones.

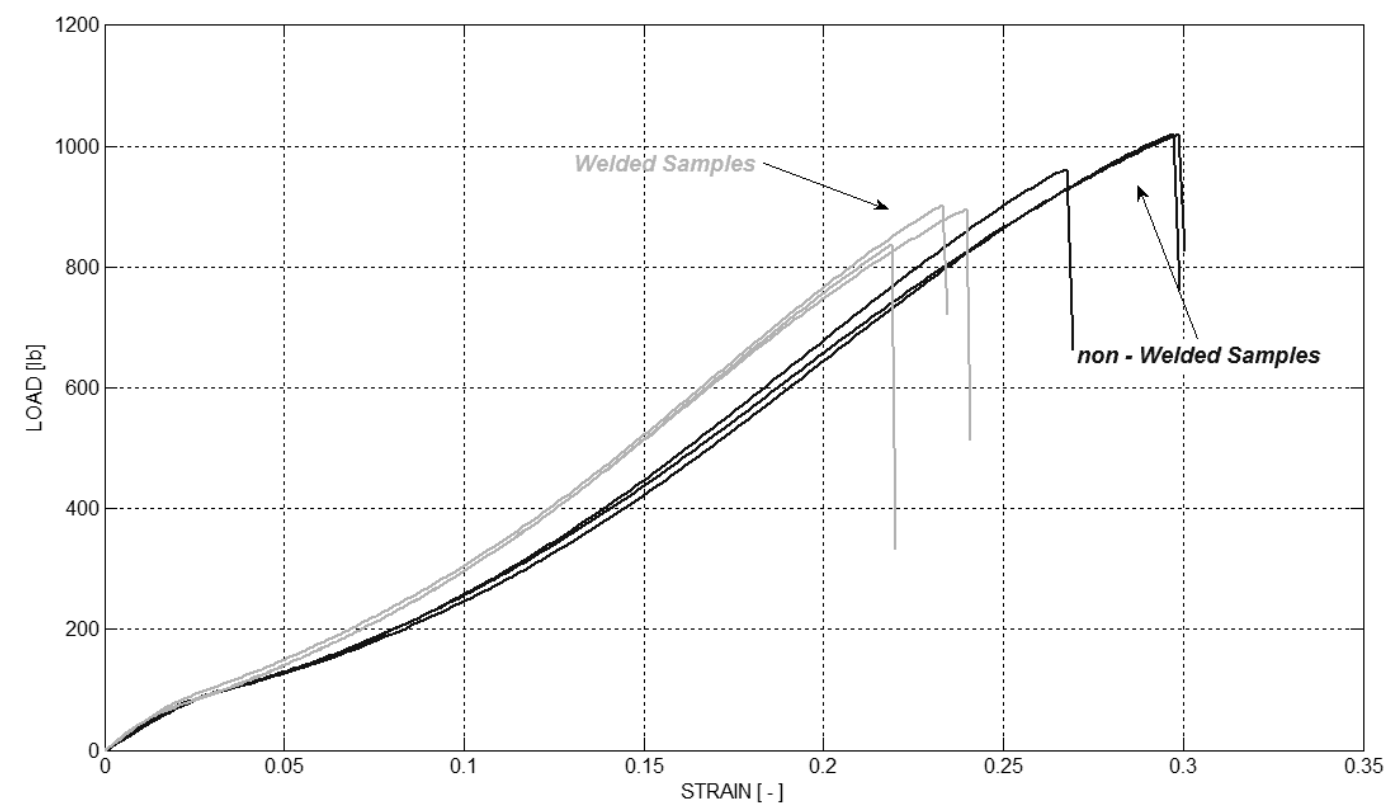

Figure 5.1.7 - Seaman fabric sample tensile test, for non-welded and weld specimens in warp direction -

Summarizing, the tensile behavior of the two set of samples, Ferrari and Seaman, is similar. In both cases the warp direction is stronger than the fill one, and in both cases the welded reduce the strength of the fabrics by only a $5 \%$. Although, the Seaman fabric is stronger than the Ferrari ones, there is a difference in that the Seaman fabric has dissimilarity in the strength of two directions by $30 \%$. In the opposite way, the Ferrari fabric has similar strength in the warp or fill direction.

Finally, if a comparison between what the fabrics manufacturer specified and the results of these tests is done, it can be mentioned that the values obtained for the Ferrari fabrics are close in both direction to the ones in the manufacturer data sheet. 
However, for the Seaman fabrics there is a considerable difference in both directions. In the warp direction the strength obtained in the results was bigger than the manufacturer data sheet, but for the fill direction the tests value is smaller than the one provided. Next table shows the differences for both fabrics.

Table 5.1.4 - Strength difference between the tensile test results and manufacturer values -

\begin{tabular}{|c|c|c|c|c|}
\hline Fabric & Fiber direction & $\begin{array}{c}\text { Manufacturer Data } \\
\text { Tensile strength value } \\
{[\mathbf{l b} / \mathrm{in}]}\end{array}$ & $\begin{array}{c}\text { Test results } \\
{[\mathrm{lb} / \mathrm{in}]}\end{array}$ & $\begin{array}{c}\text { Percentage } \\
\text { difference } \\
{[\%]}\end{array}$ \\
\hline $\begin{array}{c}\text { Ferrari Precontraint } \\
1002 \text { (formula S) } \\
\text { (white coated color) }\end{array}$ & Fill direction & 440 & 502 & $\mathbf{1 2 . 4}$ \\
\cline { 2 - 5 } & Warp direction & 435 & 436 & $\mathbf{0 . 2}$ \\
\hline $\begin{array}{c}\text { Seaman } \\
\text { Style 7150 PFF } \\
\text { (brown coated color) }\end{array}$ & Fill direction & 750 & 932 & $\mathbf{1 9 . 5}$ \\
\cline { 2 - 5 }
\end{tabular}




\subsection{Estimation of fabric's static friction coefficient against different superficies}

As it was stated in chapter one the main goal of this project is to measure and improve the friction between the tunnel wall and the structure fabric. For that, in this section a measurement of the friction coefficient in the frictional system tunnel/structure was done. Different types of wall surfaces were used to improve this frictional system. Also the tests were evaluated in dry and wet surface conditions.

Furthermore, in chapter four was mentioned that the frictional behavior of the coated fabrics is similar to the one a rubber system. Consequently, and for the purpose of this study, only one coated fabric was tested against different concrete surface treatments. Then to prove the validity of this hypothesis a second fabric with a different coated was tested.

In chapter four was explained that "a friction Test is valid if the test simulates the system in interest" [10]. Therefore a detail explanation of the test procedure regarding to this project is required. Next figure shows a schematic example of the system of interest. 


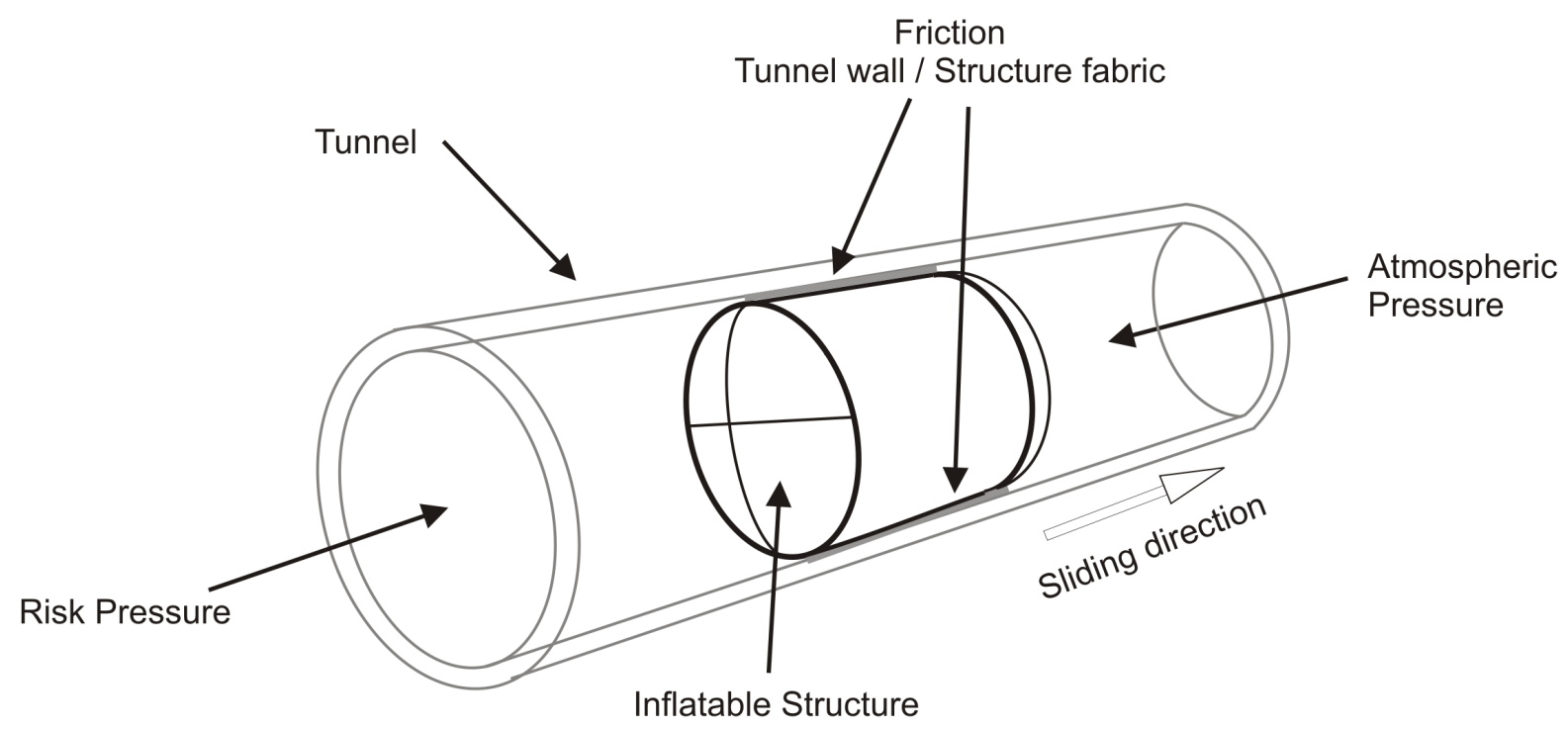

Figure 5.2.1 - Schematic sample of the tribological system fabric/concrete -

The first step is to analyze the system of interest: in this case a coated fabric sliding against the concrete wall. Basically, the inflatable structure (made with a coated fabric) will apply a pressure to the concrete wall with a certain force depending on the inflate pressure inside the structure; on the front side of the structure there is force that will tend to move the structure downwards (see figure 5.2.1). Summarizing, the frictional system should simulates:

- the contact between the fabric and the wall

- the normal force (inflatable pressure)

- the relative movement between this two materials.

Since the system is inside a tunnel, both surfaces in contact, structure fabric and wall, have a circumferential shape as figure 5.2.2 a) shows. Therefore, to simulate the contact between the two surfaces is necessary to use circumferential specimens in the test. However, since the diameter of the tunnel is large (20 feet approximate) and if a small 
fabric is chosen, the consideration of flat surfaces in contact is valid (see figure $5.2 .2 \mathrm{~b}$ )). Also, in the case when the tunnel is threatened by a water flood, a wet condition should be simulated (see figure 5.2.2 c)).

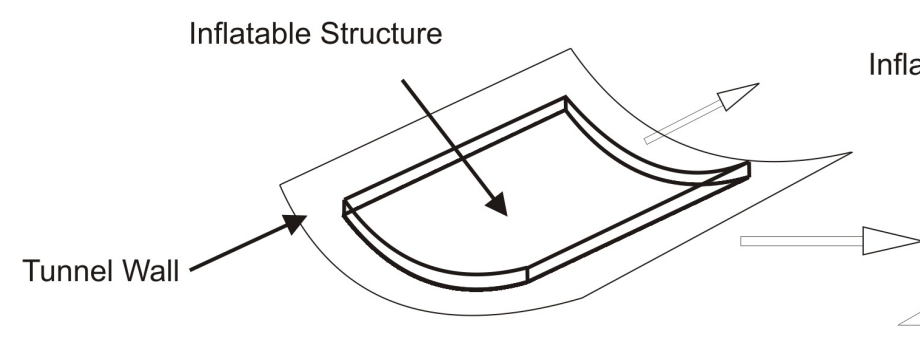

a)
Inflatable Structure

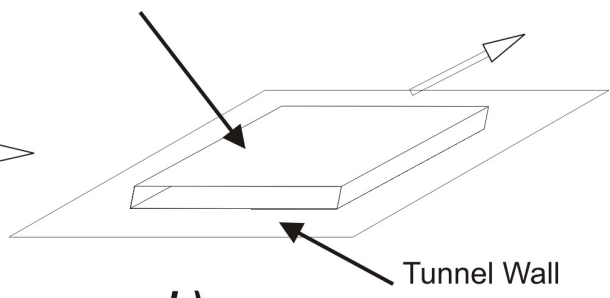

b)

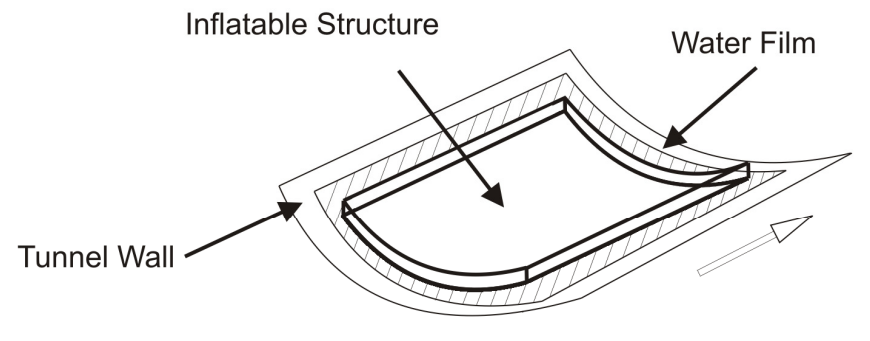

c)

Figure 5.2.2 - Schematic contact between tunnel wall and structure fabric:

a) Real tunnel circumferential shape,

b) Flat surface hypothesis, and

c) Water influence between the tunnel and the fabric -

Now to simulate the normal force, it is necessary to keep in mind the pressure at which the structure is going to be inflated, from other studies, the range of pressures is defined from 1 to 30 psi. Therefore, the normal force system should simulate a load (normal force) that corresponds to that range of pressures. Now since the pressure is defined as the force that acts in specified area, a define contact area between the wall 
and fabric is required to be fixed. For this test the area of contact will be $4 \mathrm{in}^{2}$ (see section 5.2.1.2 Sampling and specimens preparation). Figure 5.2.3 shows a simple diagram of this phenomenon.

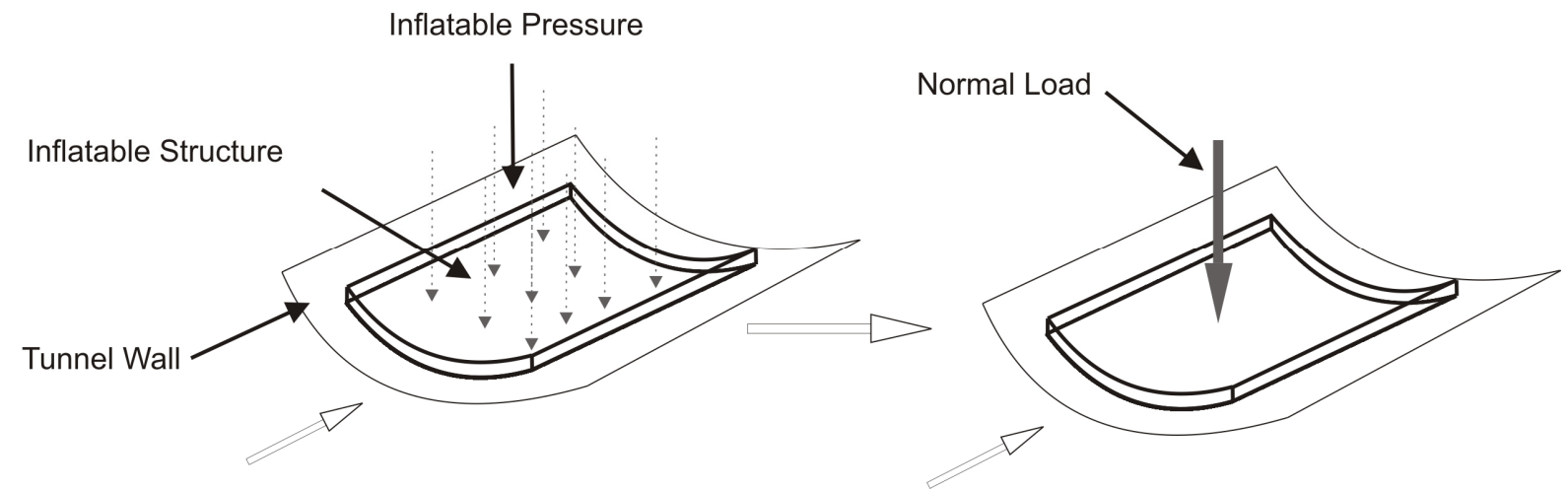

Figure 5.2.3 - Structural inflatable pressure diagram over the tunnel wall -

Finally, regarding to the relative motion is important to remember from chapter 4 that the system should move at constant speed, for that the force provided by the motion system should capable to keep that constant speed (see section 5.2.2.1). Next, analyzing the frictional system, it is noticed that the relative motion between the structure fabric and the tunnel wall will be really slow; so the motion system should be capable to reproduce a constant slow velocity. For the purpose of this project, a surface will be fixed and the other surface will move at the require speed.

\subsubsection{Friction test procedure}

Although the tribological system analyzed is unique and there is no standard to follow, the standard ASTM G 115 is used as a guide to perform this frictional test. Also, to verify the test apparatus a calibration for well known frictional systems were done, among them 
stainless steel against stainless steel, stainless steel against brass, brass against brass were tested. However, since these results are not for interest in this project, the results from those tests are not mentioned in this work.

To simulate the real tribosystem, basically, the test will consist on a hydraulic actuator that will push the sliding component (car) where the sliding specimen will be positioned, in this case the concrete. Then, normal to the car, there will be a fix rod where in the bottom part the fabric specimen will be attached (towards to the concrete), and in the top different weights will be added to simulate the normal force. A linear variable differential transformer (LVDT) will be used to measure the relative displacement of the car, and a load cell will be used to measure the required force to move the car (frictional force). A recollection data acquisition system will be used to obtain the values of frictional force, displacement and time.

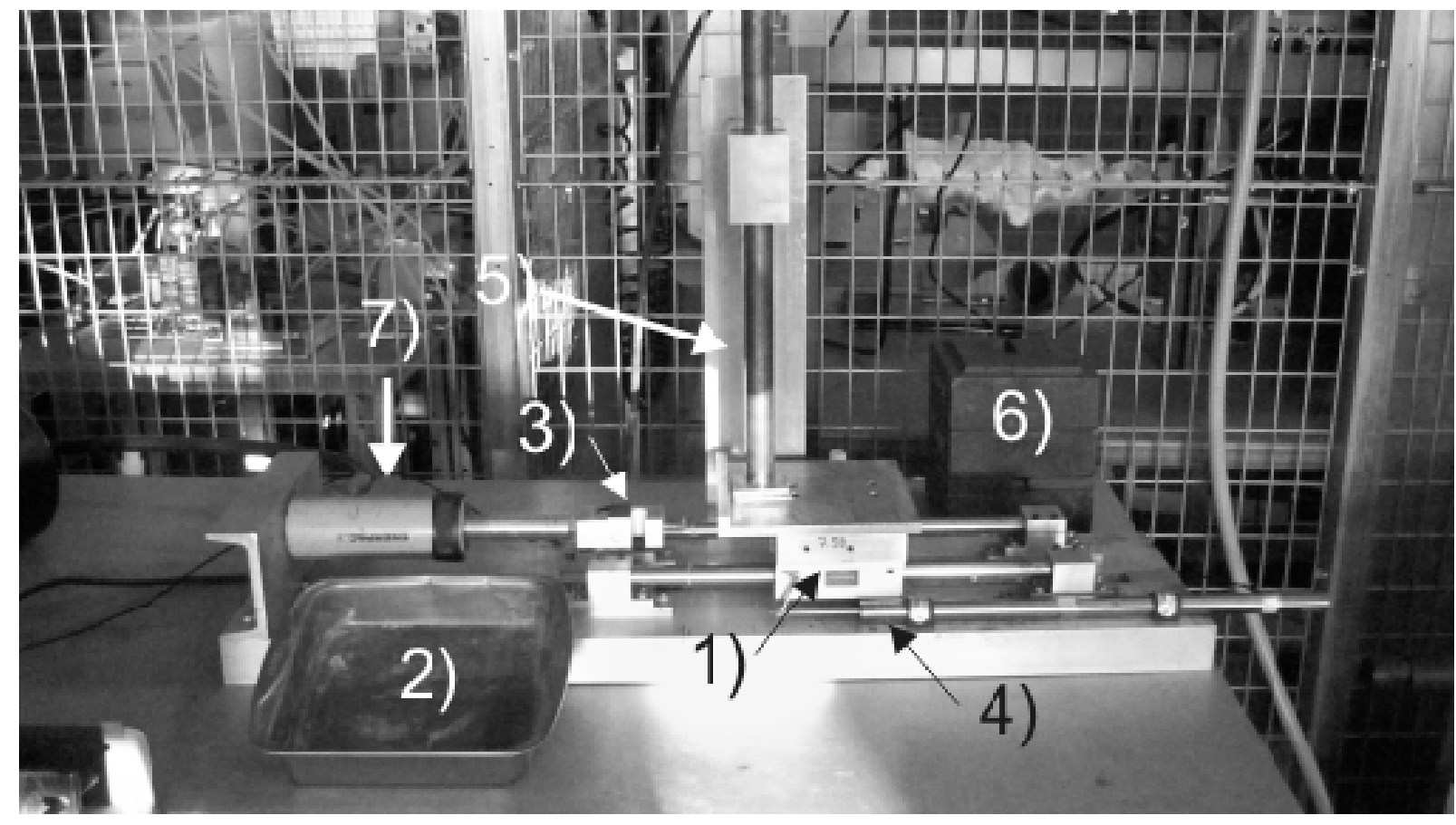

Figure 5.2.4 a) - Friction machine and its mechanical components - 


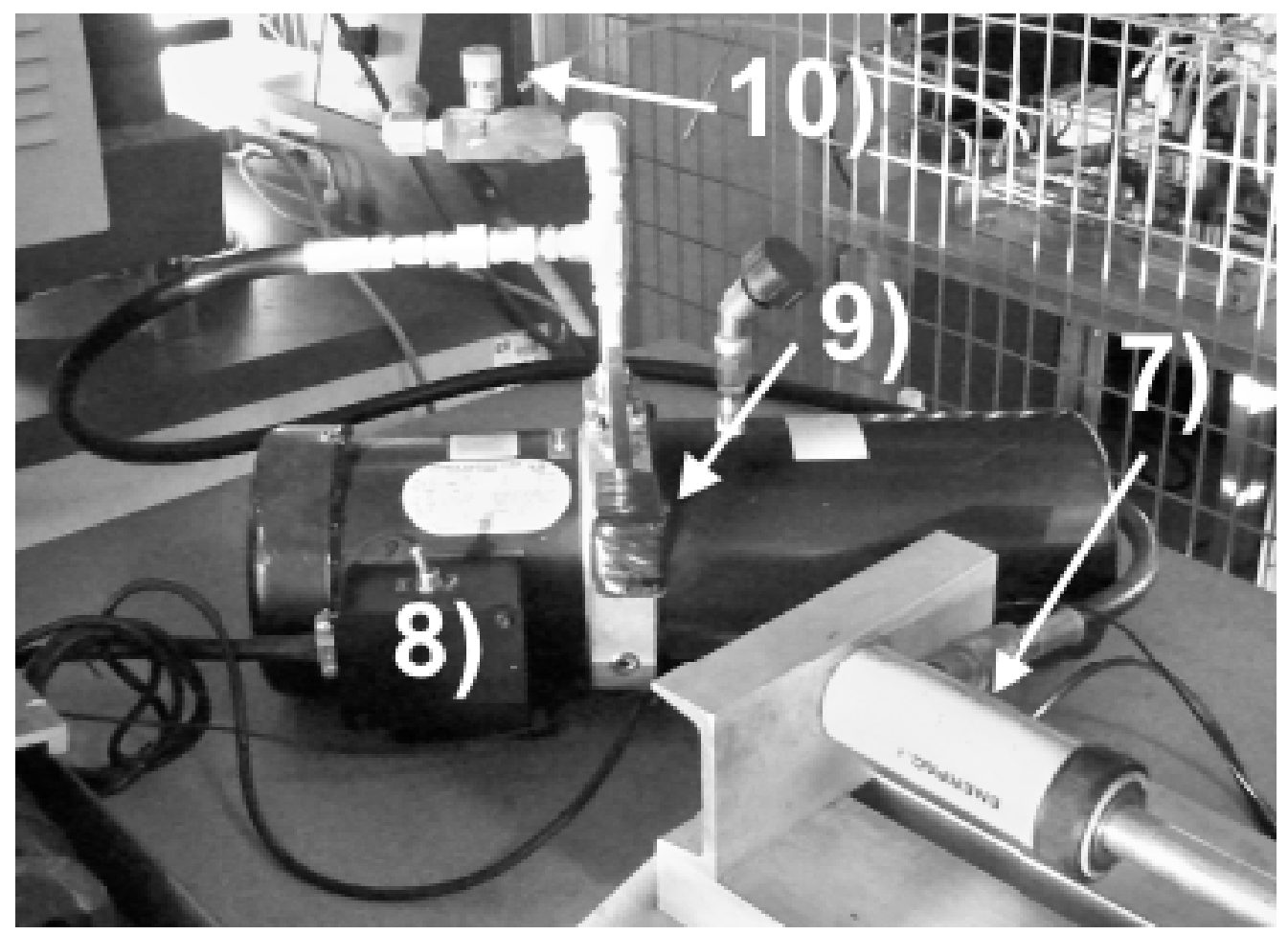

Figure 5.2.4 b) - Friction machine, hydraulic system-

Therefore the friction machine will consist in the following components (see figures 5.2.4 a) and b)):

1. Sliding car, with anti friction bearings

2. Wet test fixture (see figure 5.2.1 a))

3. Load Cell

4. LVDT

5. Normal weight fixture

6. Normal weights (20 lbs each)

7. Enerpac hydraulic pushing cylinder

8. Hydraulic pump

9. Hydraulic pressure relief lever 
10. Hydraulic mass flow valve regulator, allows to control the sliding velocity

And the data acquisition system will consist in:

11. National Instrument data acquisition card

12. National Instrument signal conditioner

13. Lab view software (see appendix B)

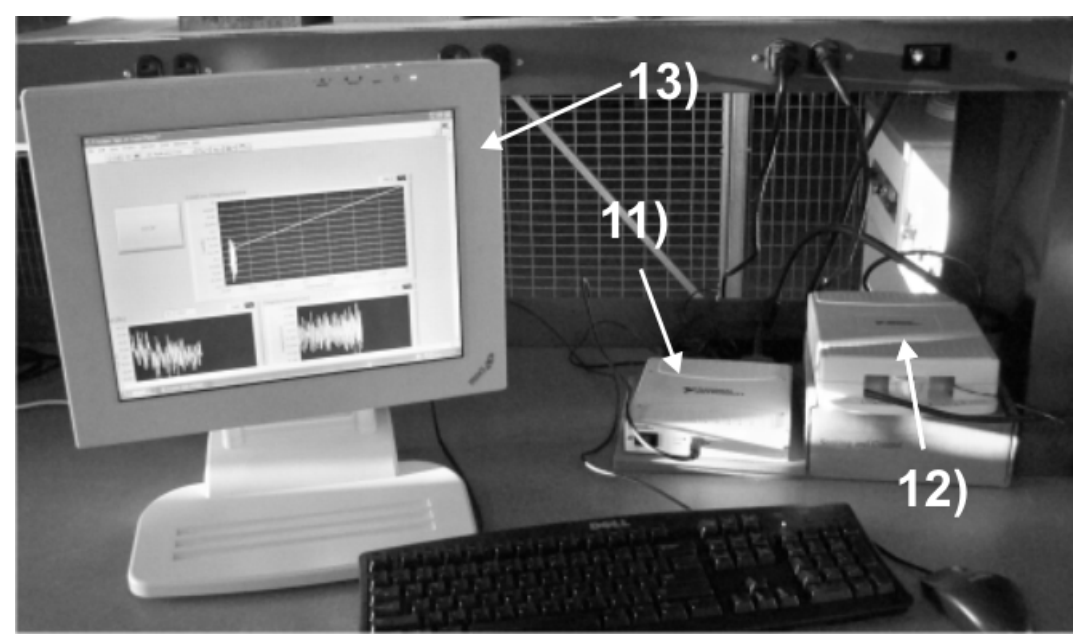

Figure 5.2.5 a) - Data acquisition system -

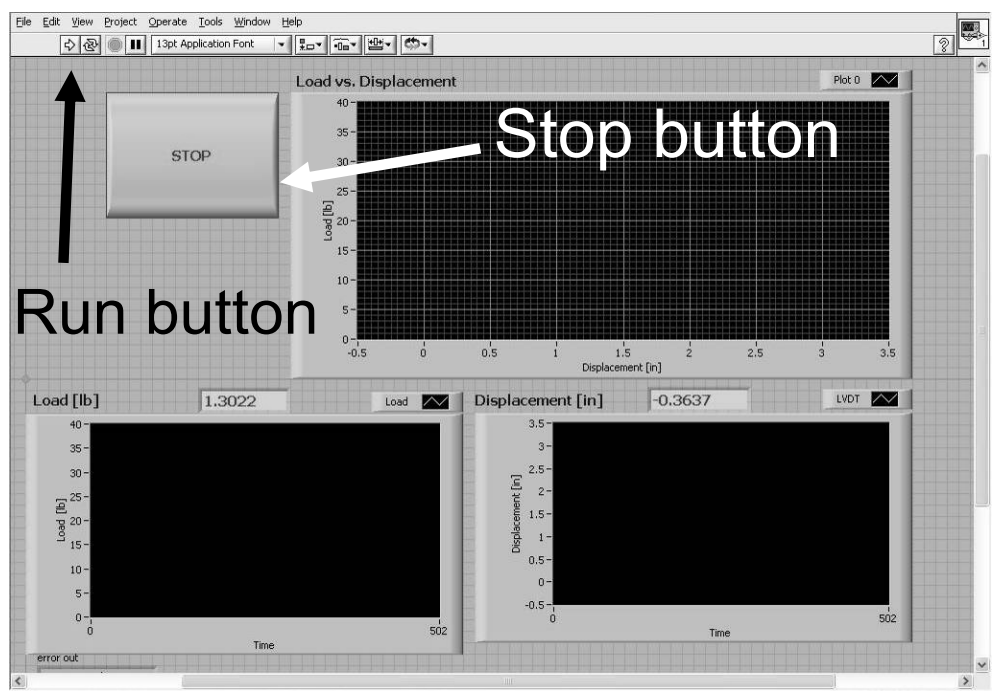

Figure 5.2.5 b) - data acquisition system lab view running program - 
To maintain the accuracy of the test measurement, the range of the load cell was selected according the frictional loads that are involved in the friction test.

A very important consideration in selecting the test apparatus is the stiffness of the friction force measuring system. Since the sliding member (car) in this test is pushed by a metal rod, a very little elastic strain prior to initiation of motion will exist. So the force measured by the load cell may not record the "spike" force ${ }^{8}$, for that reason, a small rubber will be put between the end of the pushing rod and the sliding member.

\subsubsection{Materials}

As it was mentioned in beginning of this section two different coated fabrics were tested against different concrete surfaces; also a test of a fabric against an acrylic sheet and a steel plate was performed. It is important to remember that the fixed surface is the fabric and the surface that slides are the different concrete surfaces, the steel plate or the acrylic sheet. The next table summarizes all the tests done and all the materials that were involved in each test, also, note that the denomination " $D$ " corresponds to dry tests and the denomination "W" corresponds to wet tests.

\footnotetext{
${ }^{8}$ The "spike force" is used to calculate static friction coefficient (see chapter 4).
} 
Table 5.2.1- List of tests and materials specifications in dry (D) surfaces -

\begin{tabular}{|c|c|c|}
\hline Test Number & Sliding Surface Specifications & $\begin{array}{l}\text { Fixed Surface } \\
\text { Specifications }\end{array}$ \\
\hline D1 & Concrete (mortar termination) & \multirow{9}{*}{$\begin{array}{c}\text { Ferrari Precontraint } \\
1002 \text { (formula S) fabric } \\
\text { PVC coated }\end{array}$} \\
\hline D2 & Rough Concrete & \\
\hline D3 & $\begin{array}{l}\text { Concrete enhanced with Epoxy paint } \\
\text { (Quikrete, garage floor sealer, color concrete gray) }\end{array}$ & \\
\hline D4 & $\begin{array}{l}\text { Concrete enhanced with Latex paint } \\
\text { (Olympic premium, exterior latex satin, color transparent) }\end{array}$ & \\
\hline D5 & $\begin{array}{l}\text { Concrete enhanced with Texturate paint } \\
\text { (Valspar, sand texturate paint, color white) }\end{array}$ & \\
\hline D6 & $\begin{array}{l}\text { Concrete enhanced with Anti - Skid paint } \\
\text { (Valspar, interior/exterior Skid-not, color light gray) }\end{array}$ & \\
\hline D7 & $\begin{array}{l}\text { Concrete enhanced with Asphalt paint } \\
\text { (Black Jack, asphalt cement for roof, color black) }\end{array}$ & \\
\hline D8 & $\begin{array}{l}\text { Steel plate } \\
\text { (A312 Stainless steel, mirror surface finished) }\end{array}$ & \\
\hline D9 & Acrylic sheet & \\
\hline D10 & Concrete (mortar termination) & $\begin{array}{l}\text { Polyester fabric } \\
\text { Vinyl coated }\end{array}$ \\
\hline
\end{tabular}


Table 5.2.2 - List of tests and materials specifications in wet (W) surfaces -

\begin{tabular}{|c|c|c|}
\hline Test Number & Sliding Surface Specifications & $\begin{array}{l}\text { Fixed Surface } \\
\text { Specifications }\end{array}$ \\
\hline W1 & Concrete (mortar termination) & \multirow{9}{*}{$\begin{array}{c}\text { Ferrari Precontraint } \\
1002 \text { (formula } S \text { ) fabric } \\
\text { PVC coated }\end{array}$} \\
\hline W2 & Rough Concrete & \\
\hline W3 & $\begin{array}{l}\text { Concrete enhanced with Epoxy paint } \\
\text { (Quikrete, garage floor sealer, color concrete gray) }\end{array}$ & \\
\hline W4 & $\begin{array}{l}\text { Concrete enhanced with Latex paint } \\
\text { (Olympic premium, exterior latex satin, color transparent) }\end{array}$ & \\
\hline W5 & $\begin{array}{l}\text { Concrete enhanced with Texturate paint } \\
\text { (Valspar, sand texturate paint, color white) }\end{array}$ & \\
\hline W6 & $\begin{array}{l}\text { Concrete enhanced with Anti - Skid paint } \\
\text { (Valspar, interior/exterior Skid-not, color light gray) }\end{array}$ & \\
\hline W7 & $\begin{array}{l}\text { Concrete enhanced with Asphalt paint } \\
\text { (Black Jack, asphalt cement for roof, color black) }\end{array}$ & \\
\hline W8 & $\begin{array}{l}\text { Steel plate } \\
\text { (A312 Stainless steel, mirror surface finished) }\end{array}$ & \\
\hline W9 & Acrylic sheet & \\
\hline W10 & Concrete (mortar termination) & $\begin{array}{l}\text { Polyester fabric } \\
\text { Vinyl coated }\end{array}$ \\
\hline
\end{tabular}




\subsubsection{Sampling and specimens preparation}

Essentially in all the tests there are two different specimens:

- $\quad$ Fixed specimen

- $\quad$ Sliding specimen specimen
$\Longrightarrow \quad$ Fabric specimen

$\Longrightarrow \quad$ Concrete/acrylic/steel

The fabric specimens were defined by the dimensions of the normal force fixture, 2 by 2 inches. This dimension was arbitrary chosen, between a certain range of value. If the dimension is bigger it will not represent the cylindrical shape of the real system. And if it is smaller the friction force will be punctual in one point and the incidence pressure (normal force) will not represent the inflatable pressure.

So the fabric's specimens will be 2 by 2 inches, figure 5.2 .6 shows the normal force specimen fixture.

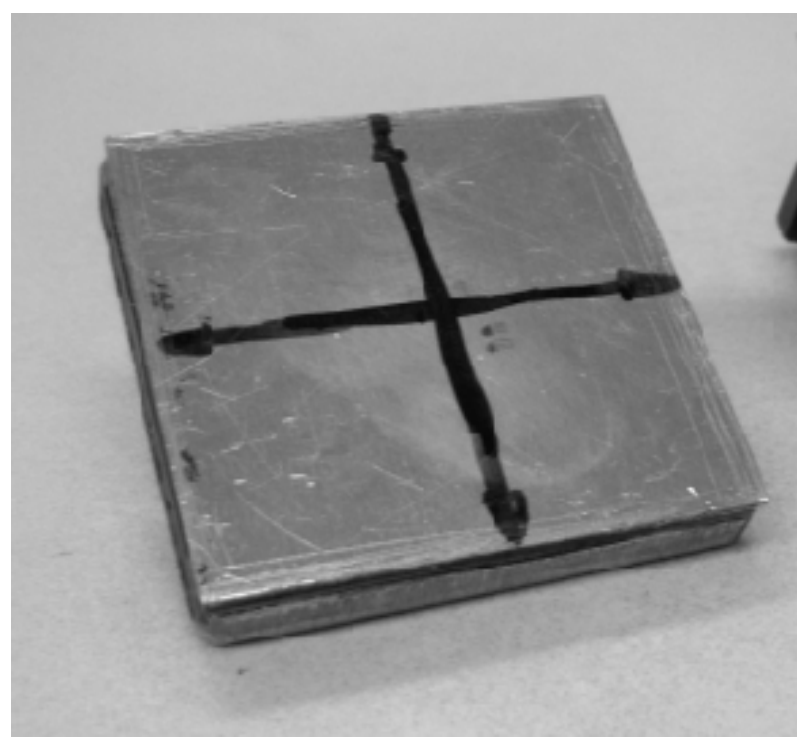

Figure 5.2.6 - Normal force specimen fixture - 
The size of sliding specimens are not too critic as the one in the fabrics specimens. The only important consideration is that the two surfaces (bottom and top) normal to the fixed specimen must be flat, by this way the full area of contact between the two surfaces is secure.

In addition all the specimens should be capable to fix in the sliding car. For the case of the concrete specimens the dimensions are 7 inches long, 4 inches wide and 1.5 inches thick. Figure 5.2.7 shows an example of a concrete specimen, in this case is the concrete with mortar finished.

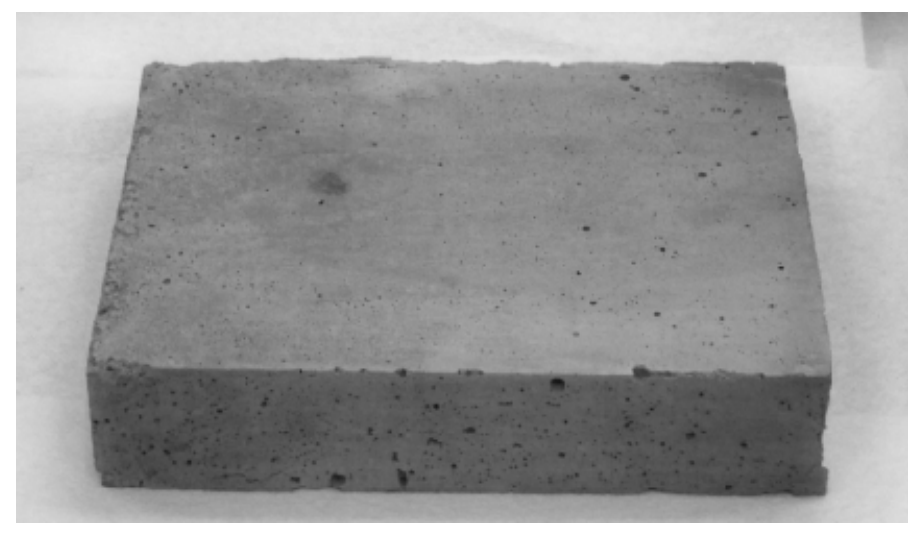

Figure 5.2.7 - Concrete specimen -

The concrete specimens were done by technicians from WVU civil engineering department, where the finished surface simulates the one in the real tunnel wall (see section 5.2.1.1 for mix specifications).

From the entire concrete sample, one was used without performing any surface treatment. On another one a rough surface was created by grinding the concrete sample with a steel bar. And then in the rest of the specimens different treatments were 
performed (e.g. epoxy paint, asphalt paint, etc.), by using the application instructions indicated by the each manufacturer (see table 5.2.1).

The dimensions of the steel or acrylic plates are 7 inches long, 4 inches wide and 1/12 inches thick.

Finally to reproduce better the tribosystem, all the contaminants that may affect the final results were removed: such as excess of concrete, excess of paint, grease, etc. The fabrics samples and the acrylic plate were cleaned with alcohol. For the concrete samples compress air was used to remove undesired particles. And, in the case of the steel surface acetone was used to remove greases and oil films.

\subsubsection{Test operation}

Once all the samples (fabric and surfaces) are prepared, the next step is to attach the fabric, fixed specimen, in the normal weight fixture (see figure 5.2.5) using a thin double stick tape. The tape should be strong enough to prevent slip neither from the fabric nor from the fixture; also it should be as thin as possible so it does not have any influence in the system elastic deformation. In addition, excess of tape outside the fixture is not recommended because it can interfere in the sliding motion. Then this specimen fixture is screw in the normal weight rod. For all the tests performing in this work a commercial Scotch double stick tape was used.

Later the sliding surface (concrete, acrylic or steel sample) is put over the sliding member (car). This specimen should be positioned adjacent to lip that is in the car, this 
will prevent the specimen to move backwards when the test is running. The next figure shows the correct position of the sliding specimen over the car.

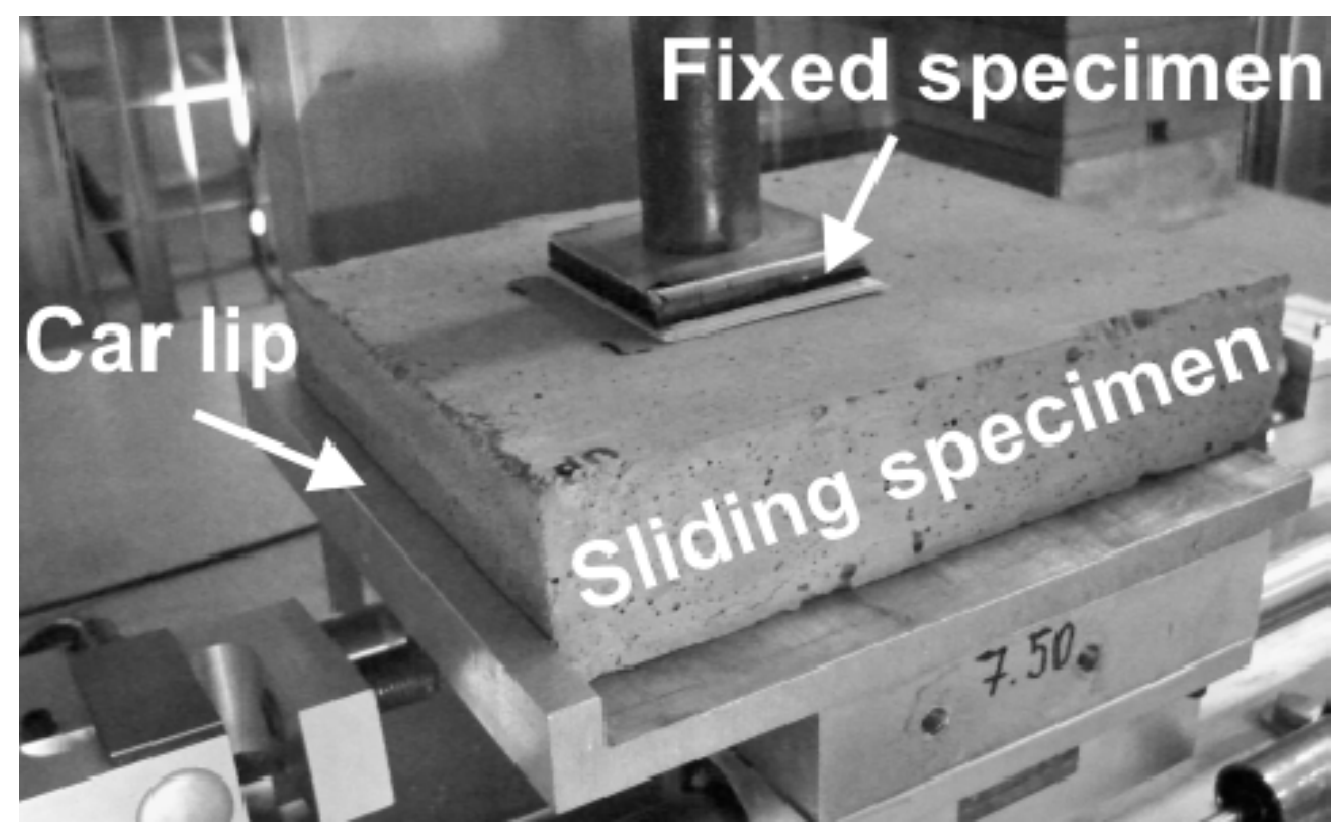

Figure 5.2.8 - Sliding surface over the car -

In the case of the steel or acrylic sheets a "C" claps were used to prevent any lateral movement when the test is running.

Once when the fabric is in the normal weight fixture and sliding specimen is positioned over the car; if there is no gap lights between the two surfaces the parallelism between them is guaranteed. Figure 5.2 .9 shows an example of the final set up of the specimens (fixed and sliding) before running the test. 


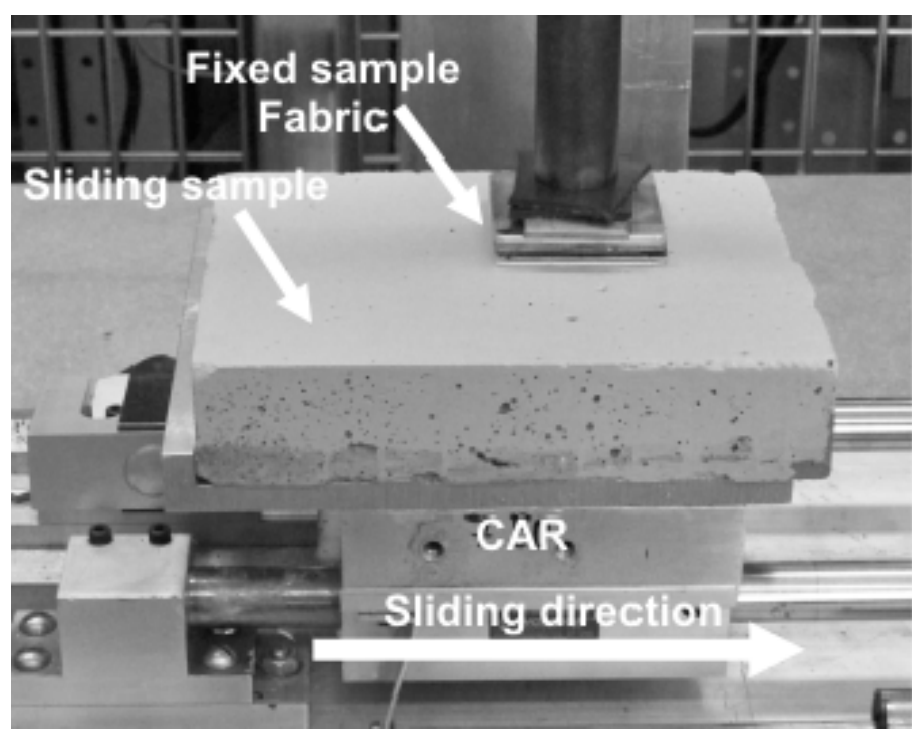

Figure 5.2.9 - Correct position of the fixed and sliding specimens -

After positioned and checking the parallelism of the specimens, is necessary to check that the car is sliding smoothly. For that, and to prevent any pre test wear, the rod of the weight fixture is hold in an upper position so there is no interference between the fabric and the sliding surface. Then the smoothness of the sliding member is checking by hand, moving the car back and forward along the rails. If any resistance is felt, is necessary to clean the rod rails and re - grease it.

Before putting the weight fixture rod in the test position, and in order to warm up all the hydraulic system, several "dry runs" (with the weight rod up) are performed. To do that "dry run" first is necessary to position the car in the beginning position, this means that the car is in contact it with the pushing rod (see figure 5.2.1 a)). Afterwards, the hydraulic pump should be turn on, then, the relief lever (see figure 5.2.1 b)) is opened, and consequently, the car will move forwards. To restart the test, close the lever, and move by hand the car back to the beginning position. With ten "dry runs" it is good enough to begin the real test. 
In this step, also is important to adjust the speed of the pushing rod by changing the position of the mass flow valve regulator (see figure 5.2.1 b)). However, this parameter can be repositioned when the real test is done.

After put all the specimens in the test apparatus, and after all the mechanics components are checked, it is required to check the data acquisition system. For that, the computer and the data acquisition card should be turn on. Then the friction test lab view program is opened and the "run" button in this program is clicked (the program starts to recollect data). With the program running, finally, another "dry run" with the normal weight fixture in the up position is done. Checking by this way all the data recollected that visualize in the test monitor. Then stop the program clicking in the "stop" button and proceed with the test.

Finally, when the specimens are in the correct position and all the components are checked, the test can be performed following this procedure:

1. Put the car in the beginning position, the pushing rod and the car must be in contact.

2. Put the normal weight rod with the fabric specimen in the down position, so the fabric and the sliding surface are in contact. Recheck again for parallelism between the two surfaces.

3. Put the desired normal weights, in the normal weight fixture rod (see figure 5.2.1 a)).

4. If the pump is off, turn it on again and wait for a couple of minutes so the pump runs in regimen. 
5. If the computer and the data acquisition card are off, turn it on again and open the lab view test program.

6. Push the "run" button in the lab view test program so data begin to be recollected. Open the lever and run the test. When the desire displacement is reached by the car or when the car is stopped at the end of the rails, click in the "stop" button in the program and the close the lever.

7. To repeat the test hold up the normal weight fixture and move by hand backwards the car to the "beginning" position, and repeat the previous step.

8. If is necessary to change the normal weight, go to step 3 and repeat the procedure (step 4 and 5 can be ignored).

9. If is necessary to change the car speed, put the regulator valve in the desire position and repeat step 6 .

Once the test has been performed, the data will be ready to be processed and analyzed.

The procedure described before was for a dry test. However, to run a wet test the only step to be added to the ones in the described procedure is to put the sliding specimen inside the wet fixture (see figure 5.1.2 a)). Then set that fixture over the car with one the faces adjacent to lip car. Later, position the normal weight rod fixture (with the fabric specimen already placed) and check for parallelism. Afterwards, water has to be added to the wet fixture. The water added should cover the fabric specimen. Finally run the test with steps described; special caution should be taken in account when the sliding speed is fast because water can splash over the load cell, LVDT or car rails. 


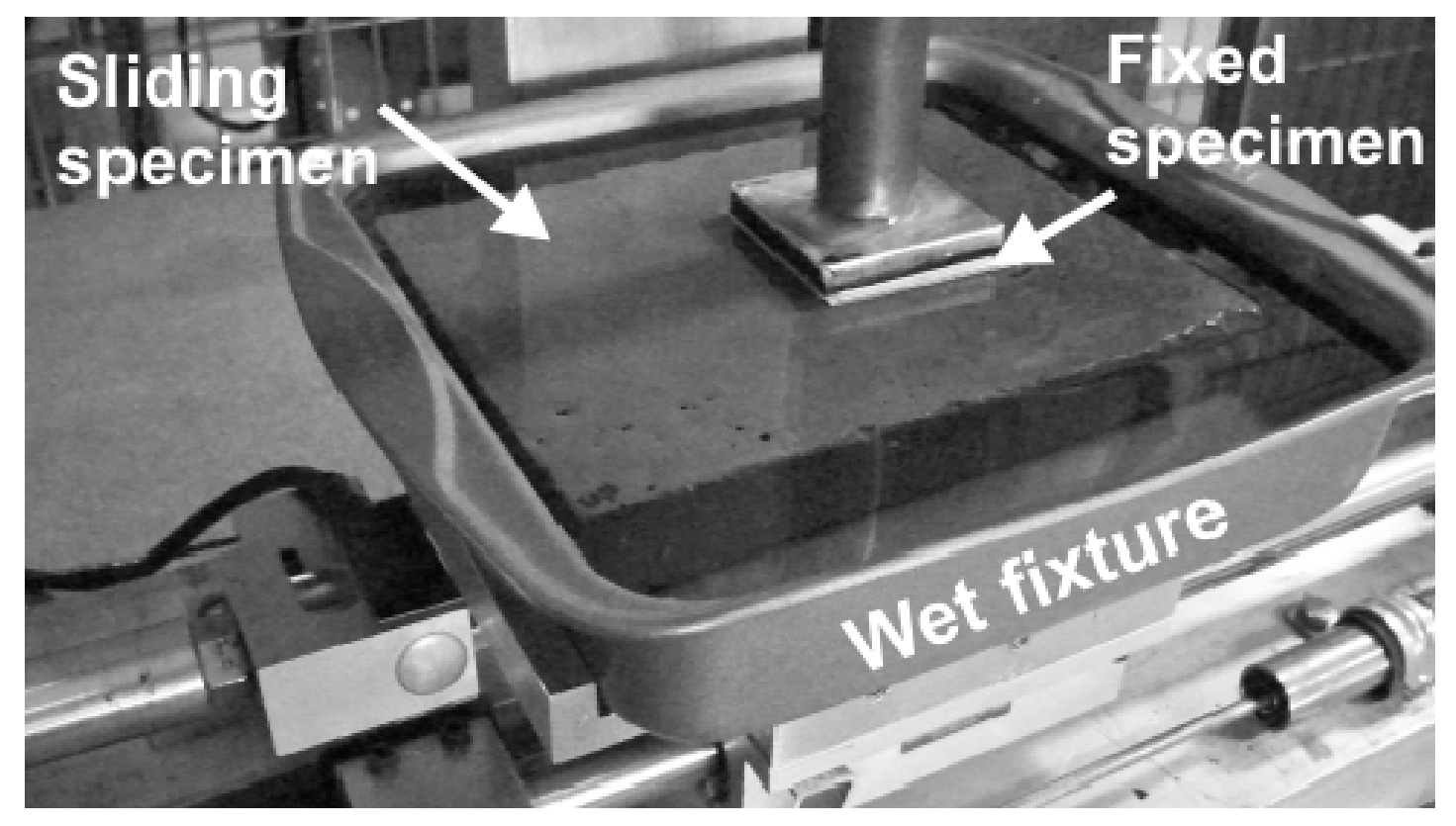

Figure 5.2.10 - Concrete specimen inside the wet fixture -

For more details in the process of the data see appendixes $B$ and $C$.

\subsubsection{Results and analysis of fabric's static friction coefficient against different superficies}

Following the procedures as it was detailed in the previous section a friction coefficient test was done for several specimens at different situations. As it was described in section 5.2.2.1 there are nine different sliding surfaces and two different fabrics to be tested. For the analysis of the project's frictional system is necessary to change different parameters in this case the speed of the push rod, the normal weights and the dry or wet condition. Next table a resume of the entire samples test and all the test condition is presented. 
Table 5.2.3 - List of tests in dry and wet surfaces -

\begin{tabular}{|c|c|c|}
\hline Fixed Surface Fabrics & Sliding Surface & $\begin{array}{c}\text { Normal Weights } \\
\text { [lbs] }\end{array}$ \\
\hline \multirow{14}{*}{$\begin{array}{c}\text { Ferrari fabric } \\
\text { Precontraint } 1002 \\
\text { (formula S) }\end{array}$} & \multirow{3}{*}{ Concrete } & 13.3 \\
\hline & & 24.5 \\
\hline & & 44.5 \\
\hline & \multirow{3}{*}{ Rough Concrete } & 13.3 \\
\hline & & 24.5 \\
\hline & & 44.5 \\
\hline & \multirow{3}{*}{ Epoxy paint } & 13.3 \\
\hline & & 24.5 \\
\hline & & 44.5 \\
\hline & \multirow{3}{*}{ Latex paint } & 13.3 \\
\hline & & 24.5 \\
\hline & & 44.5 \\
\hline & \multirow{3}{*}{ Texturate paint } & 13.3 \\
\hline & & 24.5 \\
\hline \multirow{12}{*}{$P V C$ coated } & & 44.5 \\
\hline & \multirow{3}{*}{ Anti - Skid paint } & 13.3 \\
\hline & & 24.5 \\
\hline & & 44.5 \\
\hline & \multirow{2}{*}{ Asphalt paint } & 8.9 \\
\hline & & 13.3 \\
\hline & \multirow{3}{*}{ Steel plate } & 13.3 \\
\hline & & 24.5 \\
\hline & & 44.5 \\
\hline & \multirow{3}{*}{ Acrylic sheet } & 13.3 \\
\hline & & 24.5 \\
\hline & & 44.5 \\
\hline \multirow{3}{*}{$\begin{array}{l}\text { Polyester fabric } \\
\text { Vinyl coated }\end{array}$} & \multirow{3}{*}{ Concrete } & 13.3 \\
\hline & & 24.5 \\
\hline & & 44.5 \\
\hline
\end{tabular}

All these sets of test are repeated for the wet condition; however the test for the texturate paint was not done because the paint treatment was not resistant to water.

Also each test was done at two different car speeds (vel1 and vel2), this analysis was done to see the influence of the sliding speed in the system. For that two different position of the hydraulic flow regulator valve were set (see figure 5.2.1 a)).

For each test combination (sliding surface specimen and normal load) the velocity of the car will change. Only qualitative analysis regarding to the velocity are being 
performed, therefore for the purpose of this work the sliding speed of the car will not be calculated for each test. However it can be said that the velocity ${ }^{9}$ for all the tests varies from $0.1 / 0.2 \mathrm{in} / \mathrm{sec}$ (slow velocities, V1) to $0.3 / 0.4 \mathrm{in} / \mathrm{sec}$ (fast velocities, V2), so the faster velocities (V2) are approximately two times bigger than the smaller ones (V1)

Finally, since is necessary to obtain accurate values of the static friction coefficient, each test was repeated ten times. In Appendix $C$ there is a brief explanation of how all the data obtained is processed.

In the next two sections the results are presented, first as a qualitative analysis studying and comparing the frictional phenomenon in all the surfaces listed in table 5.2.3. And second a comparative analysis of the surface treatment results is done, this study is regarding to improve the frictional system in the inflatable structure project.

\subsubsection{Qualitative analysis of the friction tests}

\section{Proportionality between the friction force and the normal load}

The first analysis suggested is to study how the frictional system changes if the normal load is increased. In chapter 4 was stated that the frictional force is proportional to the normal load. The next two figures show how the frictional load ( $y$ axis) change due to the normal load. In this case the analysis is done for the dry concrete surface sliding over the Ferrari's fabric, for three different normal weights $(13.3,24.5$ and $44.5 \mathrm{lbs}$ ) and for two different speeds ( 0.2 in/sec and $\sim 0.5 \mathrm{in} / \mathrm{sec})$.

\footnotetext{
${ }^{9}$ The denomination $\mathrm{V} 1$ and $\mathrm{V} 2$ will be used in all the tests.
} 


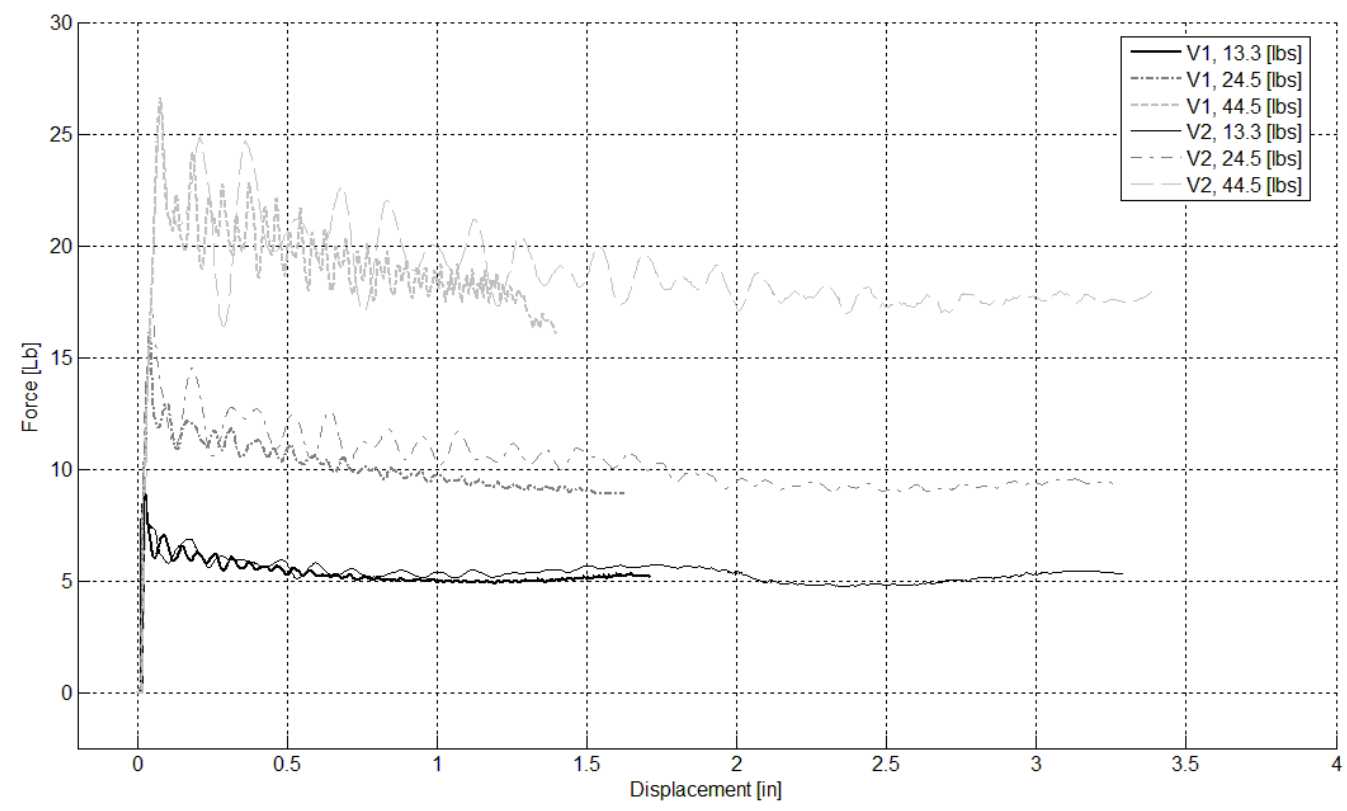

Figure 5.2.11 - Normal load behavior for concrete, with 13.3, 24.4 and 44.5 lbs normal weight -

From this figure it can be seen that, besides the friction increases with the normal load, there is a scale behavior. This means when the normal weight is increased the corresponding friction forces increase proportionality.

To see better this behavior, a figure where the maximum values of the friction force at three different weights and for the two sliding velocities is plotted. In that figure also a linear fitting curve between the normal weights is added to the plot. 


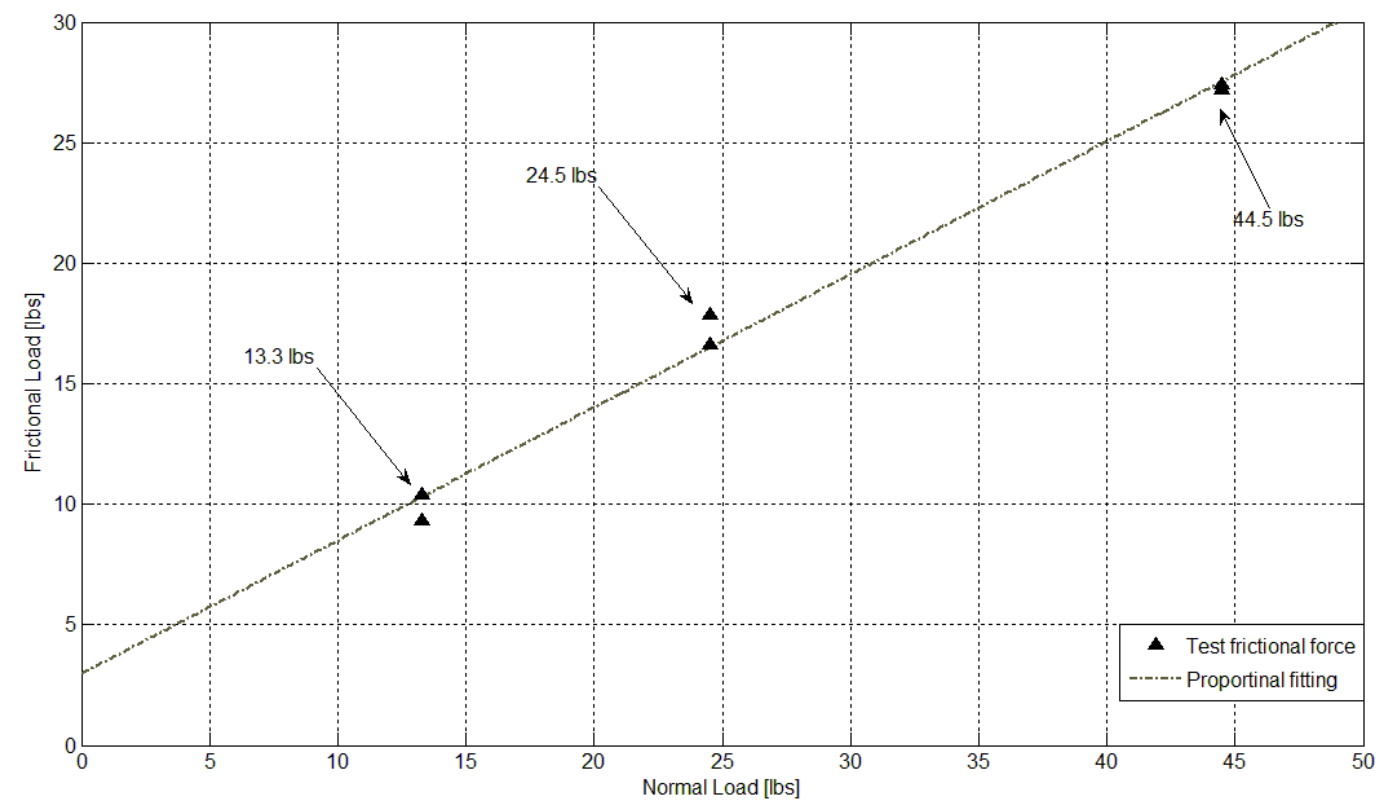

Figure 5.2.12 - Proportionality for normal load behavior for concrete, with 13.3, 24.4 and 44.5 Ibs normal weight -

From the figure above is easy to recognize that the behavior of the friction force is proportional to the normal load. Also from this figure, it can be verifying that the friction force is independent of the sliding velocity. As it was shown in the figure 5.2.12 for the same normal weight and varying velocity (vel1 $\sim 0.2 \mathrm{in} / \mathrm{sec}$ and vel2 $\sim 0.5 \mathrm{in} / \mathrm{sec}$ ) the friction force will be almost the same. 


\section{Mechanism of sliding friction}

In chapter four the friction mechanism was characterized by two different behaviors: the ploughing and the adhesion. The ploughing is due to the roughness of the surfaces and the adhesion due to the intermolecular forces attraction of the system surfaces. Although to determine to determine the percentage of influence of this mechanism is not the purpose of this investigation a qualitative analysis is done.

The next figure shows a typical behavior of different surfaces where the roughness is their main characteristic. In this case, the figure shows the behavior for the rough concrete surface, the texturate paint and the anti-skid paint, for $24.5 \mathrm{lbs}$ of normal weight and at $V 1$.

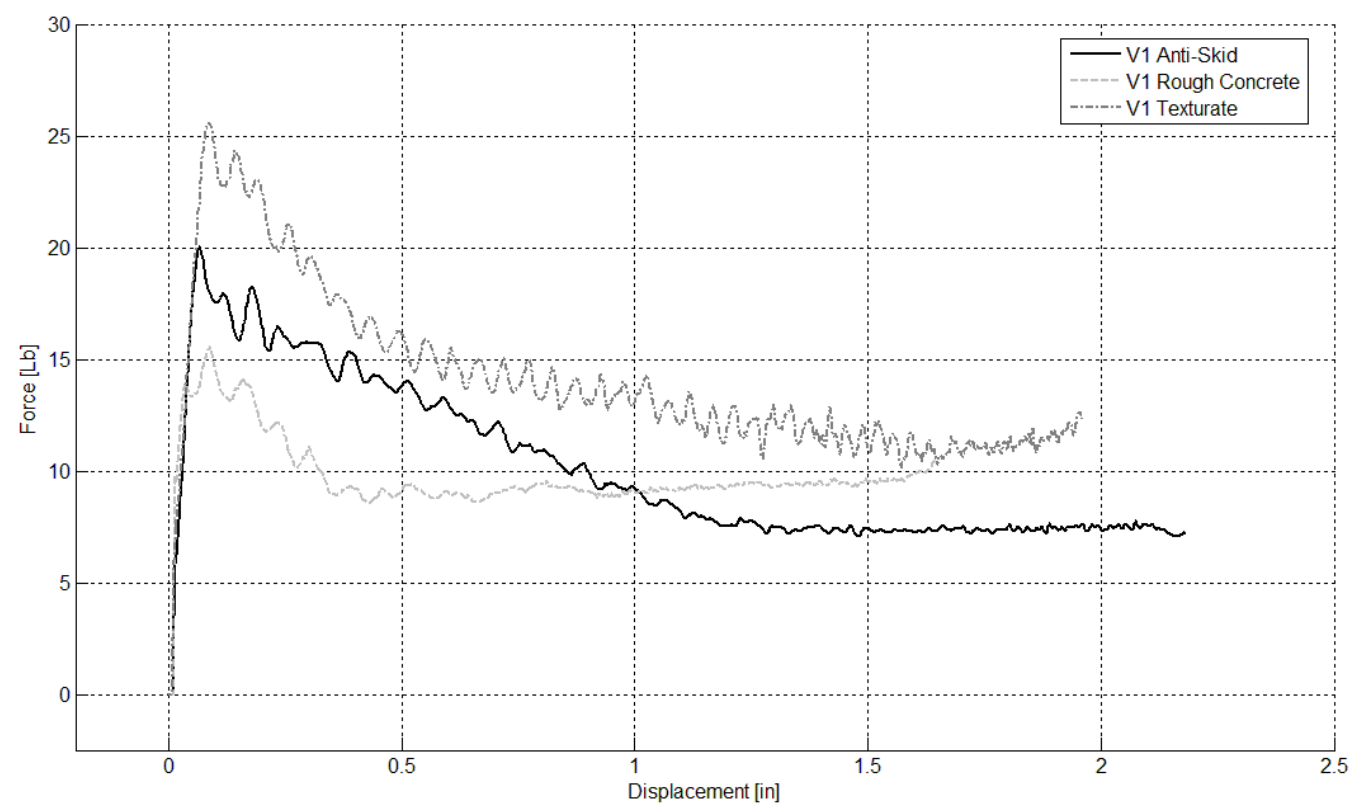

Figure 5.2.13 - Roughness influence, texturate paint, anti-skid paint and rough concrete, 24.5 lbs normal weight, at V1 - 
When the texturate paint slides over the fabric, the frictional force varies according the surface of the sliding component (the texturate brick). This means that the peaks and valleys in the brick will determine the frictional behavior of the system. When a peak is found a force resistant to the movement will appear, increasing the frictional force. This is why in the case of the texturate paint the curve shows oscillations. In the case of the antiskid paint where the sand on it creates peaks, the oscillations appear. However, since the peaks are smaller the oscillations are smaller too. For the rough concrete treatment this phenomenon is shown but in a smaller scale; not because the peaks are bigger but because the peaks are not abrupt as the others two, so the fabric will slide with not too much resistance.

The next figure shows a classical behavior of a frictional system due to adhesion. For that the figure curves are done with smooth surfaces. In this case steel, acrylic and epoxy are used. To have a contrast with a rough surface, the curve for concrete is also included in this plot. All this curves are obtained for dry surfaces, for $24.5 \mathrm{lbs}$ of normal weight and for the two velocities $V 1$ and $V 2$.

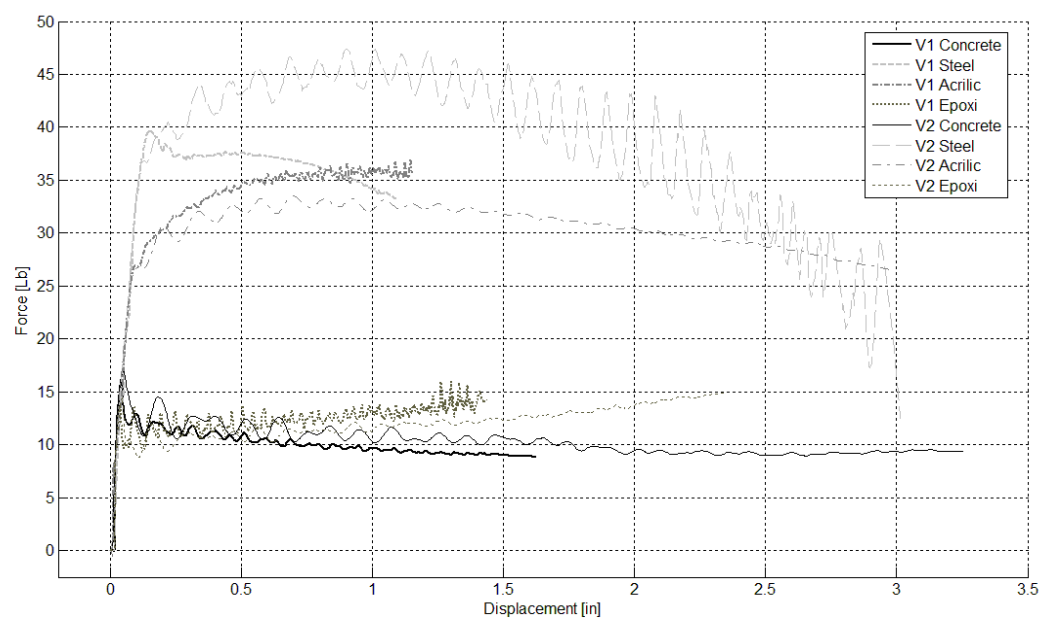

Figure 5.2.14 - Adhesion influence, epoxy paint, acrylic surface, steel surface and concrete, $24.5 \mathrm{lbs}$ normal weight, at V1 and V2 - 
As the roughness behavior there are oscillations in the frictional force meanwhile the surfaces are sliding. However, this is not due to picks or valleys from the surfaces these oscillations are from the intermolecular forces between the two surfaces. In adhesion, these oscillations are called "Stick and Slip", this behavior is originally form by the formation and destruction of the surface junctions on a microscopic scale, and, as a difference with the roughness surfaces, it depends mainly on the sliding speed.

This influence of the sliding speed can be seen in the figure 5.2.14. In the smoother surfaces epoxy, steel and acrylic the "Stick and Slip" behavior is bigger for the faster velocities (V2) than for the slower ones (V1). This means that if the speed increases, the frictional forces oscillate more along the race. However, for surfaces where the roughness dominates, in this figure concrete, the different sliding speeds do not affect too much the frictional forces.

Another important difference between the ploughing (roughness) and adhesion, is that the friction forces in a roughness mechanism is not affected to much if there is a film of water between the surfaces (hydrodynamic lubrication). However, in smooth surfaces the frictional load decrease considerably. The next figure shows an example of this behavior, where the steel, anti-skid and concrete surfaces are plotted, for dry and wet conditions, $44.5 \mathrm{lbs}$ of normal weight and for the velocity $\mathrm{V} 2$. 


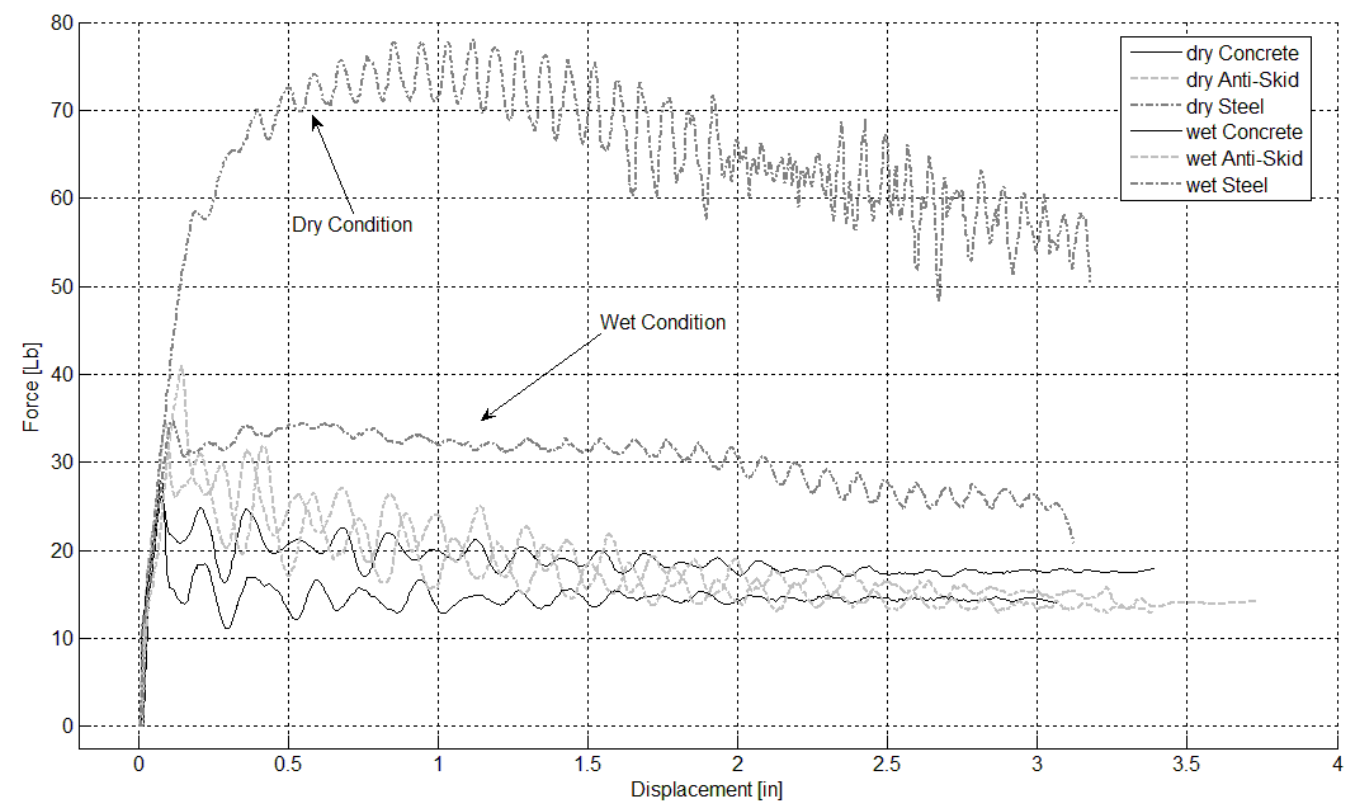

Figure 5.2.15 - Hydrodynamic influence, anti-skid paint, steel surface and concrete, 44.5 Ibs normal weight, V2 -

As figure 5.2.15 shows for the surfaces where the roughness governs, anti-skid and concrete, there is no influence of the water over the friction system. However for the steel where the surface is smooth and where the adhesion rules, the frictional force decreases due to this hydrodynamic phenomenon.

\subsubsection{Static friction coefficient results for the different sliding surfaces}

The main objective of this work is to improve the friction between the tunnel wall (concrete) and the fabric of the inflatable structure. Consequently the frictional force in that tribological system is calculated. Also, since the system is studied for the static behavior and not when it is moving, the static friction coefficient is determined. Furthermore, to compare different combinations of parameters in the test (normal weight, surfaces and 
velocities) the static friction coefficient will be useful. It is useful to remember that the normal load is proportional to the inflatable pressure from the structure, with the fabric sample chosen with $4 \mathrm{in}^{2}$ of area, the corresponding pressures will be: 0.225 psi for 13.3 Ibs, 6.125 psi for 24.5 , and 11.125 for $44.5 \mathrm{lbs}$.

There are two approaches to improve the friction of the frictional system: either applying different treatments to the wall tunnel or changing a fabric with different coating. The next table shows the final static friction coefficient for all the different wall treatments against the Ferrari's PVC coated fabric, for dry and wet conditions. (See appendix C for the static friction coefficient estimation).

Table 5.2.4 - List of the different static friction coefficient, $\mu_{S}$, in dry and wet surfaces for the PVC coated fabric -

\begin{tabular}{|c|c|c|c|c|}
\hline \multirow{2}{*}{ Surfaces Treatment } & \multicolumn{2}{|c|}{ DRY } & \multicolumn{2}{c|}{ WET } \\
\cline { 2 - 5 } & $\mu_{S}$ & STDev & $\mu_{S}$ & STDev \\
\hline Concrete & $\mathbf{0 . 6 9}$ & 0.07 & $\mathbf{0 . 7 2}$ & 0.05 \\
\hline Rough Concrete & $\mathbf{0 . 6 1}$ & 0.03 & $\mathbf{0 . 7 2}$ & 0.06 \\
\hline Anti - Skid & $\mathbf{0 . 8 2}$ & 0.05 & $\mathbf{0 . 8 6}$ & 0.07 \\
\hline Epoxy & $\mathbf{0 . 6 3}$ & 0.08 & $\mathbf{0 . 6 3}$ & 0.04 \\
\hline Texturate & $\mathbf{1 . 0 4}$ & 0.08 & - & - \\
\hline Latex & $\mathbf{1 . 2 7}$ & 0.26 & $\mathbf{1 . 1 4}$ & 0.13 \\
\hline Asphalt & $\mathbf{6 . 7 4}$ & 0.15 & $\mathbf{2 . 2 2}$ & 0.35 \\
\hline Steel & $\mathbf{1 . 6 8}$ & 0.46 & $\mathbf{0 . 7 6}$ & 0.07 \\
\hline Acrylic & $\mathbf{1 . 2 9}$ & 0.25 & $\mathbf{0 . 8 3}$ & 0.09 \\
\hline
\end{tabular}

Reduction due water [\%]

$-5.25$

$-17.20$

$-5.5$

$-1.13$

\begin{tabular}{|c|}
\hline- \\
\hline 10.5 \\
\hline 67.10 \\
\hline 54.75 \\
\hline 35.75 \\
\hline
\end{tabular}


As it can be seen in the table there are a wide range of values of static friction coefficient. The concrete surface simulates the real tunnel wall, therefore which ever treatment that has a larger value of the static friction coefficient will means a frictional improvement to the system, and if it is below the concrete's value will be the opposite. The static friction coefficient for the concrete in this system is 0.69 .

Analyzing first the dry condition, the biggest static friction coefficient, 6.74 , is when asphalt paint is used as the concrete treatment. This value is real large ${ }^{10}$ making this treatment a potential solution to increase the friction between the tunnel and structure fabric. Basically this happens due to the viscous property of the asphalt, where the asphalt as a real thick fluid resists to the motion implies by the external loads of the system (risk pressure).

On the opposite, the lowest value for the static friction coefficient is for the rough concrete, 0.61 . Only the macro roughness of this treatment actuates as an improvement for the friction, there is no other property that contributes neither to the ploughing nor to the adhesion. Due to this macro roughness there is severe abrasive wear from the rough concrete to the structural fabric.

Other good treatments are the texturate (1.04), the anti-skid (0.82) and the latex (1.27) paints. The first two improve the friction of the system because of their roughness. But the second one, which is smoother than the other two, the friction will increase due to the

\footnotetext{
${ }^{10}$ It is necessary to apply approximately seven times the normal load to move the fabric specimen, if the normal load is $10 \mathrm{lbs}$ it required almost $70 \mathrm{lbs}$ to move it.
} 
frictional adhesion properties. Also an epoxy paint was used, but the static friction coefficient obtained $(0.63)$ does not differ too much from the regular concrete.

Since the acrylic and the steel are not a possible treatment of the tunnel, they will not be analyzed. However, they are useful to understand better the behavior of smooth surfaces.

The next figure shows the difference in the frictional force between concrete, latex and asphalt. These tests were done for $13.3 \mathrm{lbs}$ of normal weight, at dry conditions, and for V2.

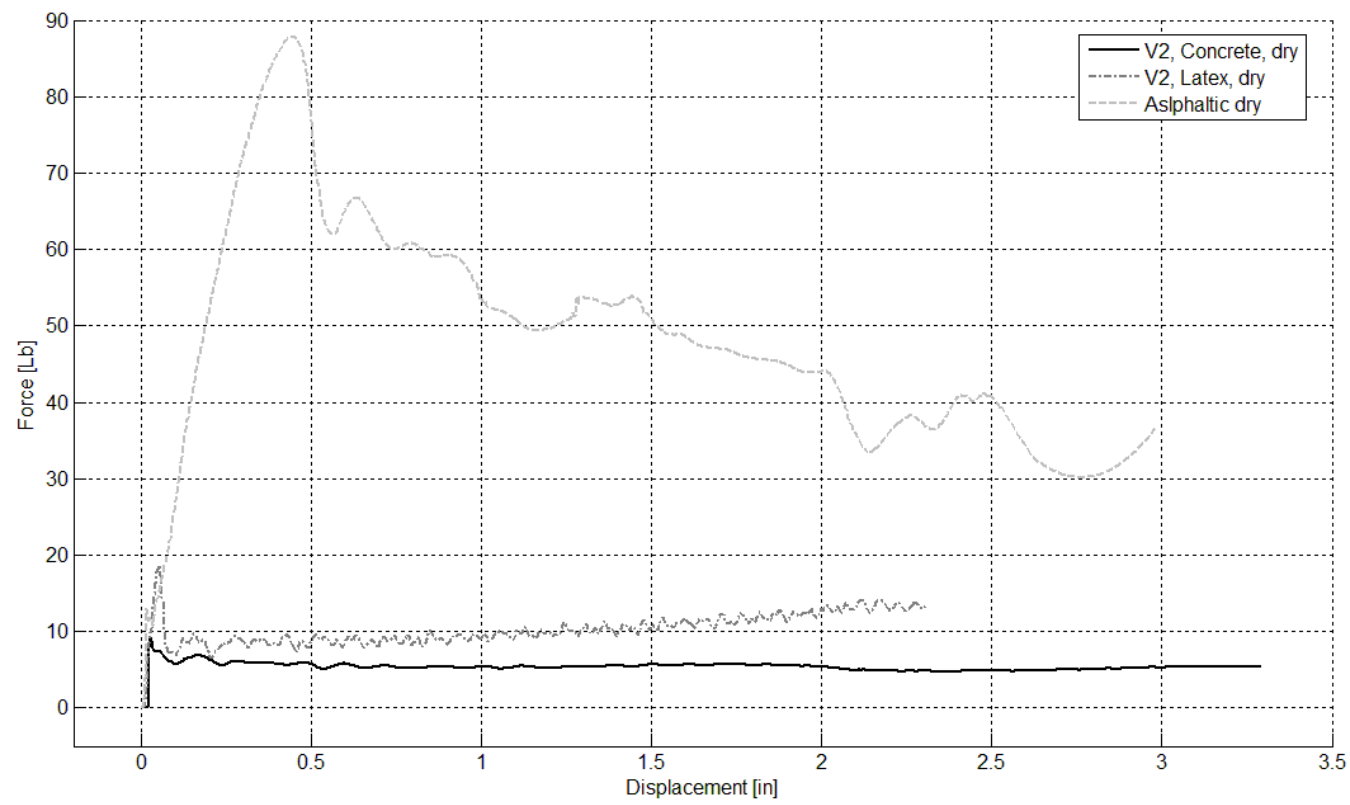

Figure 5.2.16 - Frictional forces differences between concrete, and asphalt and latex wall treatments, $13.3 \mathrm{lbs}$ normal weight, $\mathrm{V} 2$ -

As figure 5.2.16 shows the asphalt is the one that increases most the frictional forces, then the steel and later the latex. The maximum value of frictional forces, or peak, will 
corresponds to the static friction coefficient (see chapter four), so the asphalt corresponds to the one that has static friction.

Now, analyzing the friction for the wet condition, there is an unexpected result in several of the wall treatments. The common hypothesis is when water is over a surface and another surface slides over it, the movement will tend to be slippery. However, for the epoxy treatment, the anti-skid treatment, the rough concrete, and the regular concrete, this hypothesis is not true. Surprisedly the values of the static friction coefficient in those cases will increase for the wet condition.

From table 5.2 .3 it can be seen that the values increases but not much. This phenomenon could happen due to the porous surface of the concrete. When the water spills all over the wall surface (concrete, epoxy, anti-skid, etc.) not all the cavities (porous) are filled with water, creating small vacuum zones in the surface. Consequently, and due to the phenomenon of surface tension inward attracting forces will appear, increasing the resistant sliding force (friction force).

However, for surfaces where there are no cavities (steel, acrylic, asphalt), when they are spilled with water the surface tension will not appear, and therefore, the friction forces will not increase. Table 5.2.3 shows the percentage values for the water influence on the tribosystem, more porosity in the wall the best is the resistance force (friction). For smoother surfaces without cavities the water will cause low frictional resistance, acting as a lubricant.

After analyzing the different wall treatments the change of fabric is studied. In this case, the fabric was changed from a PVC coated nylon fabric to a vinyl coated polyester 
fabric. The study of the frictional behavior was done only against the concrete surface. Figure 5.2.17 shows the difference between these two fabrics sliding over the concrete. These curves were done dry and wet conditions, for $44.5 \mathrm{lbs}$ of normal weight and for the slow velocity $V 1$.

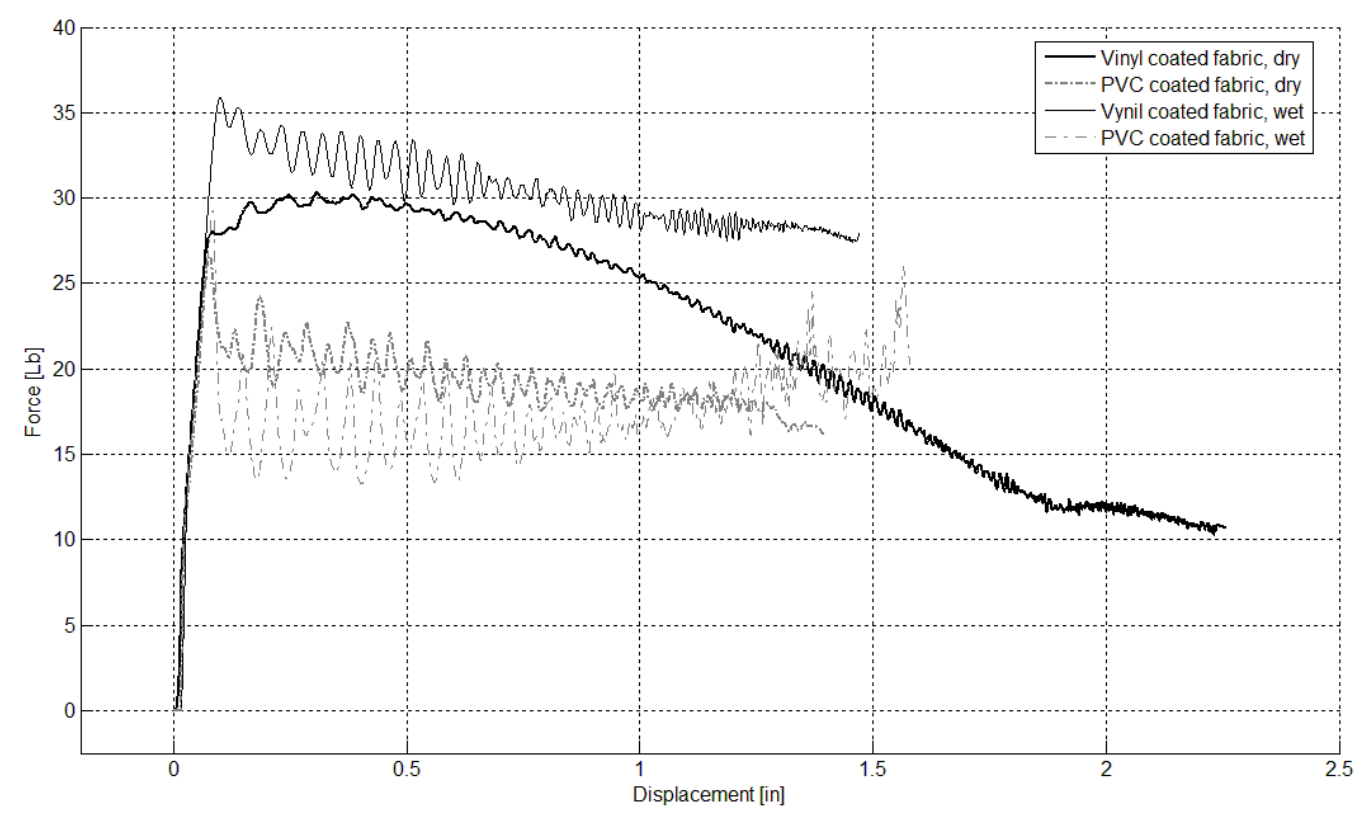

Figure 5.2.17 - Vinyl and PVC coated fabrics sliding against wet and dry, $44.5 \mathrm{lbs}$ normal weight, V1 -

As figure 5.2.17 shows the vinyl coated fabric has more friction against the concrete for wet conditions; but for the dry condition the friction is similar. However, this increment is not significant when are compared to the results obtained for the PVC coated fabric. Since this difference is not important, it does not justify the election of one fabric or another. Furthermore, for the purpose of this work, the election of the fabric will be ruled by the stress in the structure. Table 5.2 .4 shows the values of the static friction coefficient for the fabrics against the concrete wall at dry and wet conditions. 
Table 5.2.5- PVC and vinyl coated fabrics static friction coefficient, $\mu_{S}$, in dry and wet concrete surface -

\begin{tabular}{|c|c|c|c|c|}
\hline \multirow{2}{*}{ Surfaces Treatment } & \multicolumn{2}{|c|}{ DRY } & \multicolumn{2}{c|}{ WET } \\
\cline { 2 - 5 } & $\mu_{S}$ & STDev & $\mu_{S}$ & STDeV \\
\hline PVC coated fabric & $\mathbf{0 . 6 9}$ & 0.07 & $\mathbf{0 . 7 2}$ & 0.05 \\
\hline Vinyl coated fabric & $\mathbf{0 . 6 8}$ & 0.04 & $\mathbf{0 . 9 8}$ & 0.08 \\
\hline
\end{tabular}

Reduction due water [\%]

$-5.25$ $-45$

Concluding this analysis, there are different ways to improve the friction between the tunnel wall and the structure fabric. But for the ones investigated painting the concrete with asphalt paint will be the one which increase the static friction to 7 times if it is dry, or 2.2 times, if it is wet. Treating the concrete wall with latex is other possibility to increase the static friction, 1.27 times if it is dry or 1.14 times if it is wet. The next figure shows the frictional behavior of these two paints and for concrete without treatment, for $13.3 \mathrm{lbs}$ normal weight, fast velocity $V 2$.

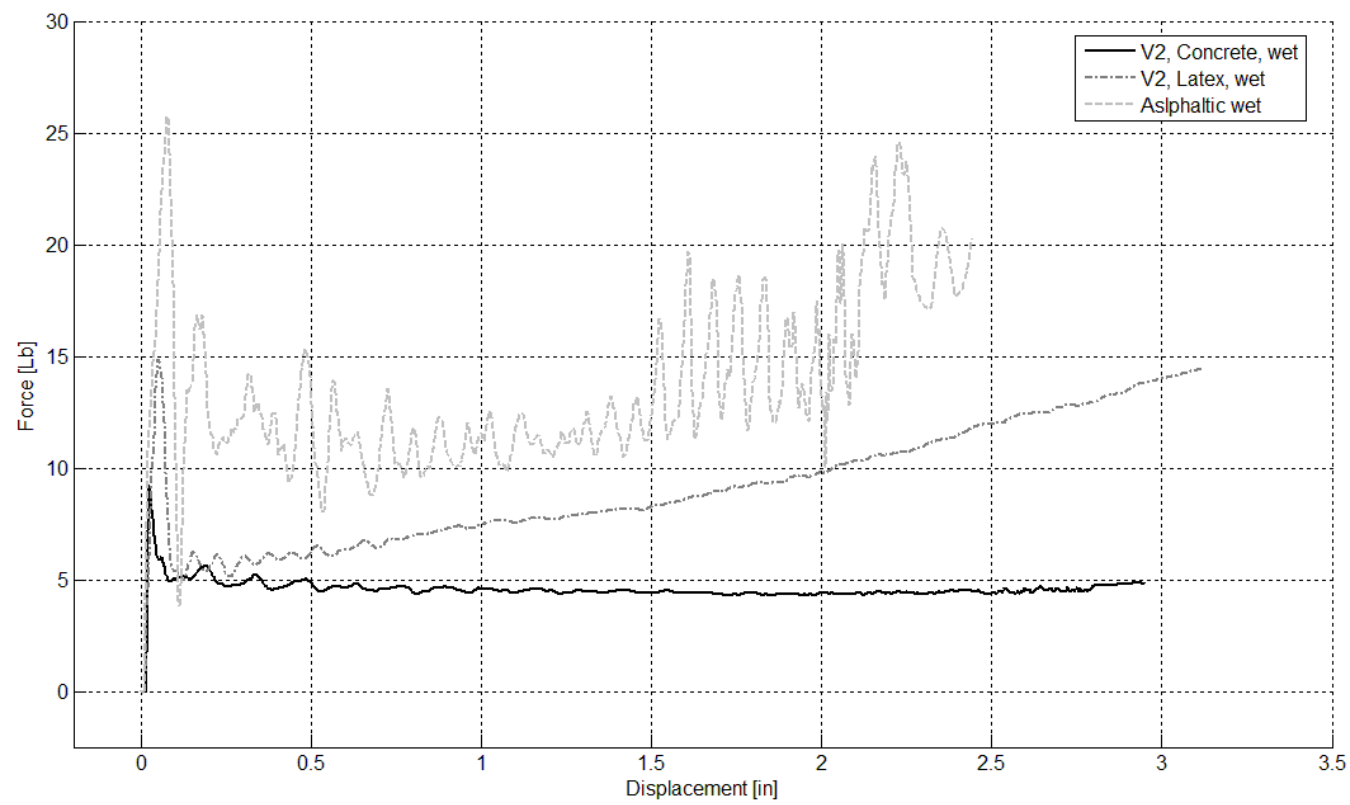

Figure 5.2.18 - PVC coated fabric sliding against WET concrete, and asphalt and latex wall treatments, 13.3 lbs normal weight, V2 - 
As figures 5.2.16 and 5.2.18 shown the best treatment is the asphalt paint, either dry or wet conditions. However, the friction created by the latex treatment is also considerable, besides it is almost the same for dry or wet. Finally a table summarizing the static friction coefficient values of two treatments is shown.

Table 5.2.6- PVC coated fabric static friction coefficient, $\mu_{S}$, in dry and wet, concrete, latex and asphalt surfaces

\begin{tabular}{|c|c|c|c|c|}
\hline \multirow{2}{*}{ Surfaces Treatment } & \multicolumn{2}{|c|}{ DRY } & \multicolumn{2}{c|}{ WET } \\
\cline { 2 - 5 } & $\mu_{S}$ & STDeV & $\mu_{S}$ & STDev \\
\hline Latex & 1.27 & 0.26 & $\mathbf{1 . 1 4}$ & 0.13 \\
\hline Asphalt & $\mathbf{6 . 7 4}$ & 0.15 & $\mathbf{2 . 2 2}$ & 0.35 \\
\hline $\begin{array}{c}\text { Concrete } \\
\text { (without treatment) }\end{array}$ & $\mathbf{0 . 6 9}$ & 0.07 & $\mathbf{0 . 7 2}$ & 0.05 \\
\hline
\end{tabular}




\section{Chapter 6: Conclusions and Future work}

\subsection{Summary}

Always in the design process of a structure is desired to find the ideal material, but this selection is not always possible. Most of the time there are many of variables in the structure environment that the engineer will have to study and analyze, therefore, a characterization of the materials properties according to that environment is required. In this work, the structure analyzed was an inflatable structure which works as a plug inside a tunnel. Hence, according to this structure, the mechanical characterization of the possible used fabrics was done. The fabric selected should support as much tensile stress as possible and improve the frictional properties between itself and the tunnel wall.

Not only was required to characterize the tensile strength of the fabric, it was also necessary to study the strength when different pieces of fabric are welded. Therefore, to analyze these two strength properties several fabrics were tested in a tensile test. Two fabrics were tested: Ferrari's and Seaman's fabric; the tests were done in the two fiber direction (warp and fill) and for non-welded and welded fabric conditions. In both cases the warp direction is stronger than the fill one, this fiber behavior was shown for nonwelded and welded samples. Also, for both fabrics, it was found that the tensile strength of welded sample, compared with the non-welded, is reduced only by a $5 \%$, however, the sample is more fragile than the non-welded one. Finally from the two fabric studied, although Seaman's fabric has better tensile strength than Ferrari's one, this last fabric was selected as the one to be used for the prototype inflatable plug. The main reason for that is because the fabric is lighter, and also, because the strength will be enough for a prototype model. 
The other fabric's property studied was the friction that this fabric could achieve against the tunnel wall. Besides measuring this frictional phenomenon, this work also studied the possible variables to improve the friction of this system. Consequently different friction tests were done. The tests were done for different wall surface treatments and for two different fabrics; also the tests were performed for dry and wet conditions. From all these tests not only the most suitable surface treatments is chosen, also the behavior of these friction tests can be analyzed.

It was showed that the friction not only increase if the roughness of the surface increase, also increase when the surface is smooth. An example for that is the stainless steel or the acrylic, which surfaces are mirror finished. These phenomena is due to the "adhesion" characteristic of the friction, where the smoother the surfaces are, the more real area of contact is and the more molecular force attraction between the surfaces is. On the other hand, the roughness increases the "ploughing" between the surfaces, where the "peaks" and "valley" of that rough surface domain the friction. Another behavior that can be described from the experiments is when the surfaces are wet, in smooth surfaces where the adhesion rules the friction forces decrease, however, for rough surfaces where the ploughing rules the friction forces do not decrease. Therefore it can be said that water acts as a lubricant for smooth surfaces.

Now, regarding to the tunnel plug project, from the tests was found that among all the concrete wall surface treatments the one that improves better the friction in the system is the asphalt paint having a static friction coefficient of almost 7 in dry conditions and 3 on wet ones. However, and according to the purpose of this work, asphalt paint is flammable so it is not recommended to use inside a tunnel where a fire accident could occurred. As a result of this analysis, the latex wall treatment is the one which is recommended to use for 
the improvement of the friction between the structure fabric and the tunnel wall. Latex, besides having excellent frictional properties in this system (the static friction coefficient is 1.27 for dry and 1.24 for wet condition), it does not wear the fabric of the structure, and it is a well known paint which is affordable and easy to use it.

\subsection{Recommendations}

The present study examined two different fabric properties. For that a corresponding test was performed. In the case of the characterization of the tensile strength of the fabrics the test was done according to standards: ASTM D 5034 and ISO 1421. Therefore, following these two standards the test was simple to achieve. However, the test used to characterize the friction properties of the fabric was done without following any standard. Hence, to study the frictional behavior of the fabric a new test procedure was done. Based on the learned from this test the following recommendations are made:

- Regarding to the tunnel plug project it is not recommend to use rough surfaces due to the wear of the structural fabric.

- If a new friction test is design it will be only valid if simulates the frictional system that is going to be investigated.

- When a friction handbook value is searching, it is required to pay attention if that value would be representative for the frictional system which is studied.

- It has been studied that the concrete tunnel wall and the structure fabric system is sensitive to several parameters, including normal load, velocities, contacting surfaces, etc. And since these frictional tests performed where carried out in a laboratory on a particular device, only tendencies of the 
frictional behavior of the system can be confirmed. Therefore all results obtained are "estimated" and not determined. Always a designer should use a design safety factor when one is calculating a phenomenon where friction force is involved.

\subsection{Further works}

For an advance study of mechanical properties of fabrics in inflatable structures and according to the project under investigation there are more properties that are suggested to be analyzed such as:

- packability

- permeability

- aging

Besides all of these properties, there are other important ones that should study in further works like elongation, abrasion and flammability. 


\section{REFERENCES CITED}

[1] Cassapakis, C. and Thomas, M. "Inflatable Structures Technology Development Overview", American Institute of Aeronautics and Astronautics, (AIAA 95-3738) (1995).

[2] Bill Christensen, "Carbon Nanofiber Makes Smart Yarn", Live Science, 24 Nov. 2004 (http://www.livescience.com/technology/technovel_nanofiber_041124.html).

[3] Celanese Acetate LLC. , (2001) "Complete Textile Glossary".

[4] Kuraray America, Inc. Vectran technical data.

[5] Rabinowicz E., (July 1995) "Friction and Wear of Materials" (2 ${ }^{\text {nd }}$ edition). Wiley-Interscience.

[6] ASTM Standard G-40-93: "Standard Terminology Relating to Erosion and Wear"

[7] Dowson D. , (1979) "History of Tribology”. Longman.

[8] Neale M. J., (1995) “The Tribology Handbook”. Butterworth-Heinemann

[9] Batchelor, A.W. and Stachowiak, G.W. "Revealing the Hidden World of Wear and Friction", Mechanical Engineering Transactions, Journal of the Inst. of Engineers, Australia, ME 20:1, pp 5-13 (1995)

[10] Blau P. J., (October 1995) "Friction Science and Technology". Marcel Dekker, Inc.

[11] ASM international (volume 18), (October 1992) "Friction, Lubrication and Wear technology handbook".

[12] Blau P. J., "The significance and use of the friction coefficient", Tribology International, Volume 34, Number 9, September 2001, pp. 585-591(7) 
[13] Moore D. F., (1972) "Friction and Lubrication of Elastomers". Pergamon. Oxford.

[14] Leclerq S., "The prevention of slipping accidents: a review and discussion of work related to the methodology of measuring slip resistance", Safety Science, Volume 31, Number 2, March 1999, pp. 95-125(31)

[15] Oñate E. and Kröplin B., (October 2005) "Textile Composites and Inflatable Structures II". Cimne Barcelona

[16] Timoshenko S. and Woinowsky-Krieger S., (1959) "Theory of plates and shells" ( $2^{\text {nd }}$ edition). McGraw-Hill.

[17] Moore D. F., (1975) "Principles and applications of tribology". Pergamon. Oxford.

[18] Airbags used in the Mars Exploration Rover mission are the same type that $\begin{array}{llll}\text { Mars } \quad \text { Pathfinder } & \text { used }\end{array}$ (http://mars.jpl.nasa.gov/MPF/mpf/edl/edl1.html).

[19] Warp and weft in plain weaving, (http://en.wikipedia.org/wiki/lmage:Kette_und_Schu\%C3\%9F.jpg).

[20] Knitted fabrics, (http://en.wikipedia.org/wiki/Knitted_fabric). 


\section{APPENDICES}

Appendix A - Fabrics Tests

This appendix shows all the results obtained for the tensile test of the fabrics described in chapter 5 (section 5.1).

Table A.1 - Ferrari (Style 7150 PFF) fabric tensile test results -

\begin{tabular}{|c|c|c|c|c|}
\hline & $\begin{array}{c}\text { Specimen } \\
\text { number }\end{array}$ & $\begin{array}{c}\text { Maximum Tensile } \\
\text { Strength } \\
\text { [lb/in] } \\
\end{array}$ & $\begin{array}{c}\text { Displacement at } \\
\text { maximum Load } \\
\text { [in] }\end{array}$ & $\begin{array}{c}\text { Strain at maximum } \\
\text { Load } \\
{[\%]}\end{array}$ \\
\hline \multirow{4}{*}{ 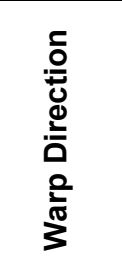 } & Test 1a NWW & 516.9 & 0.8668 & 21.67 \\
\hline & Test $1 b$ NWW & 486.3 & 0.7946 & 19.86 \\
\hline & Test 1c NWW & 485.9 & 0.8274 & 20.68 \\
\hline & Test 1d NWW & 519.3 & 0.8668 & 21.67 \\
\hline \multirow{4}{*}{ 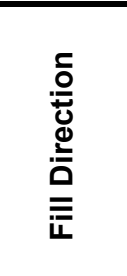 } & Test 1a NWF & 449.1 & 0.8931 & 22.33 \\
\hline & Test $1 b$ NWF & 431.5 & 0.8668 & 21.67 \\
\hline & Test 1c NWF & 440.5 & 0.8734 & 21.83 \\
\hline & Test 1d NWF & 423.2 & 0.8405 & 21.01 \\
\hline \multirow{3}{*}{ 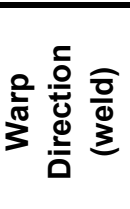 } & Test 1a WW & 478.3 & 0.985 & 16.42 \\
\hline & Test $1 b W W$ & 495.9 & 1.005 & 16.74 \\
\hline & Test $1 c W W$ & 459.1 & 0.6764 & 16.91 \\
\hline \multirow{3}{*}{ 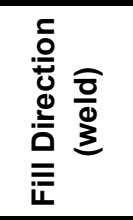 } & Test 1a WF & 406.7 & 1.07 & 17.84 \\
\hline & Test $1 b$ WF & 428 & 1.116 & 18.61 \\
\hline & Test 1c WF & 426.7 & 1.031 & 17.18 \\
\hline
\end{tabular}


Table A.2 - Seaman Corporation (Style 7150 PFF) fabric tensile test results -

\begin{tabular}{|c|c|c|c|c|}
\hline & $\begin{array}{c}\text { Specimen } \\
\text { number }\end{array}$ & $\begin{array}{c}\text { Maximum Tensile } \\
\text { Strength } \\
\text { [lb/in] }\end{array}$ & $\begin{array}{c}\text { Displacement at } \\
\text { maximum Load } \\
\text { [in] }\end{array}$ & $\begin{array}{c}\text { Strain at maximum } \\
\text { Load } \\
{[\%]} \\
\end{array}$ \\
\hline \multirow{4}{*}{$\begin{array}{l}0 \\
\stackrel{0}{0} \\
\stackrel{0}{0} \\
.0 \\
0 \\
\frac{2}{\pi / 2} \\
3\end{array}$} & Test 2a NWW & 1020 & 1.189 & 29.71 \\
\hline & Test $2 b N W W$ & 962.3 & 1.07 & 26.76 \\
\hline & Test 2c NWW & 1021 & 1.195 & 29.88 \\
\hline & Test $2 d N W W$ & 727.5 & 0.9128 & 22.82 \\
\hline \multirow{4}{*}{ 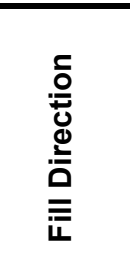 } & Test 2a NWF & 682.6 & 1.688 & 42.19 \\
\hline & Test $2 b$ NWF & 672 & 1.642 & 41.04 \\
\hline & Test 2c NWF & 650.4 & 1.537 & 38.41 \\
\hline & Test 2d NWF & 639.4 & 1.569 & 39.24 \\
\hline \multirow{3}{*}{ 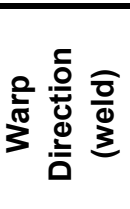 } & Test 2a WW & 901.7 & 1.399 & 23.31 \\
\hline & Test $2 b W W$ & 895 & 1.438 & 23.97 \\
\hline & Test 2c WW & 837.8 & 1.313 & 21.89 \\
\hline \multirow{3}{*}{ 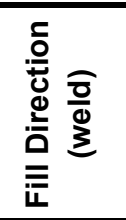 } & Test 2a WF & 657.2 & 2.055 & 34.26 \\
\hline & Test $2 b W F$ & 671.1 & 2.213 & 36.88 \\
\hline & Test 2c WF & 653.3 & 2.055 & 34.26 \\
\hline
\end{tabular}




\section{Appendix B - Lab View data acquisition program}

Next figure shows the block diagram used to acquire the data from the load and displacement signal.

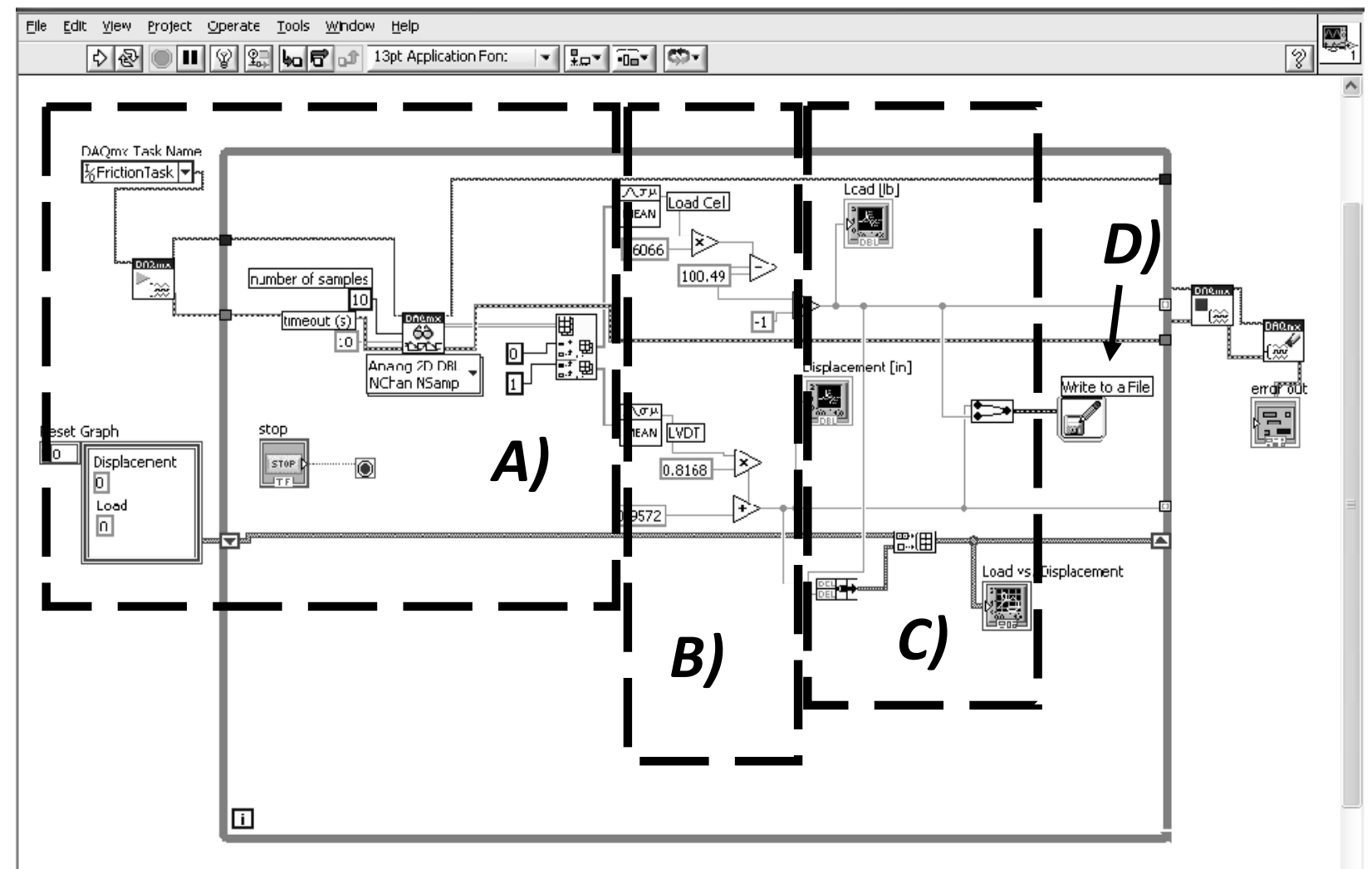

Figure B.1 - Lab View block diagram program -

Basically, the signals from the load cell and from the LVDT, that are picked by the data acquisition card, are collected and conditioned for being use by the first part block diagram (a). Then the collected signal from the load cell and LVDT are calibrated to the real values, second part of the diagram (b). When the signal is calibrated "display" windows are created for the load vs. test time, displacement vs. test time and load vs. displacement, part (c) of the diagram. Finally the results are writing to a file, part (d). 


\section{Appendix C - Friction test data processing}

For each particular case, 10 tests were performed maintaining the test conditions as unchanged as it was achievable. This means, for example, that 10 tests were conducted for wet Concrete with Latex paint using velocity V1 and a normal load of 24.5 lbs.

Each set of 10 tests was plotted together for comparison. As expected, the majority showed a similar behavior (similar maximum peak, similar amplitude in the oscillations, etc.), see chapter five. However, a few tests in each set showed a visible difference with all the others of the same group. These differences can be attributed to uncontrollable changes in the test conditions, unavoidable changes in environmental variables, unseen or unmeasured test parameters. The tests that showed this kind of unique patterns within each set were removed from the further analysis and considered to be faulty tests. After each set of tests was "cleaned up" as explained above, the required static friction coefficient was calculated for each particular test (obtaining various values for each case).

To have a clear illustration of a representative result for each case that would allow comparing all the different cases taken into consideration, some post processing was carried out. For this purpose, the data available was attached into a single set of data. This bigger set of data was then used to create a trend line for each particular case. Considering the amount of data represented by each test and the big variations implied, a fitting curve (robust loess, quadratic fit) was selected from Matlab to give the best results. 
The following figure shows an example of how all these trend line curves were generated. The plot corresponds to dry Concrete with Anti-Skid paint using velocity V2 and a normal load of $13.3 \mathrm{lbs}$. The cloud of points plotted as circles represents the raw data (after removing faulty tests) as was obtained directly from the testing equipment. The trend line shown captures the global behavior of the whole set of tests..

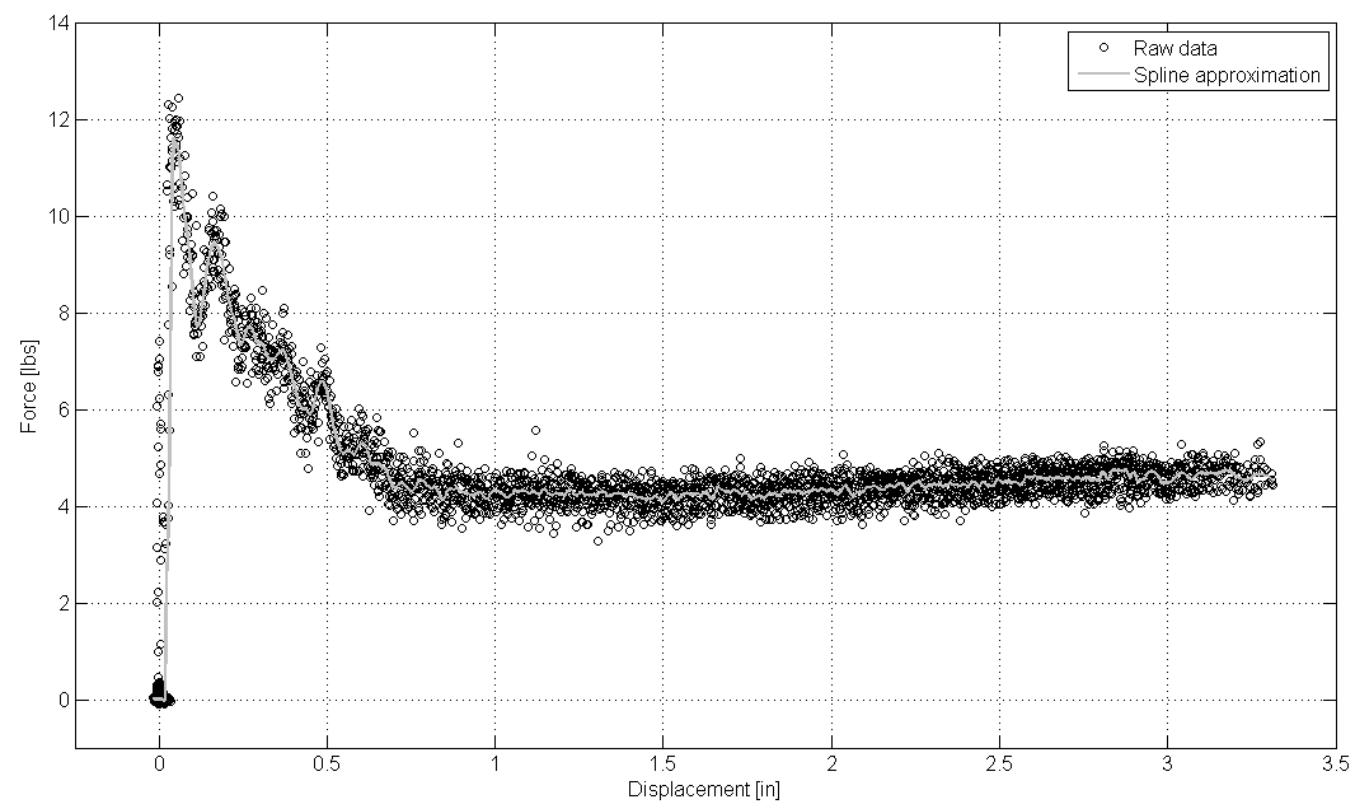

Figure C.1 - Anti-Skid, dry, V2, 13.3 [lbs] -

Due to the way these trend lines were created, they do not necessary match the value presented in this thesis for the static friction coefficient. However, this is not the purpose of these approximations and so they are used as an indication of the results for each case

The following fitting figures show the respective test results for all the surfaces investigated and for dry and wet conditions, including in each figure all the possible variables (combination of normal weight and velocities). 


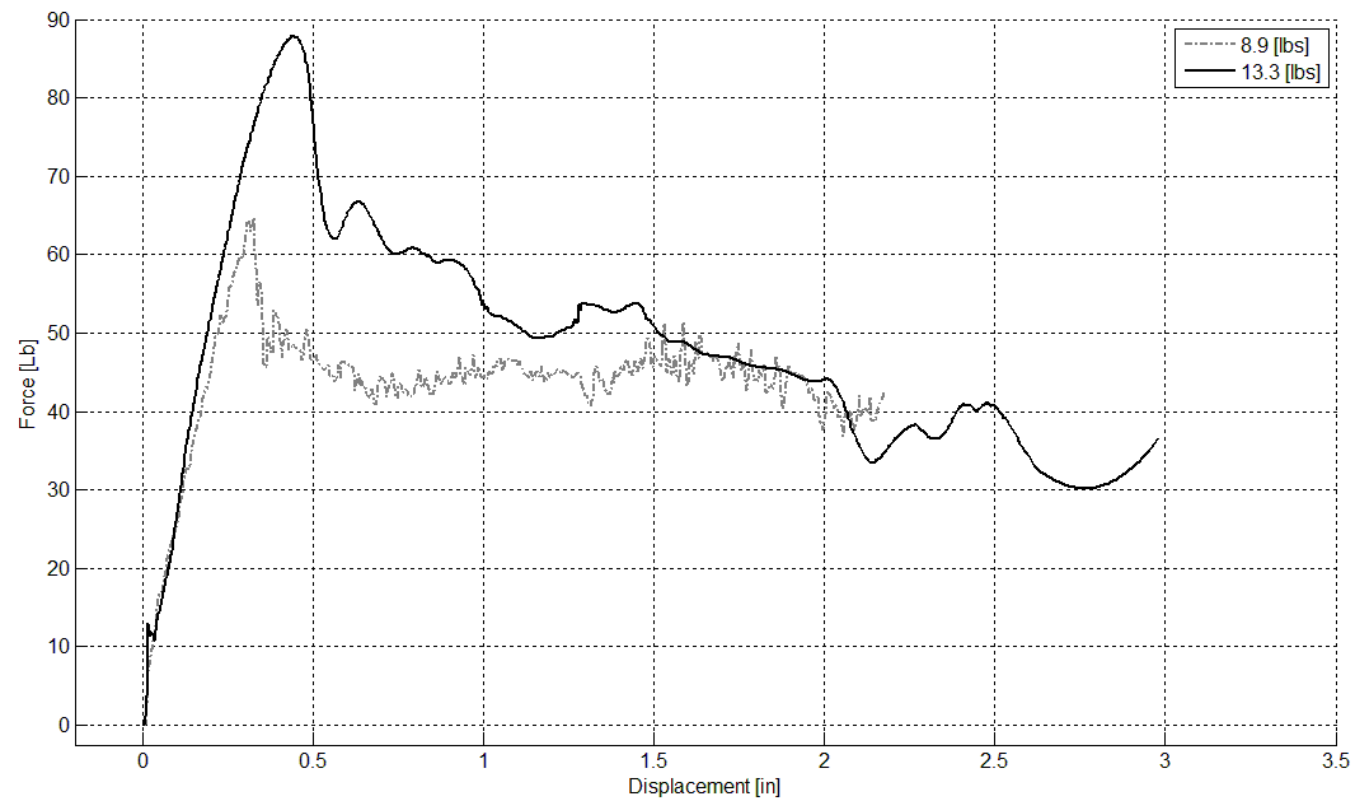

Figure C.2 - Asphaltic dry -

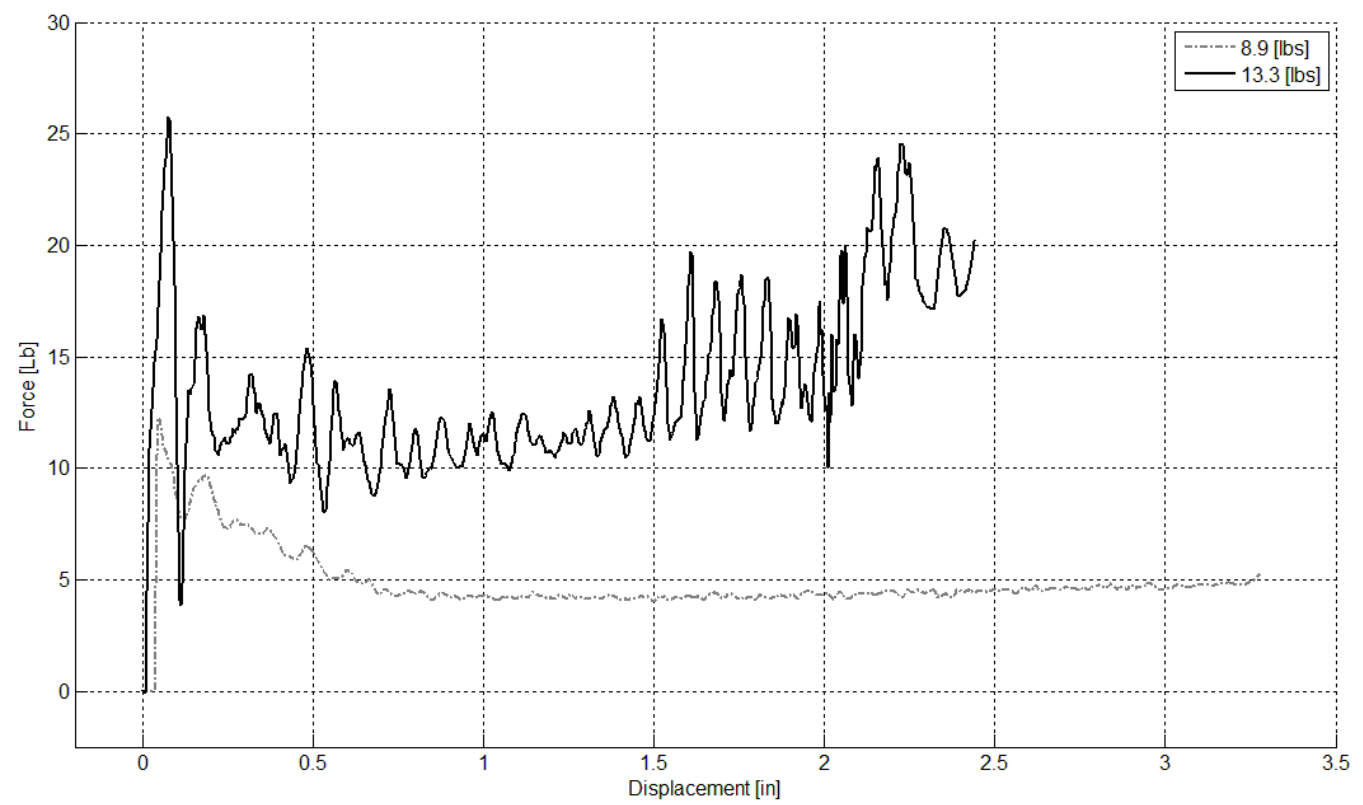

Figure C.3 - Asphaltic wet - 


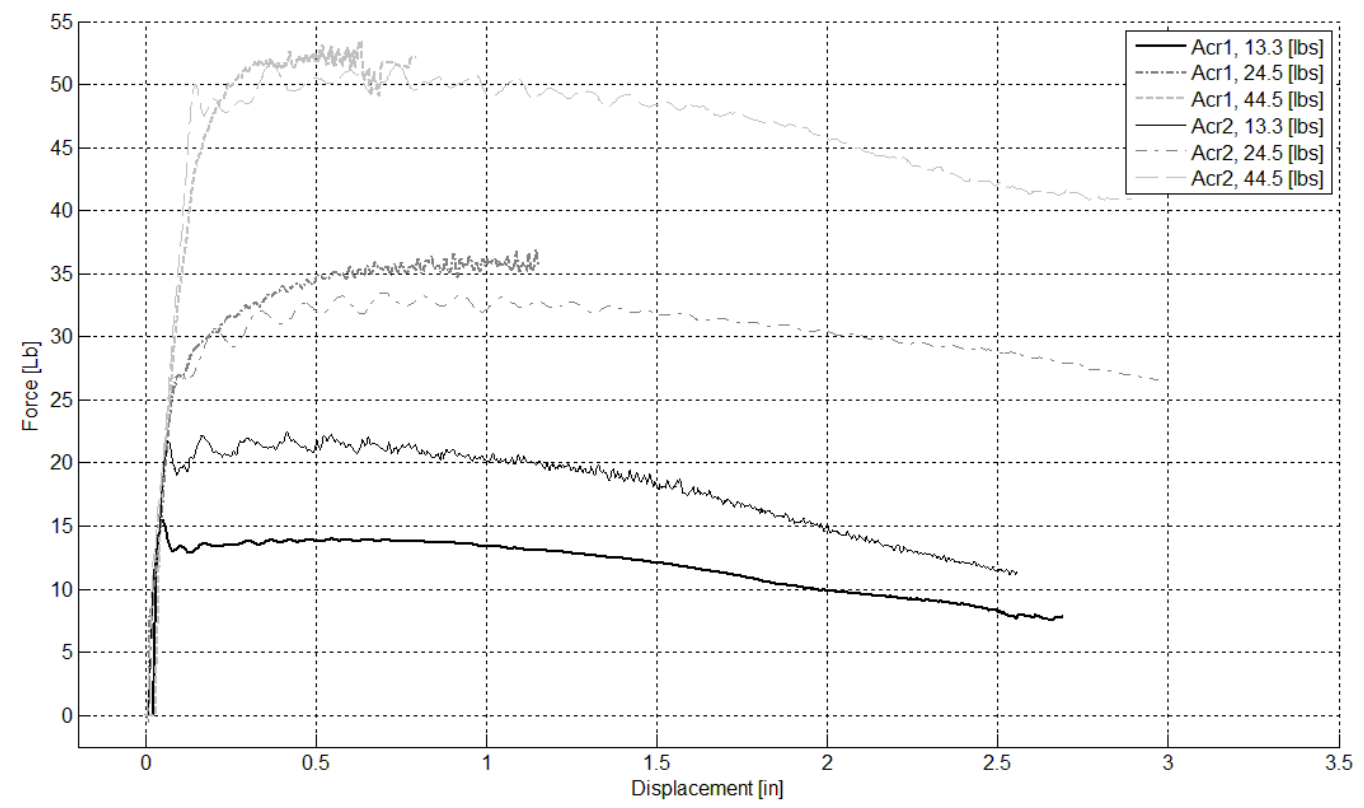

Figure C.4 - Acrylic dry -

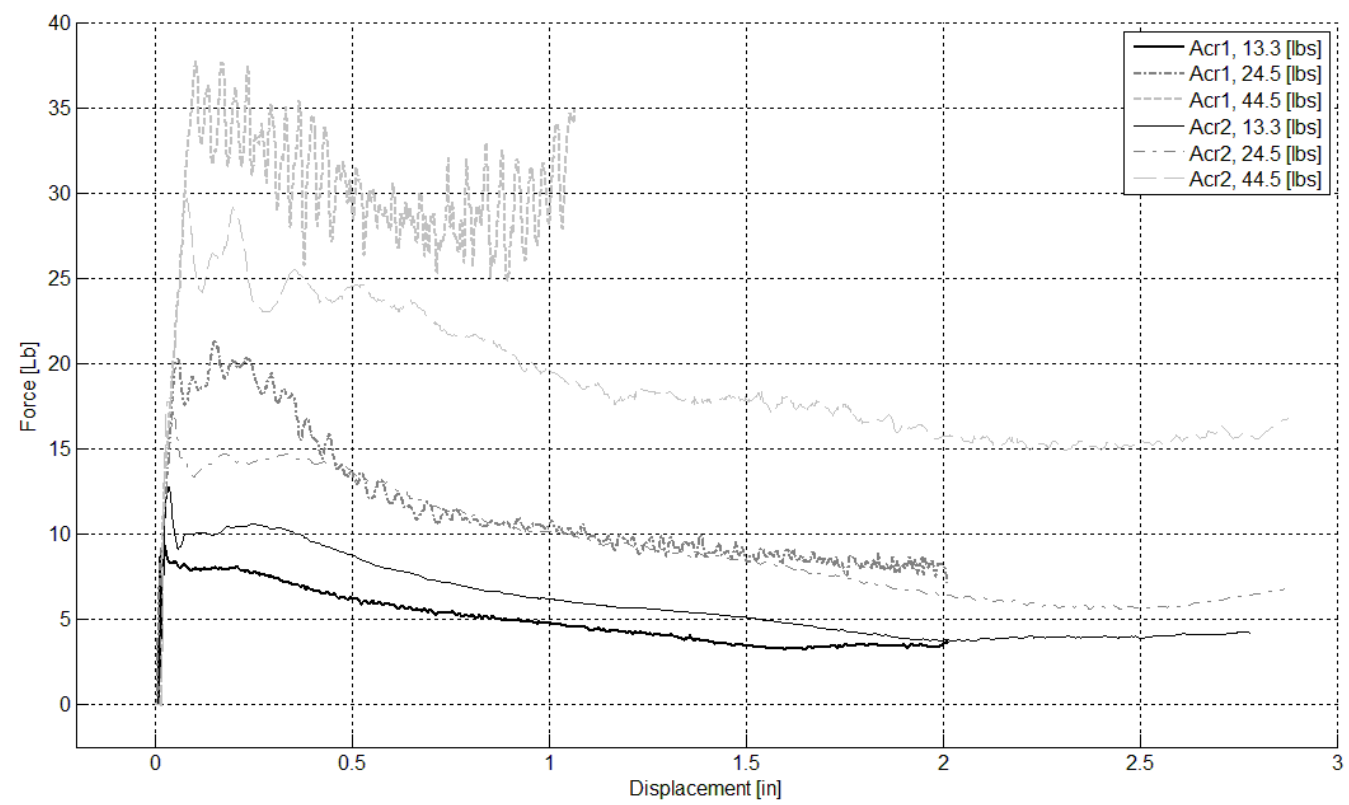

Figure C.5 - Acrylic wet - 


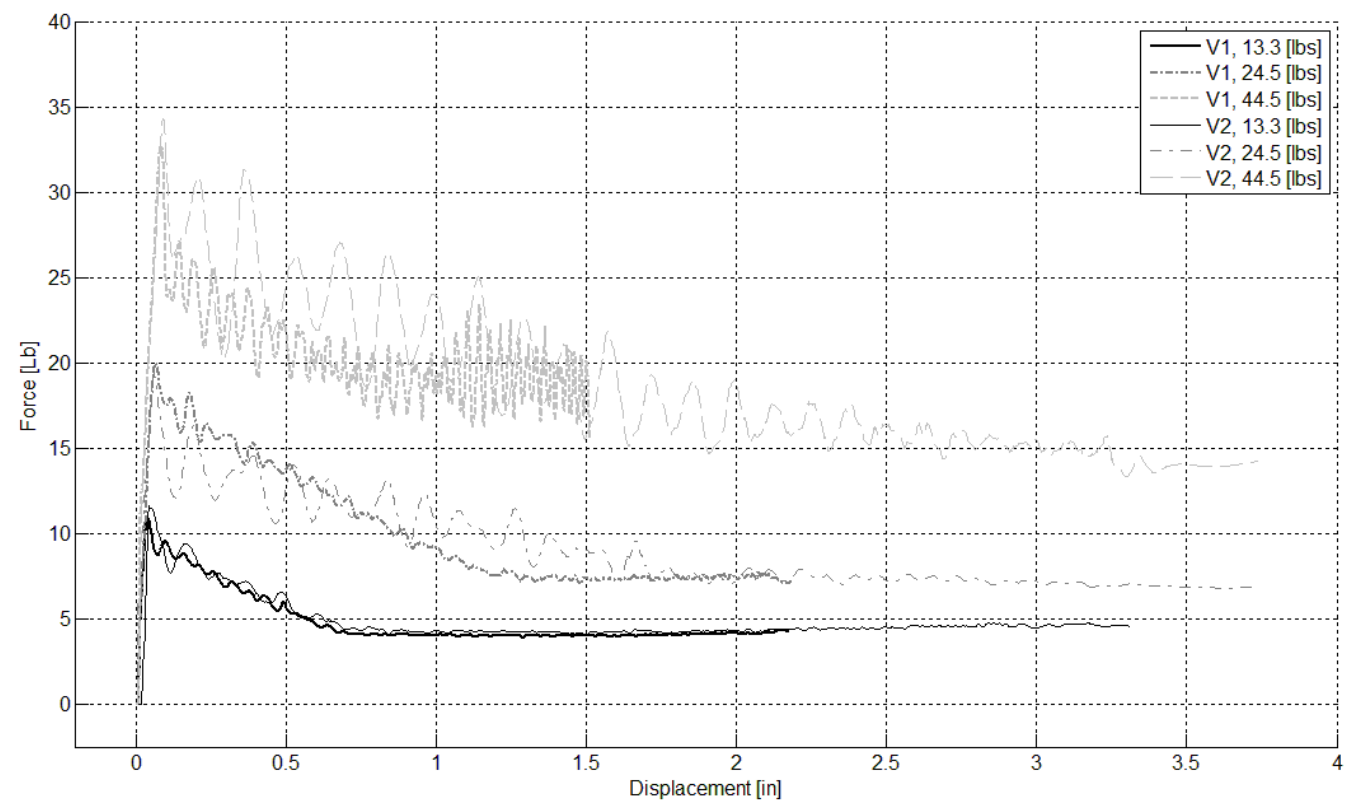

Figure C.6 - Anti-Skid dry -

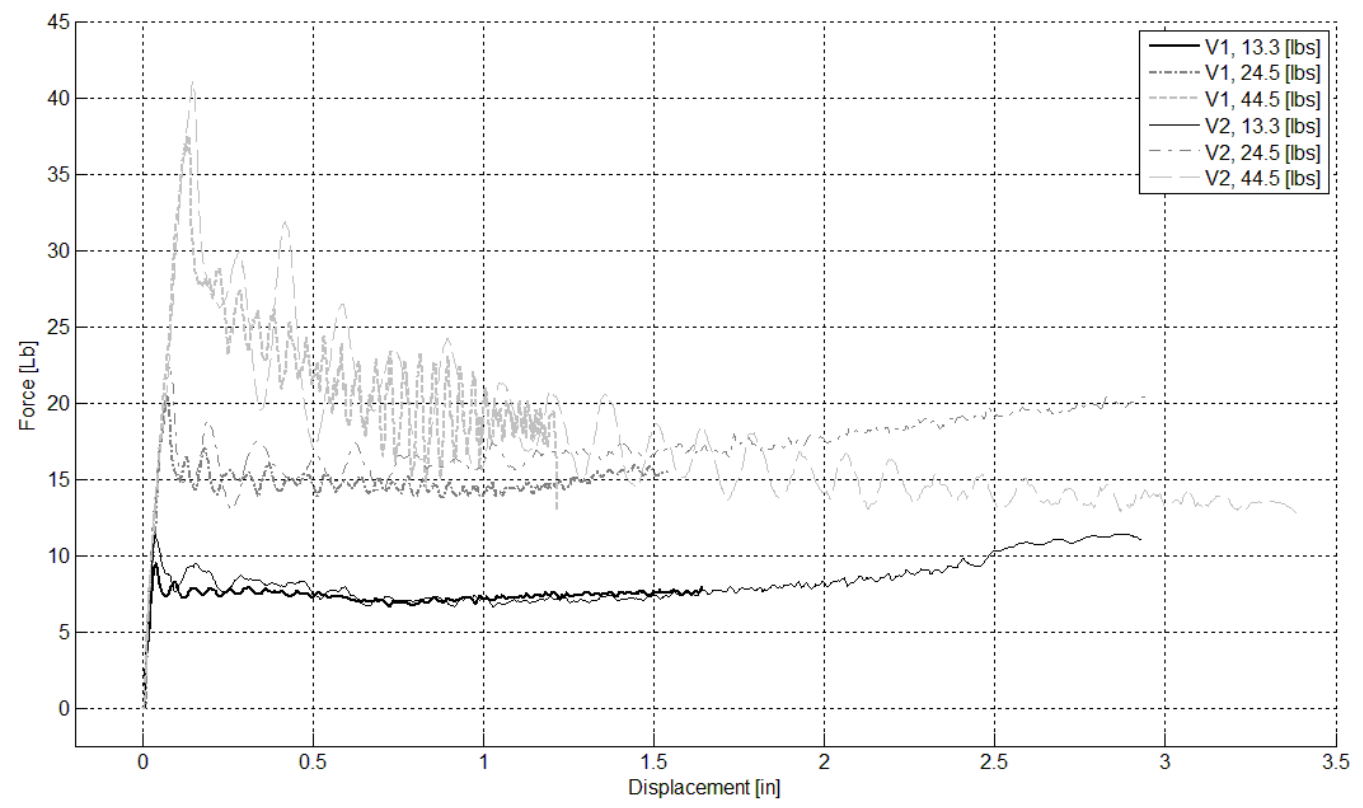

Figure C.7 - Anti-Skid wet - 


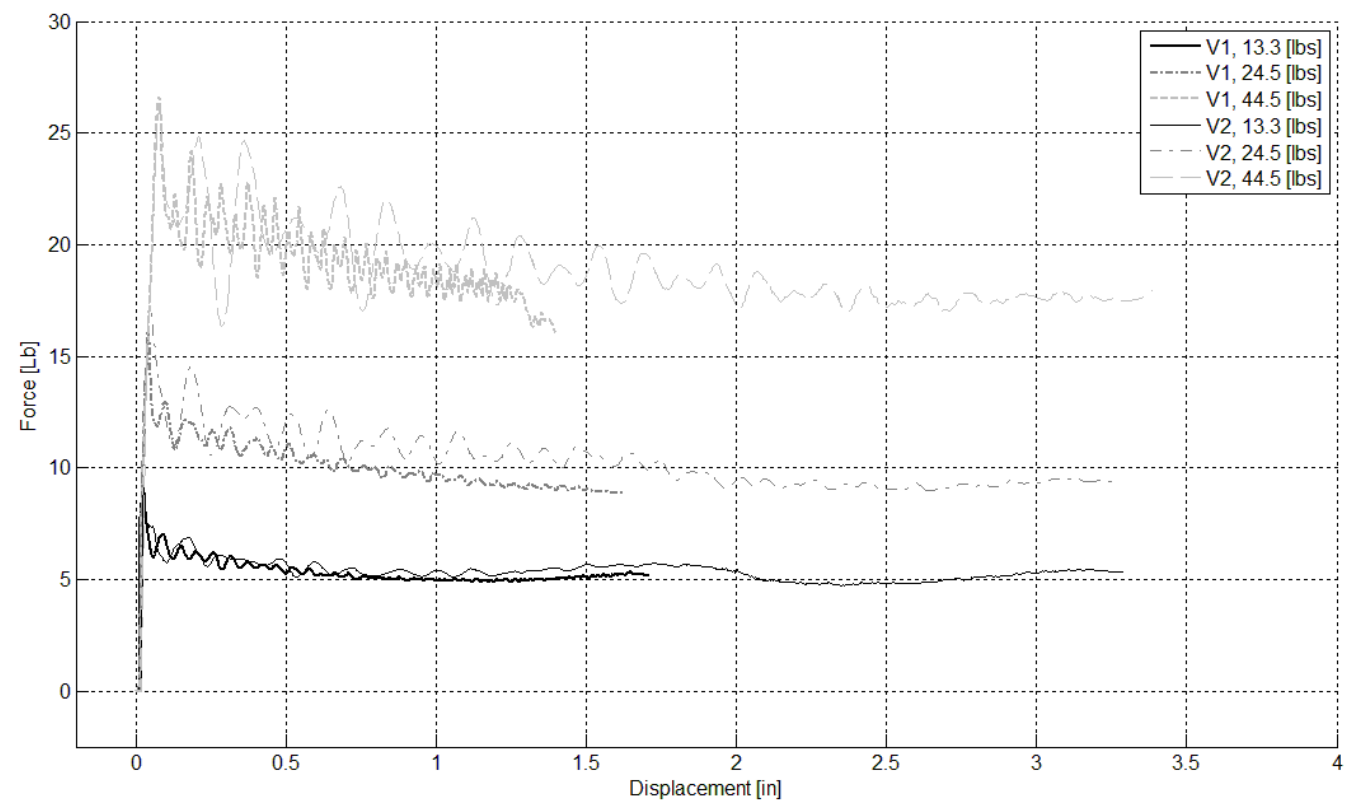

Figure C.8 - Concrete dry -

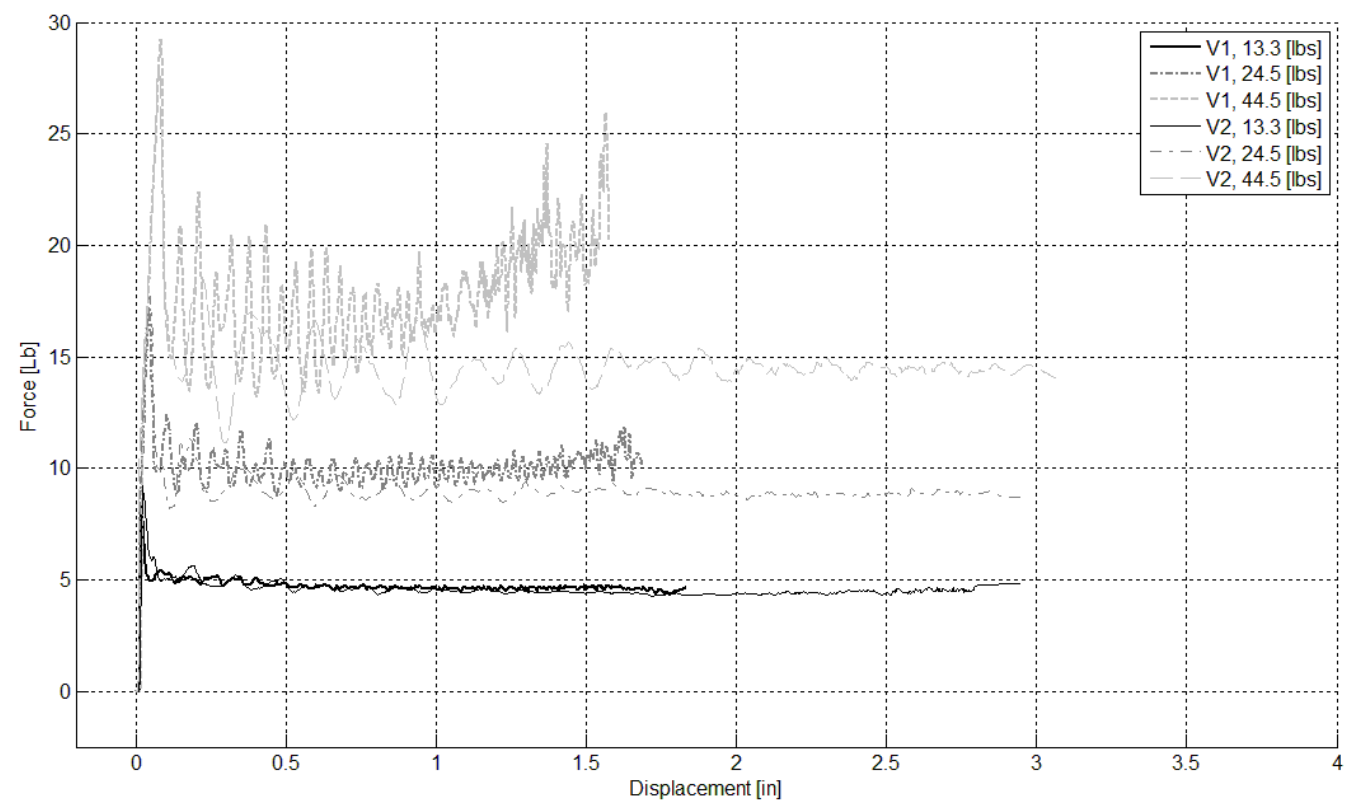

Figure C.9 - Concrete wet - 


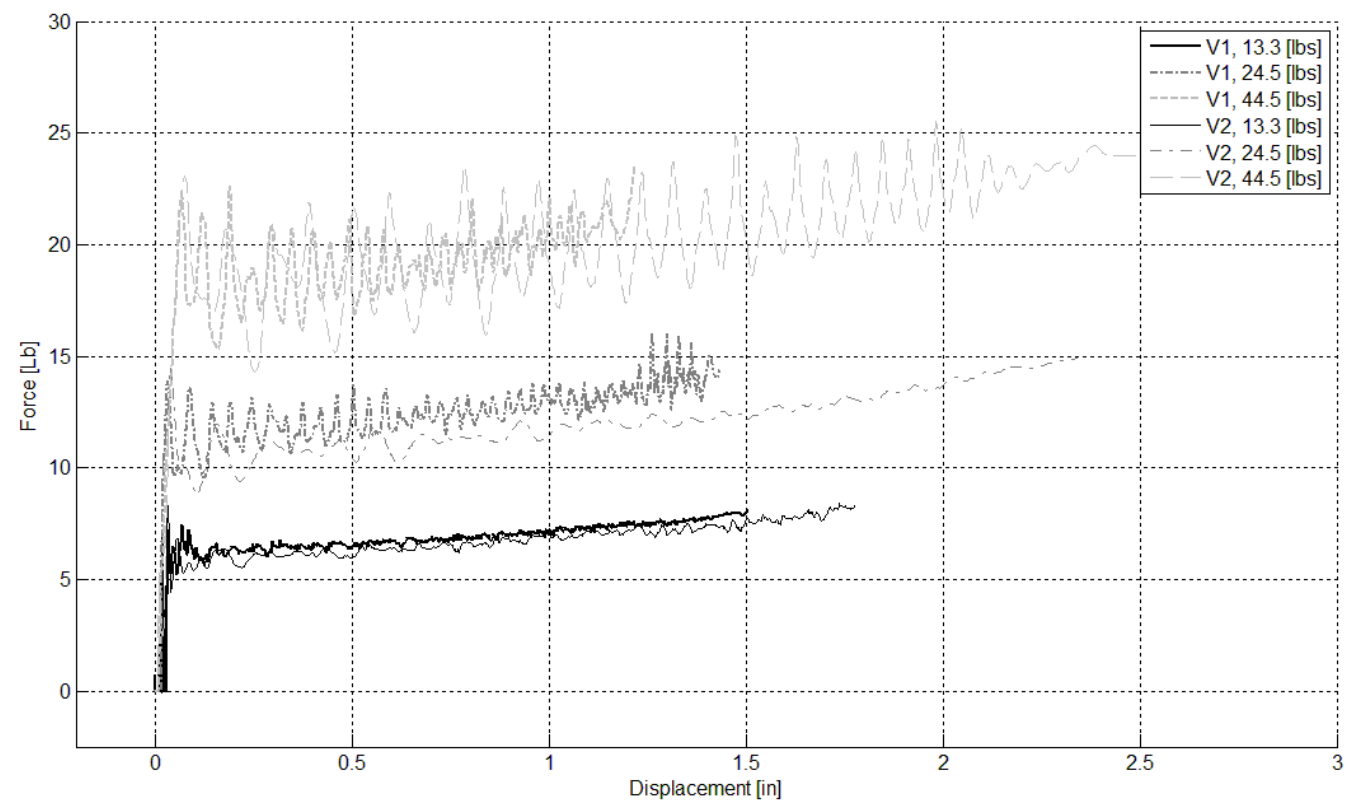

Figure C.10 - Epoxy dry -

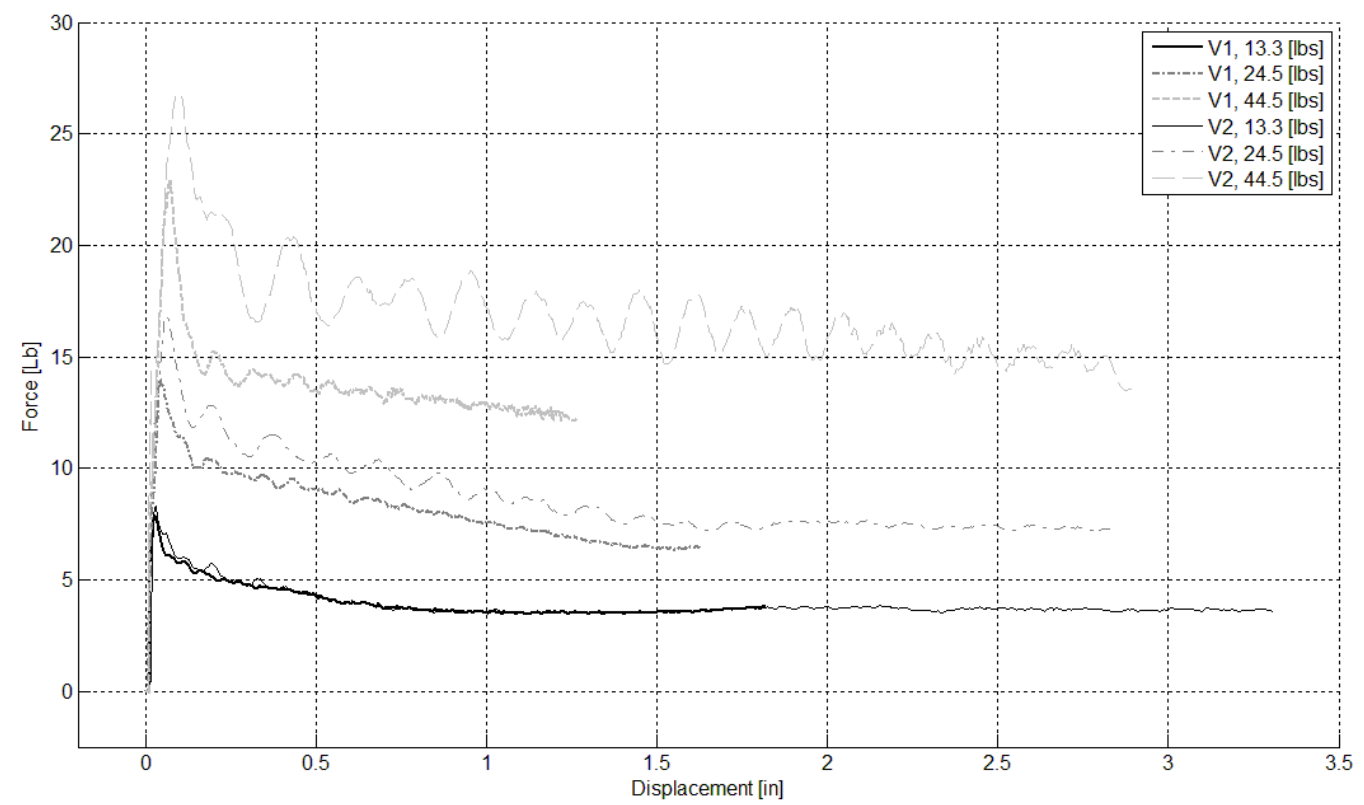

Figure C.11 - Epoxy wet -

$$
\text { A - } 10
$$




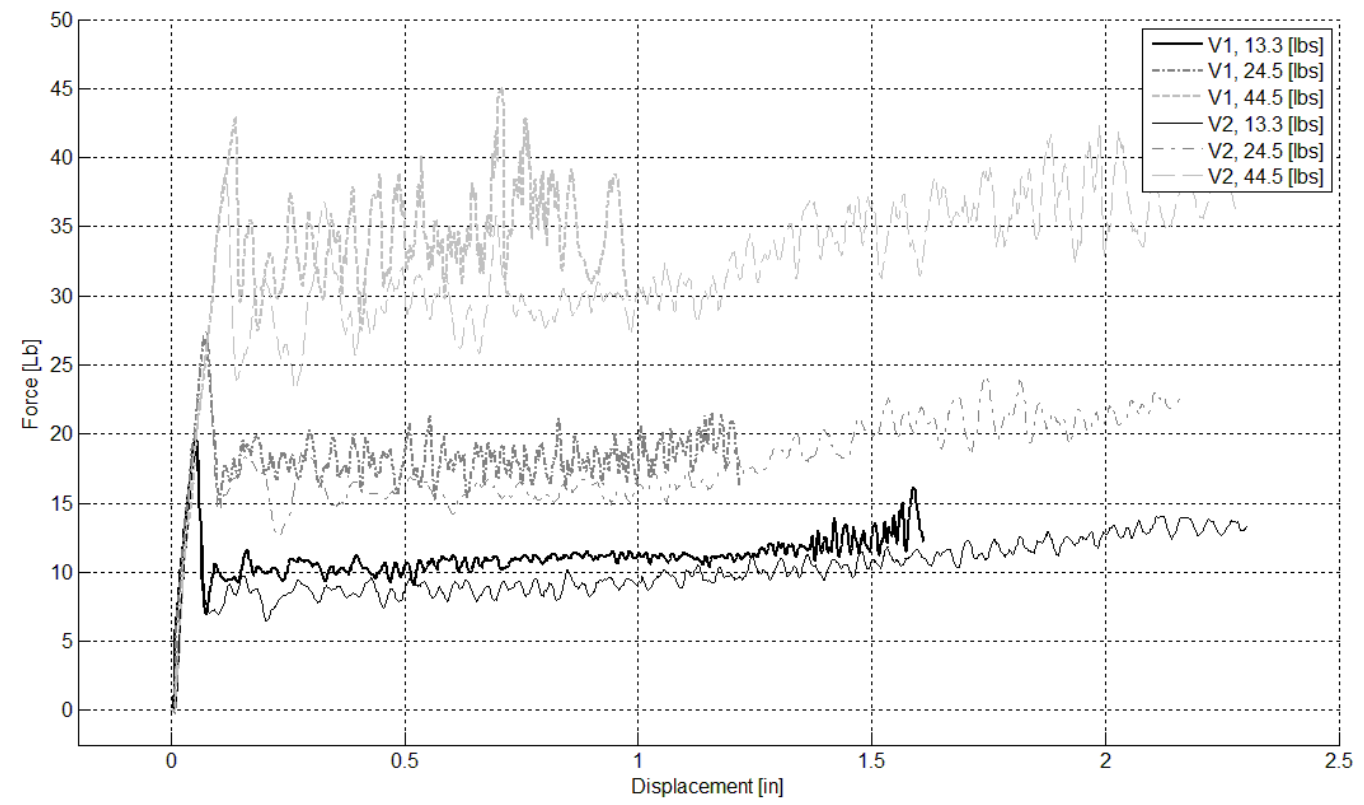

Figure C.12 - Latex dry -

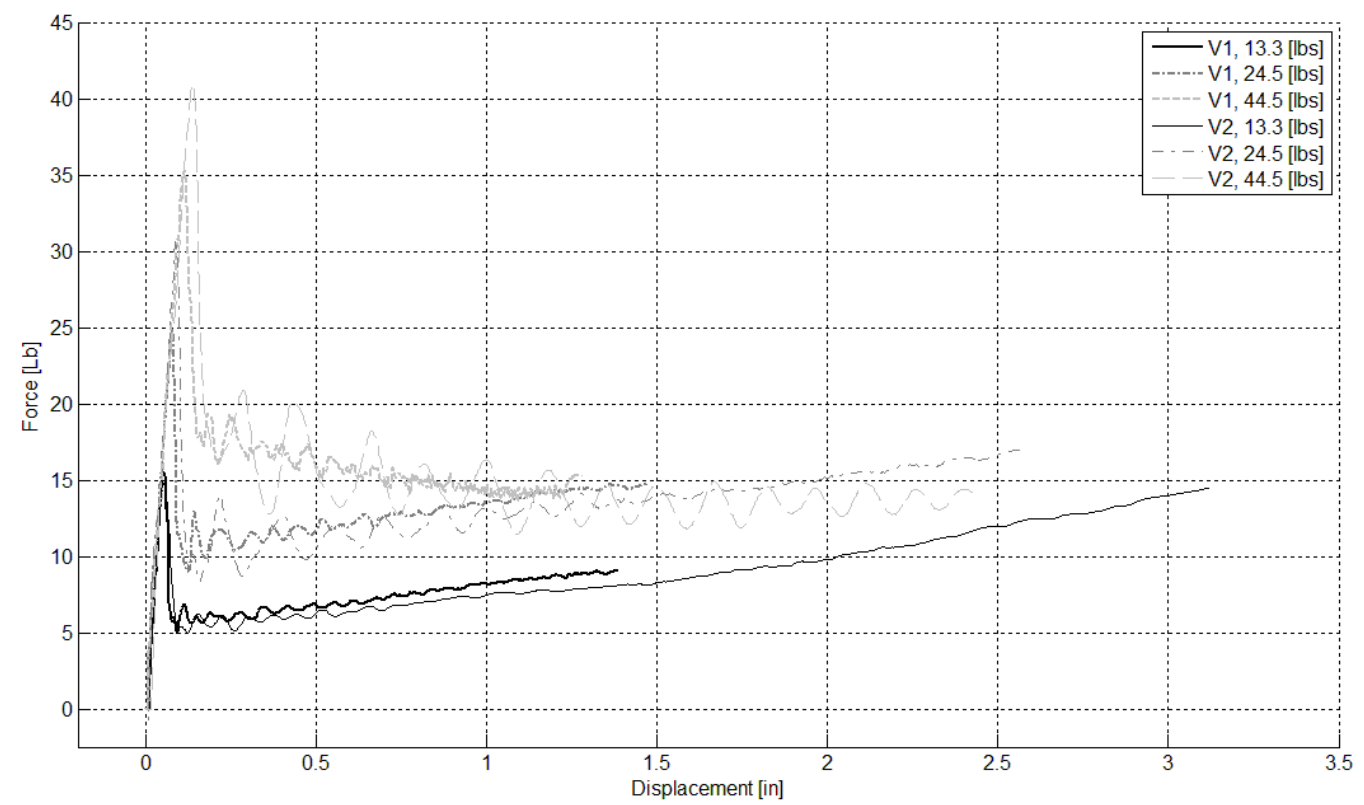

Figure C.13 - Latex wet - 


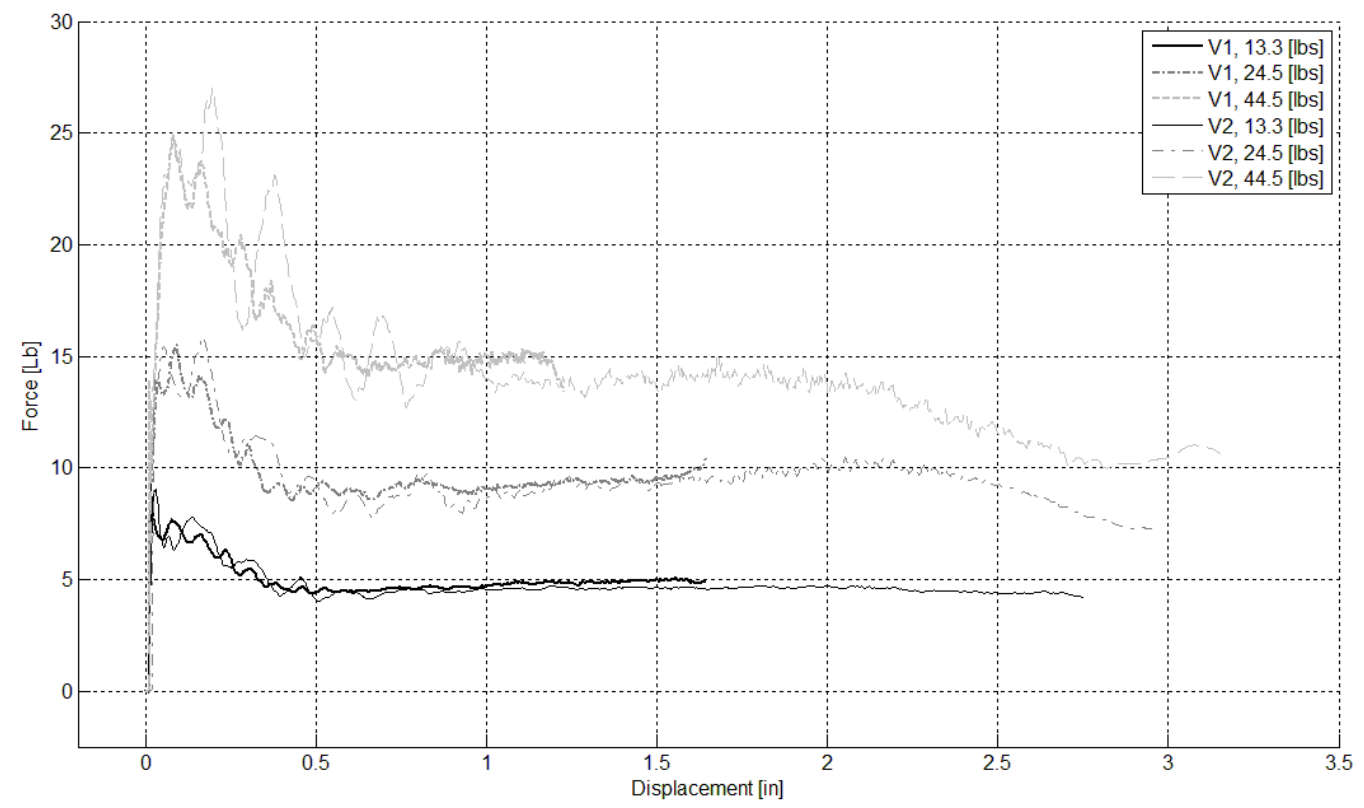

Figure C.14 - Rough Concrete dry -

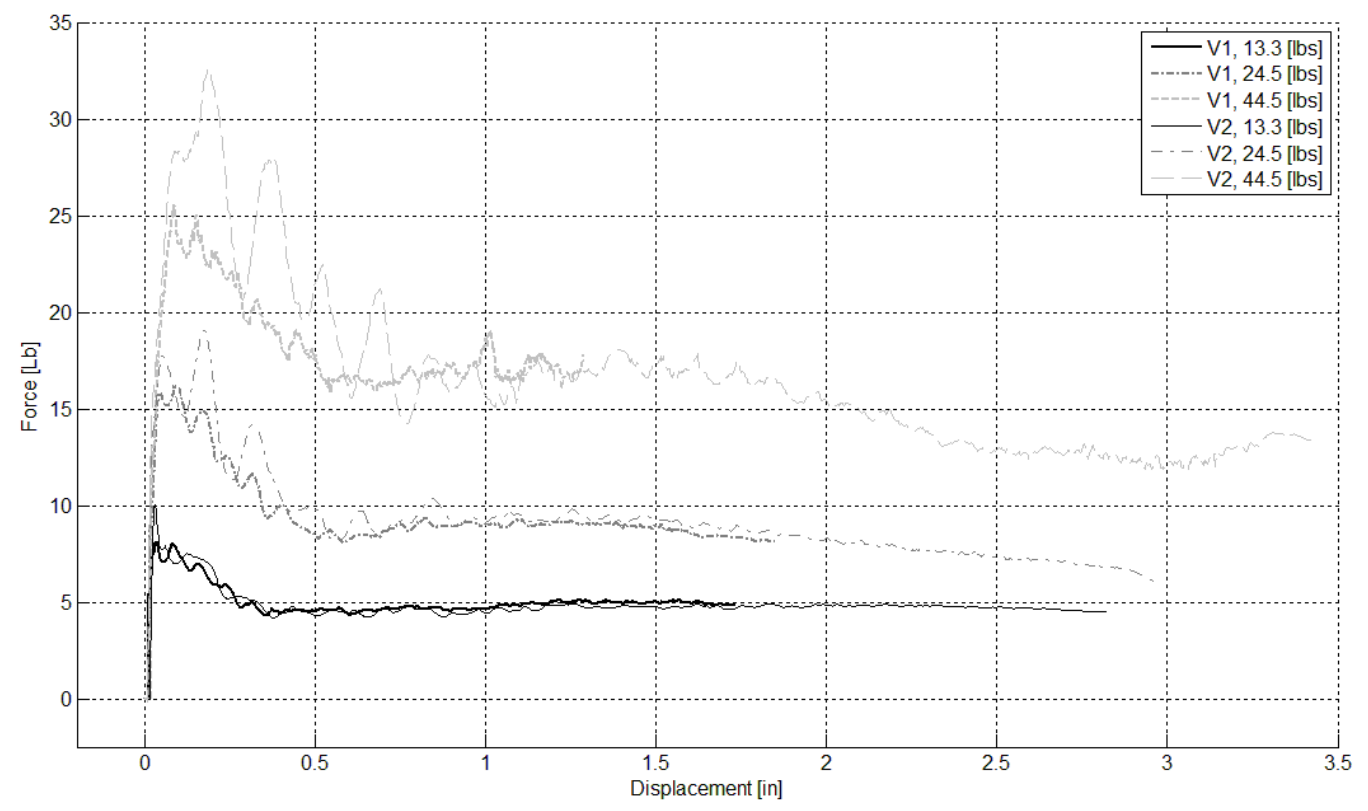

Figure C.15 - Rough Concrete wet -

$$
\text { A }-12
$$




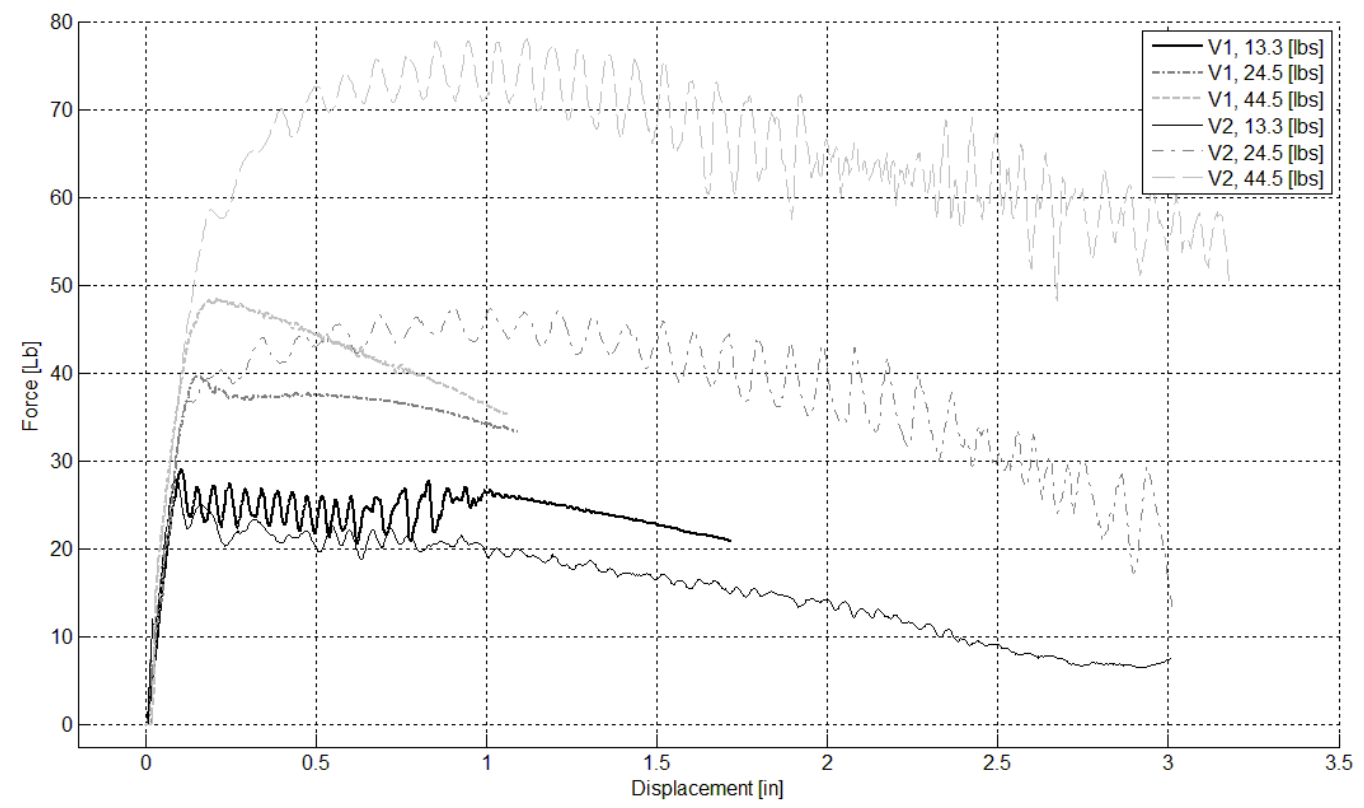

Figure C.16 - Steel dry -

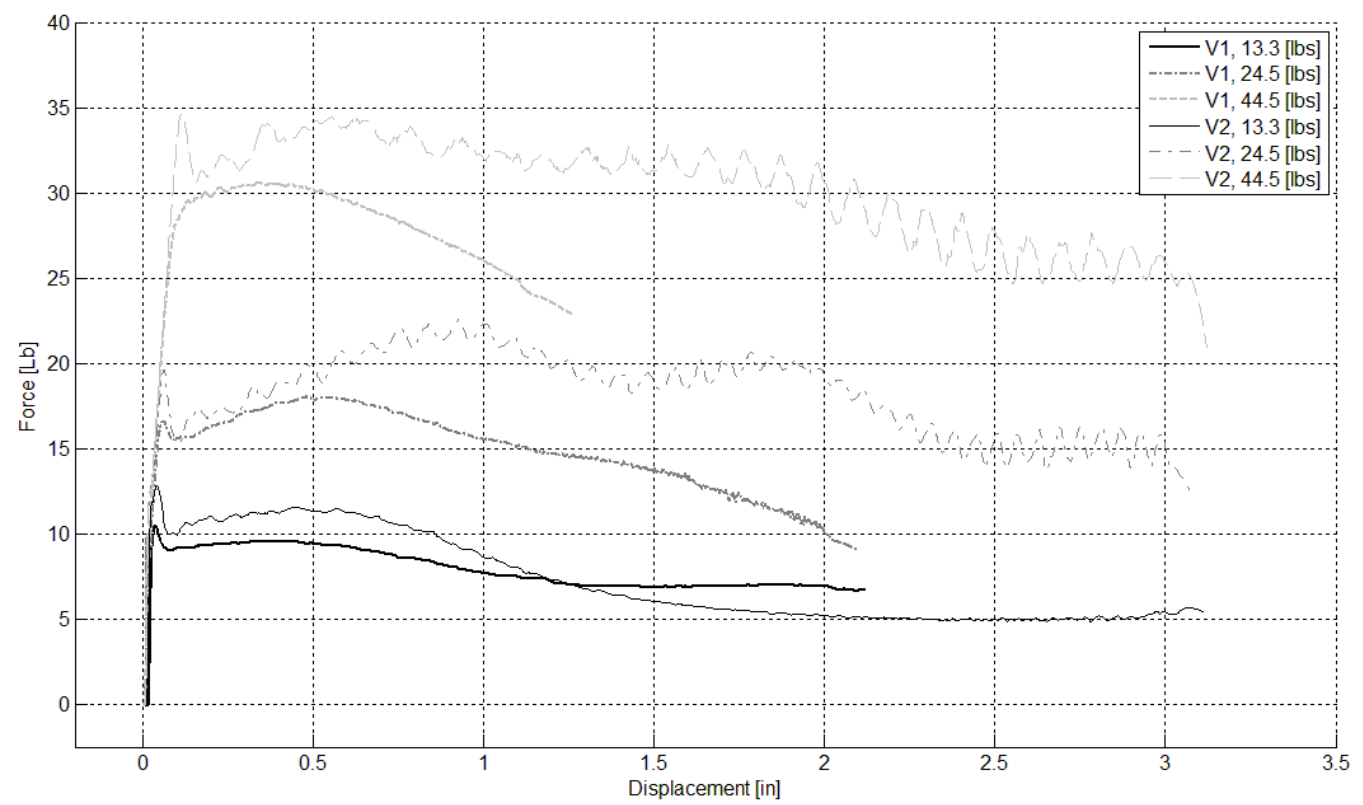

Figure C.17 - Steel wet - 


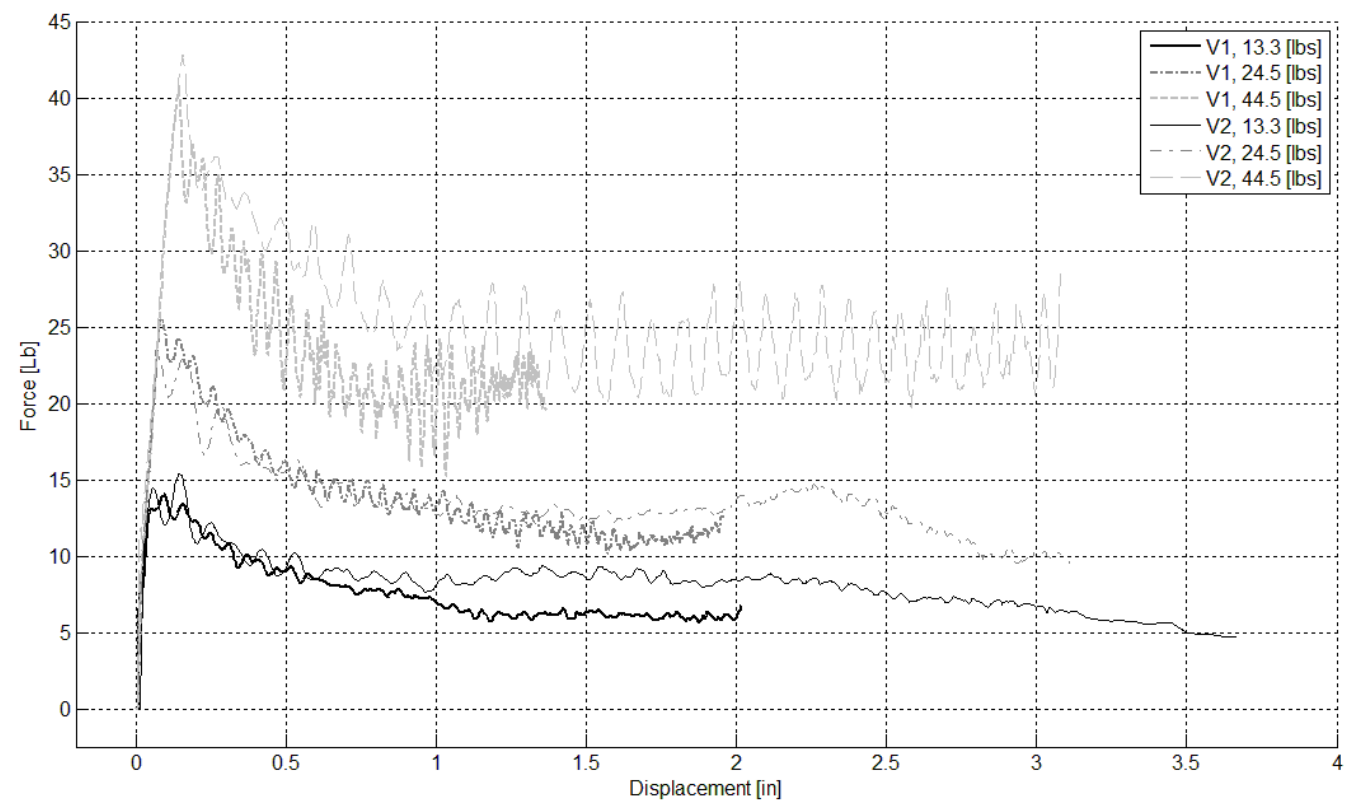

Figure C.18 - Texturate dry -

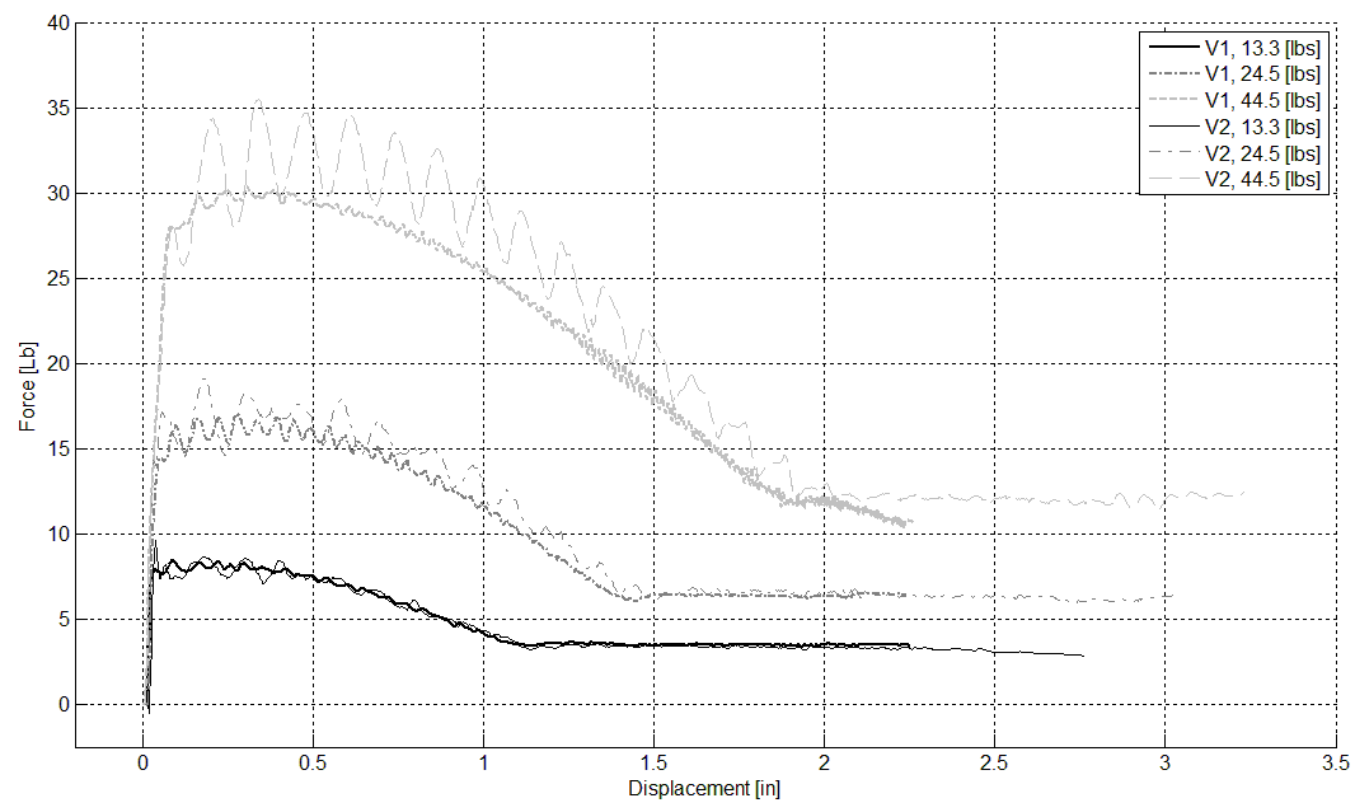

Figure C.19 - Vinyl dry - 


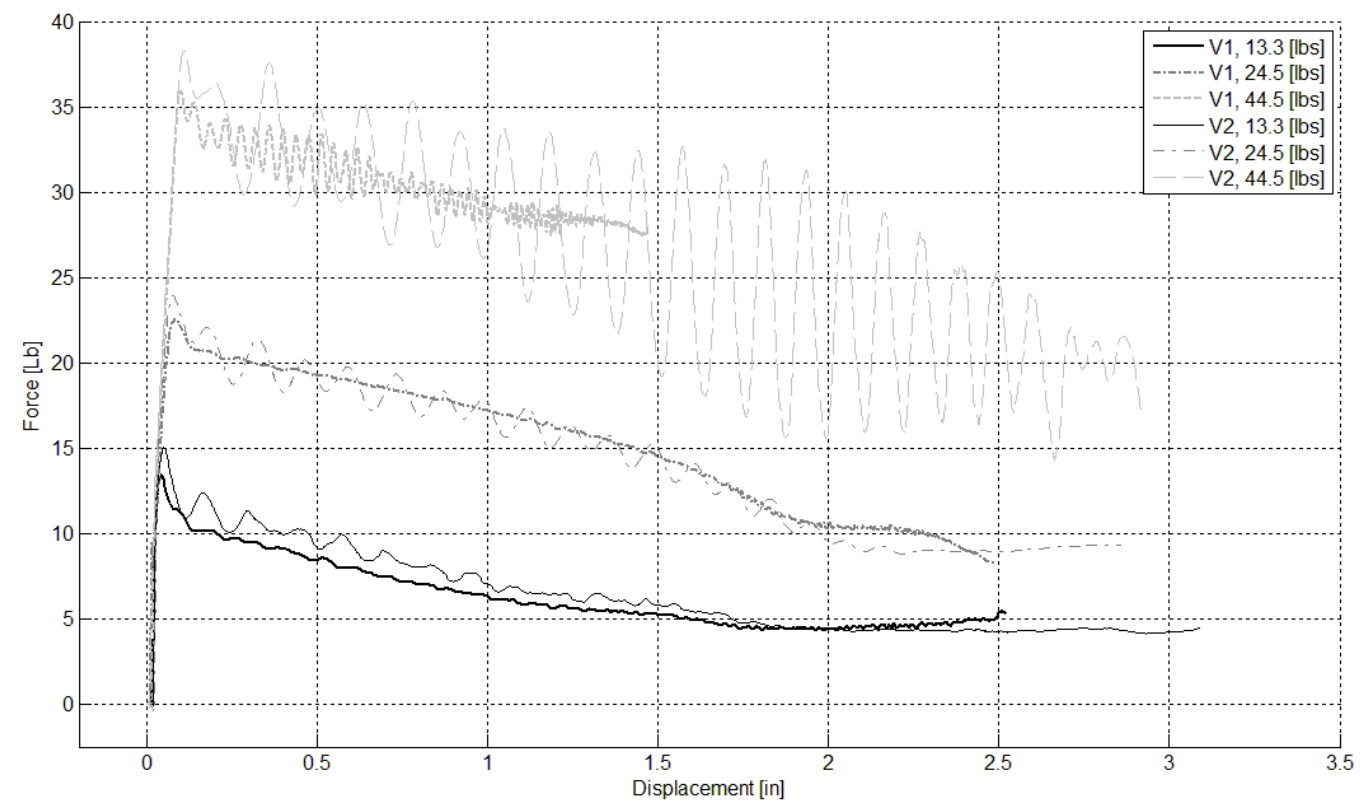

Figure C.20 - Vinyl wet - 